\title{
EFFECT OF THE PROPERTIES OF COAL SURFACE AND FLOCCULANT TYPE ON THE FLOCCULATION OF FINE COAL
}

\author{
by \\ JORGE RICARDO PALMÉS \\ B.A. Sc., National University of San Juan, San Juan, Argentina, 1986. \\ A THESIS SUBMITTED IN PARTIAL FULFILLMENT OF \\ THE REQUIREMENTS FOR THE DEGREE OF \\ MASTER OF APPLIED SCIENCE \\ in \\ THE FACULTY OF GRADUATE STUDIES \\ (Department of Mining and Mineral Process Engineering)
}

We accept this thesis as conforming

to the required standard.

THE UNIVERSITY OF BRITISH COLUMBIA

April, 1996

(C) Jorge Ricardo Palmés, 1996. 
In presenting this thesis in partial fulfilment of the requirements for an advanced degree at the University of British Columbia, I agree that the Library shall make it freely available for reference and study. I further agree that permission for extensive copying of this thesis for scholarly purposes may be granted by the head of my department or by his or her representatives. It is understood that copying or publication of this thesis for financial gain shall not be allowed without my written permission.

Department of Mining and Mineral Processing Cupineering

The University of British Columbia

Vancouver, Canada

Date Aprit 18, 1996 


\begin{abstract}
Three coal samples, selected out of eight with well-characterized surface properties, were used in flocculation tests. A synthetic mixture of coal and silica was used in the selective flocculation experiments.
\end{abstract}

The flocculants tested included: a hydrophilic polyacrylamide (PAM) and a semihydrophobic (F1029-D) flocculants and a totally hydrophobic latex prepared by emulsion polymerization (FR-7A).

Good hydrophobic agglomeration and selectivity were observed with the totally hydrophobic latex on non-oxidized hydrophobic coal only; increased coal hydrophilicity clearly affected agglomeration and selectivity. For the polyelectrolyte and the semihydrophobic flocculants, the flocculation vs. shear rate curves exhibited a maximum, while for the totally hydrophobic latex the degree of flocculation increased continuously over the whole tested range. The flocculation versus flocculant dosage curves displayed a maximum for the polyelectrolyte whereas for both semi-hydrophobic polymer and for the latex the degree of flocculation did not vary significantly beyond a certain dosage. Flocculation was found to be $\mathrm{pH}$ dependent: while better flocculation was observed in acidic solutions, better selectivity (deashing) was obtained in alkaline $\mathrm{pH}$ ranges. 


\section{TABLE OF CONTENTS}

ABSTRACT. .ii

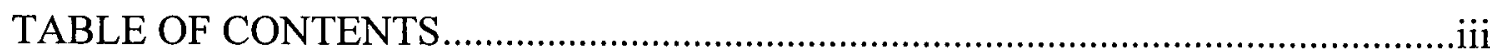

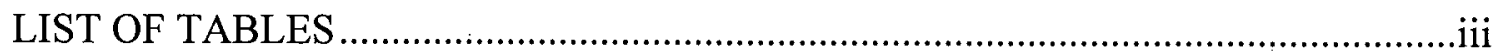

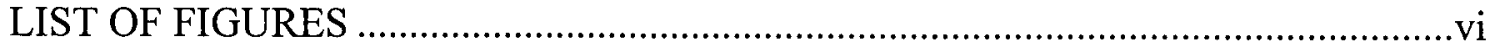

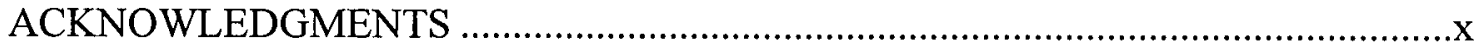

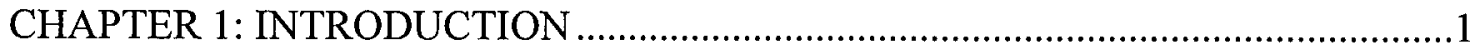

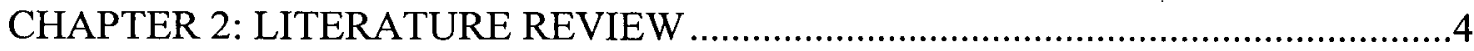

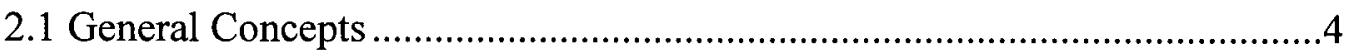

2.1.1 Coagulation, flocculation, agglomeration......................................

2.1.2 Polymeric Flocculants....................................................................

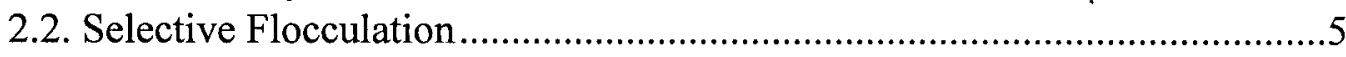

2.2.1 Design of a selective flocculation process ......................................6

2.3. Fundamentals of selective flocculation.......................................................

2.3.1. Dispersion of the ore constituents..................................................

2.3.2. Selective flocculant adsorption and floc formation .......................

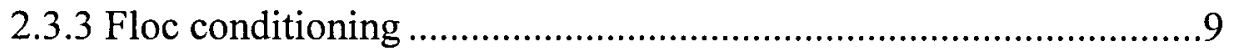

2.3.4 Floc separation ............................................................................ 10

2.4 Applications of selective flocculation............................................................11

2.4.1 Selective flocculation of coal.......................................................11

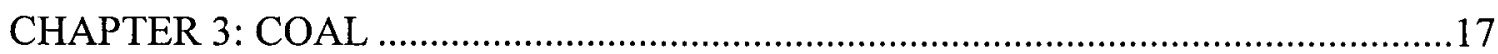

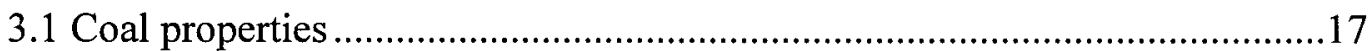

3.1.1 Chemical composition of coal ......................................................17

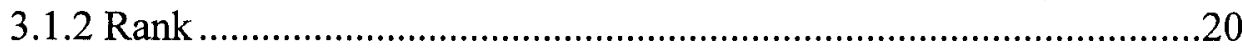

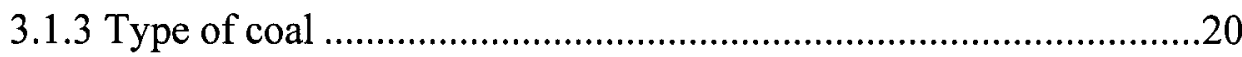

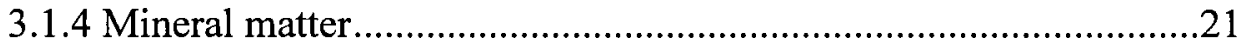

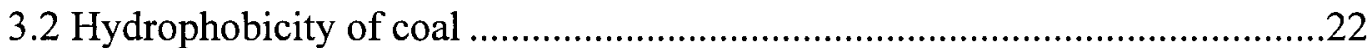

3.2.1 Hydrophobicity theories.............................................................22

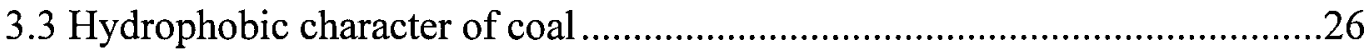

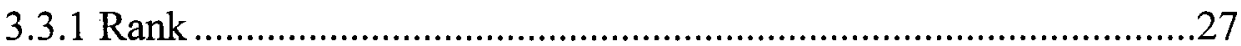

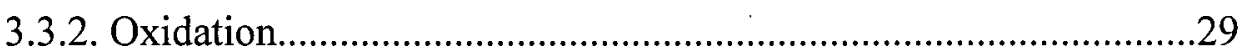

3.3.3 Electrical Charge ..........................................................................30

3.3.4 Petrographic composition ..........................................................33

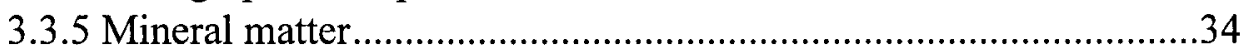

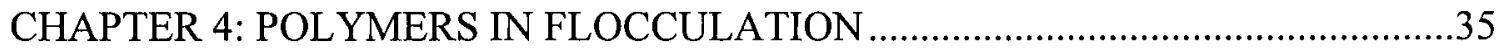

4.1 Natural Flocculants ...................................................................................

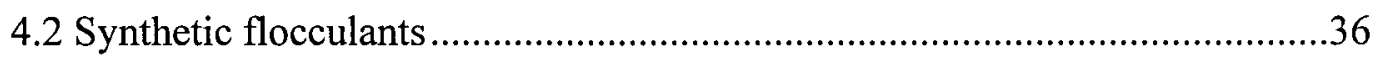

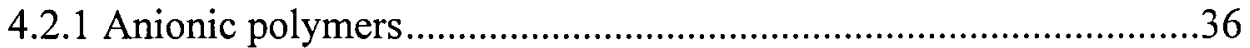

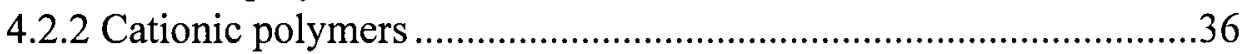

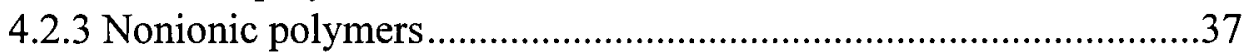

4.3. Mechanisms of Adsorption of Polymeric Flocculants..................................37 


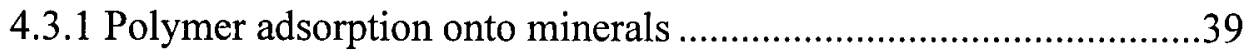

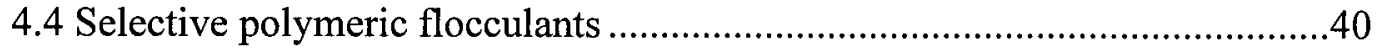

4.5 Design of selective flocculant polymer..........................................................

4.5.1 Design of the polymer's selective functional groups. ......................42

4.6. Possible mechanisms for selective adsorption ..............................................42

4.6.1 Selective polymers based on chemisorption ......................................43

4.6.2 Selective polymers based on hydrophobic effect..............................43

4.7 Production of hydrophobic polymers............................................................

CHAPTER 5: SHEAR RATE IN FLOCCULATION TESTS .......................................46

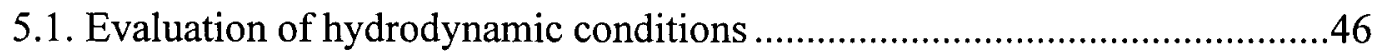

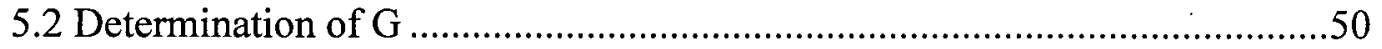

5.3 Measurement of the shear rate .....................................................................

5.3.1 Experimental set up and procedure .................................................52

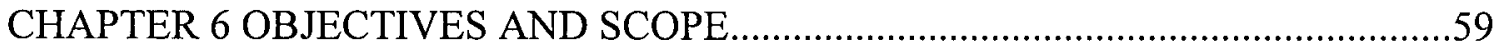

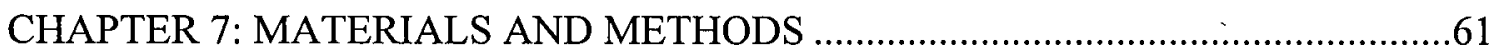

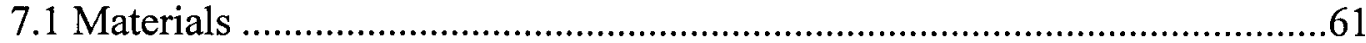

7.1.1 Charaterization of Coal Samples ...................................................61

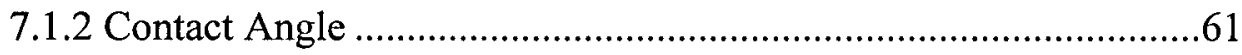

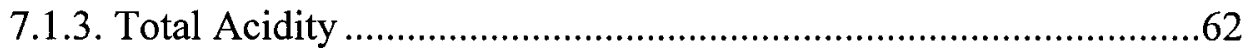

7.1.5. Equilibrium moisture ………….................................................62

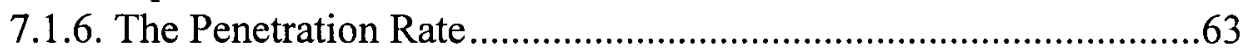

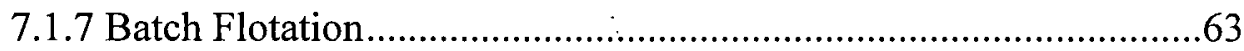

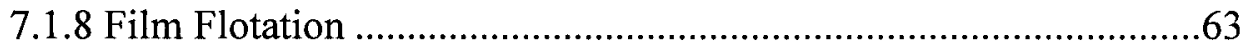

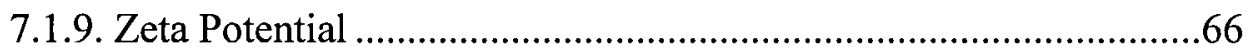

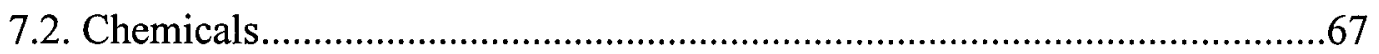

7.3. Sample Preparation for Flocculation Tests ..................................................68

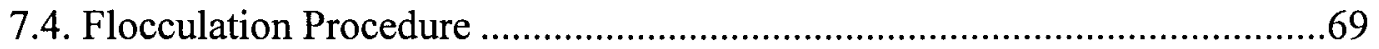

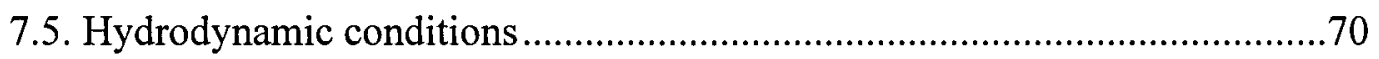

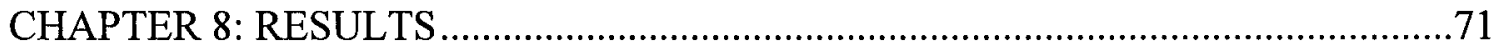

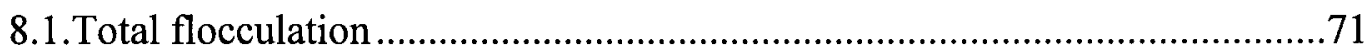

8.1.2. Effect of sodium hexamethaphosphate .........................................73

8.1.3. Effect of flocculant type and dosage..............................................73

8.1.4. Effect of shear rate ......................................................................73

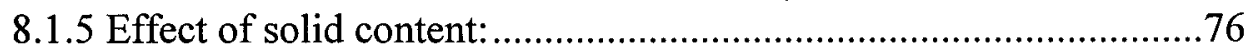

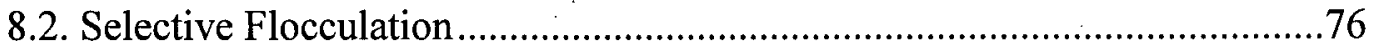

8.2.1. Effect of sodium hexamethaphosphate ………………....................76

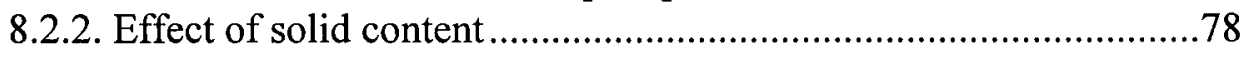

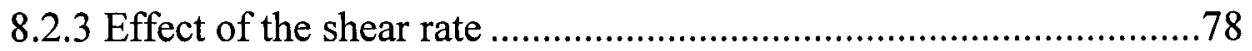

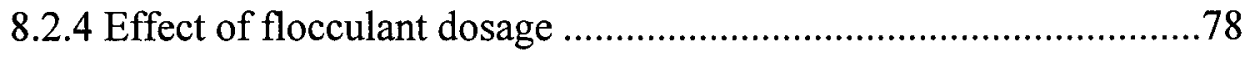

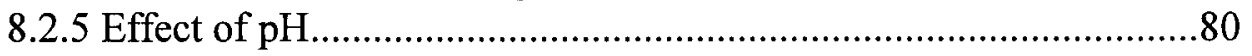




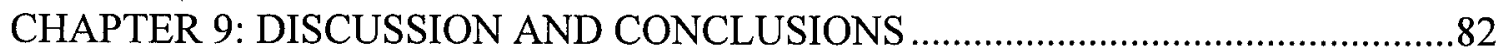

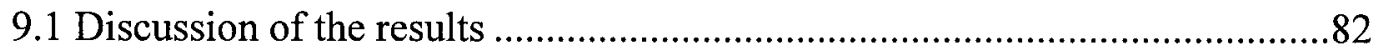

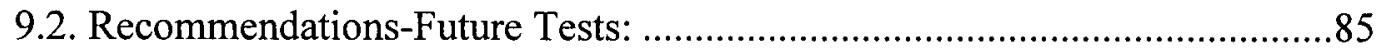

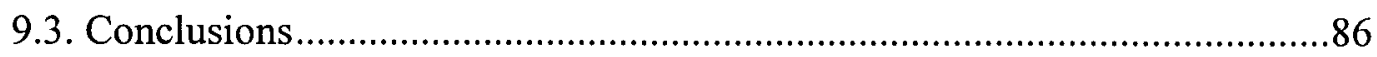

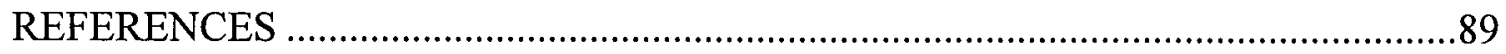




\section{LIST OF TABLES}

Table

Page

2.1 Laboratory test results on the selective flocculation of coal.

3.1 Coals arranged in ascending order of carbon content.

18

5.1 Power requirement for a blade impeller at no load and load conditions.

7.1 The results of characterization of coal samples by various techniques.

7.2 Proximate Analyses of samples used in flocculation test. 


\section{LIST OF FIGURES}

Figure

Page

2.1 Schematic representation of selective flocculation subprocesses.

3.1 Carbon distribution in coals of different ranks.

3.2 The Wiser Model of structural groups and connecting bridges in bituminous coals.

3.3 The effect of the work of cohesion and adhesion of liquid to solid on the solid wettability.

3.4 Contact angles for coals of different ranks measured by captive bubble and sessile drop technique.

3.5 Distribution of oxygen groups in coals of different ranks.

3.6 Generalized zeta potential versus $\mathrm{pH}$ diagrams for coals of various ranks.

3.7 Isoelectric points for coal of varying ranks.

5.1 Schematic diagram of baffled stirred tank containing dead-space compartment.

5.2 Impeller speed vs. velocity gradient curve obtained by the electrical method proposed in this study.

5.3 Scheme diagram of the Hudson jar constructed for the present study.

5.4 Impeller speed vs. power requirement curves at load and no load conditions. $\quad 58$

7.1 The relationship between contact angle and total acidity. 
7.2 The results of zeta-potentials of coal samples at various $\mathrm{pH}$ values.

73 The chemical formula for the partially hydrophobic flocculant F1029-D

8.1 The relationship between flocculant dosage and flocculation degree for Fording 71 4 Coal.

8.2 The relationship between flocculant dosage and flocculation degree for Line 72 Creek 7 Coal.

8.3 The relationship between flocculant dosage and flocculation degree for Fording 72 13 Coal.

8.4 The relationship between sodium hexametaphosphate dosage and flocculation $\quad 74$ degree for Fording 4 Coal.

8.5 The relationship between shear rate and flocculation degree for Fording 4 Coal. 74

8.6 The relationship between shear rate and flocculation degree for Line Creek $7 \quad 75$ Coal.

8.7 The relationship between shear rate and flocculation degree for Fording $13 \quad 75$ Coal.

8.8 The relationship between solids content and flocculation degree for Fording 4 77 Coal.

8.9 The effect of HMP on selectivity and on clean coal yield for a 1:1 Mixture: Minusil silica, Fording 4 Coal.

8.10 The effect of solid content on selectivity and on clean coal yield for a 1:1 79 Minusil Silica, Fording 4 Coal Mixture. 
8.11 The effect of shear rate on selectivity and on clean coal yield for a 1:1 Minusil Silica, Fording 4 Coal Mixture.

8.12 The effect of flocculant dosage on selectivity and on clean coal yield for a 1:1 81 Mixture: Minusil Silica, Fording 4 Seam Coal.

8.13 The effect of $\mathrm{pH}$ on selectivity and on clean coal yield for a 1:1 Mixture: Minusil silica, Fording 4 Coal.

9.1 The effect of FR-7A and UBC-1 lattices and PAM on receiding contact angle $\quad 83$ on coal. 


\section{ACKNOWLEDGMENTS}

The author wishes to express his deepest gratitude to Dr. Janusz S. Laskowski under whose kind direction and guidance this work was undertaken.

The technical assistance provided by Mrs. S. Finora is gratefully acknowledged.

The author also wishes to express his gratitude to Professors John Meech and George Poling for their valuable teaching in some very interesting and useful courses, and to all the fellow students in the Department of Mining and Mineral Process Engineering, The University of British Columbia.

My special thanks are given to my beloved wife, Bettina Storni for encouragement, understanding, care and enduring love and for sharing in the happiness and hardships of the past years.

This work is dedicated to my wife, Bettina, and to my son, Lorenzo, who gave me the might to complete this assignment.

The author wishes to express his gratefulness to Mr. Adam Gordon for his financial assistance. 


\section{CHAPTER 1: INTRODUCTION}

The problem of processing fine and ultrafine particles is well documented and still constitutes a challenge for engineers working in the area of mineral processing. Problems with fines are not only encountered in the mineral processing area, but also in other areas such as: food processing, petrochemical technology, biotechnology, pollution control, etc.

Fine grinding is commonly required to achieve sufficient liberation in the mineral processing circuits. On the other hand, flotation and solid/liquid separation processes are not very efficient if the particles are too fine. These two tendencies are obviously contradictory: while fine grinding is required to achieve adequate liberation, any excessive grinding makes flotation and subsequent dewatering processes less effective.

In general, fine particles respond poorly to the conventional froth flotation process due to the changes in mineralogy and surface composition (Fuerstenau et al., 1979) or due to the direct effect of the size on the collision and adhesion probability between particles and air bubbles (Dejarguin and Dukin, 1981). In fine particles systems surface properties dominate bulk properties. Fine particles may be carried into the flotation froth, also by entrainment in the liquid or by mechanical entrapment with the particles that are floated. Carry over of fine gangue reduces concentrate grade.

Flotation rate studies have confirmed that fine particles float more slowly than those of intermediate sizes (Trahar, 1981). The reason for this can be traced (Dejarguin and Dukin, 1981) to two main factors: inefficiencies in collision between a very fine particle and a bubble and the difficulty of rupturing the thin liquid film between a particle and an approaching air bubble. If a low attachment rate limits the flotation of fine particles an increase in the time of flotation would lead to improved recovery. However, entrainment and entrapment of fine gangue, among other factors, increase significantly with longer 
flotation times, leading to a reduction in selectivity (Trahar and Warren, 1976, Trahar, 1981).

Methods aimed at improving the recovery of fine particles generally focus on increasing size by aggregating fine particles in some fashion to move the resultant aggregates into a hydrodynamicaly more efficient region (Jameson et al., 1977). Flocculation is one such technique which has received close attention in recent years.

Current theories of the collision regime (Yoon and Luttrel, 1989) suggest that the collision efficiency is proportional to :

$$
C e=A \times\left(\frac{d_{\text {paricle }}}{d_{\text {bubble }}}\right)^{N}
$$

where $d$ is diameter and $\mathrm{A}$ and $\mathrm{N}$ are constants that depend on the Reynolds number. For Stokes and intermediate flow regimes $(\operatorname{Re}<100)$, pertinent to most flotation operation, $\mathrm{N}$ is equal 2 . There is clearly some benefit to be gained in controlling bubble size and some experimental evidence suggests that air bubbles with $\mathrm{d}<100 \mu \mathrm{m}$ may float fine particles more efficiently. However, the control of such fine bubbles is difficult to achieve --bubbles of diameter around $1 \mathrm{~mm}$ or so are commonly observed in flotation cells-- for coalescence of smaller bubbles occurs readily, unless there is a substantial barrier to coalescence (Leja, 1982). For this reason, the development of new types of columns and improvements in sparging to produce finer bubbles have attracted a great deal of attention in various research centers. Consequently, the best means of extending froth flotation to lower size ranges is the selective aggregation of fines. 
Presently, the only particle-size enlarging process that can be incorporated in flotation circuits is oil agglomeration (agglomerate flotation), although it has a drawback: the consumption of oil may be as high as 2 to $10 \%$ wt. To improve dewatering operations the industry uses flocculating agents. These are polyelectrolytes, highly hydrophilic, water-soluble polymers, and since flotation requires collectors that render mineral particles hydrophobic, the use of commercial flocculants is incompatible with flotation.

Coals are not currently ground to fine sizes before beneficiation and gravity methods are used for cleaning coarse and intermediate size fractions, while fines are treated by froth flotation. There is no satisfactory technology available for processing ultrafine coal $(<50 \mu \mathrm{m})$.

Selective flocculation has been shown to be a promising technique for cleaning ultrafine coals and in some cases floc flotation has also provided encouraging results (Osborne, 1978, Soto and Barbery, 1988). Rubio and Kitchener (1977) described a hydrophobic flocculation process in which solids, either naturally hydrophobic or made hydrophobic by using surfactants, can be treated. Although totally hydrophobic polymers were evaluated in the last decade (Littlefair and Lowe, 1985; Yu and Attia, 1987) and some new ones including the innovative use of hydrophobic bacteria to selectively flocculate coal (Misra et al., 1992, Raichur, Misra and Smith, 1995) have recently been tested, information available on the chemistry of the tested agents is meager.

The role of coal chemistry (wettability) in the flocculation with polymers has never been evaluated. Therefore, the main objective of this work has been to investigate the relationship between coal surface properties and flocculant type in the flocculation of coal fines. 


\section{CHAPTER 2: LITERATURE REVIEW}

In the treatment of coal fines a variety of techniques have emerged in the last twenty years. Some have shown to be more promising than others; total flocculation and selective flocculation, in particular, belong to this group. However, a lack of understanding of the theories upon which flocculation is based has thwarted it from more extensive applications.

Some relevant basic theories will be briefly reviewed in the following sections.

\subsection{General Concepts}

\subsubsection{Coagulation, flocculation, agglomeration}

If fine mineral particles are products of conminution processes (to bring about liberation), the energy imposed on the rock, in breakage, in part is stored in the form of surface energy. The fragment of rock increases its energy upon fracturing as a result of breaking chemical bonds. Aggregation of primary fine particles into larger aggregates is then the first step towards reduction of the total surface free energy of the system. It can be achieved either by reducing the interparticle repulsion through neutralization of particle charge or compression of the electrical double layer surrounding the interacting particles, or by bridging with the use of polyelectrolytes. The former mechanism of aggregation is known as coagulation and the aggregates are referred to as coagula, while the latter is termed flocculation and the aggregates are known as flocs. When the aggregation results from the action of an inmiscible organic liquid, such as oil in an

aqueous dispersion, the process is called agglomeration and the aggregates are called agglomerates. 
The International Union of Pure and Applied Chemistry (IUPAC, 1972) recommends that the term aggregation be used to describe the process or the result of the formation of a group of particles held together in any manner, coagulation to describe the specific type of aggregation that leads to the formation of aggregates which are compact and flocculation to decribe the specific process that yield aggregates that are loose and open. In practice coagulation is caused by simple inorganic electrolytes, while flocculation is induced by polymeric additives.

\subsubsection{Polymeric Flocculants}

A typical flocculant is a water-soluble polymer with a molecular weight of $10^{6}$ or greater. Either natural, synthetic, or derivatized hybrid organic products are used as flocculants. Due to their great molecular chain lengths, such macromolecules are capable of adsorbing on several particles simultaneously with different ends. The resulting bridging action is believed to be the chief mechanism for binding the adjoining particles within flocs (Slater and Kitchener, 1966).

There are many ways of classifying polymeric flocculants. The classification may be based on one or more of the polymer properties, such as molecular weight, functional groups, charge, chemical structure or origin. Krishnan and Attia (1988) have tabulated examples of polymeric flocculants. Some of the flocculant features are summarized later in Chapter 4.

\subsection{Selective Flocculation}

Selective flocculation takes advantages of the difference in the physical-chemical properties of various mineral components in mixed suspension. It is useful to view the process as consisting of four major sub-processes. These are: (1) slurry dispersion, in which the suspension is stable with uniformly distributed individual particles, (2) 
selective adsorption of the flocculant and floc formation, (3) floc conditioning to obtain flocs with minimum entrapment of dispersed particles for their subsequent separation and (4) floc separation from the suspension. These sub-processes are further analyzed in this work.

It might be appropriate to briefly introduce the concept of a new technique closely associated with selective flocculation: selective dispersion. It also utilizes the differences in the minerals' surface chemical properties, and it is based on the preferential adsorption of a selective dispersant on the particular mineral to be dispersed, leaving the remainder of the suspension particles flocculated by a general-type flocculant (Attia,1992).

\subsubsection{Design of a selective flocculation process}

The first and most important decision in the design of a selective flocculation process is the selection of the mineral components of the ore which are to be selectively flocculated. Either valuable components or gangue components may be flocculated and the selection depends on which route is more technically feasible and economically viable.

In the processing of iron ore at Tilden Mine (Frommer and Colombo, 1966, Iwasaki, 1986), the valuable components (iron oxides) are selectively flocculated, while silicates remain dispersed. The enriched iron mineral flocs are separated from the suspension by gravity in a thickener. In another application, the unwanted clay minerals are flocculated with PAM, while sylvite is floated from and halite with amines (Banks, 1979).

Selective flocculation can be utilized as either a pretreatment stage ahead of flotation or as an independent process. For instance at Tilden Mine (Iwasaki,1986) the selective flocculation precedes reverse flotation, which is subsequently used to further upgrade the final product by removing coarse silica by floating with amines. The route that would 
ultimately result in lower reagent consumption, more efficient separation and lower operating cost would obviously be the preferred choice.

\subsection{Fundamentals of selective flocculation}

As mentioned earlier, there are four sub-processes in selective flocculation (see Figure 2.1). Each of them is discussed individually in the section that follows.

\subsubsection{Dispersion of the ore constituents}

In selective flocculation the main aim of dispersion is to attain a homogenous distribution of the particles in the mixing vessel. Dispersion can be defined as the condition by which all suspended particles are separated from one another and do not exist as small aggregates or slime coatings (Yarar and Kitchener, 1970).

For an ore suspension the quality of water is also very important. For instance in a study on the selective coagulation of hematite, Pugh and Kitchener, (1970) found that a stable dispersion of quartz forms in the range of $\mathrm{pH} 3-12$. When the $\mathrm{pH}$ is below 3 slow coagulation occurs because of the reduction in the surface charge of the quartz particles. When the $\mathrm{pH}$ is above 12 , aggregation occurs probably due to the precipitation of insoluble metal silicates or due to the high ionic strength of the solution.

\subsubsection{Selective flocculant adsorption and floc formation}

The mayor concerns at this stage of the process are to ensure that the flocculant will selectively adsorb onto the particular solid particles, and this selectivity will persist irrespective of changes in the process water chemistry and temperature.

The effect of the process water chemistry is of the cardinal importance. Indeed, the commercial success of the process is largely controlled by the chemical composition of the process water used in the operation. High concentrations of multivalent ions may 
affect the selective flocculant adsorption. These effects include coiling or salting-out of the flocculant, coagulation of the fine particles, and random activation of the gangue minerals. Attia and Fuerstenau (1982) and Heerema and Iwasaki (1982) noted that excessive amounts of ionic species such as $\mathrm{Ca}^{2+}$ and $\mathrm{Mg}^{2+}$ in the iron ore system tend to form precipitates under certain conditions. These precipitates apparently aggregate with quartz particles by heterocoagulation.

Although the importance of the chemical aspects of flocculant adsorption and floc formation should not be underestimated, the effects of hydrodynamic conditions and other process parameters are also important. Floc formation may be considered as a step that is almost inseparable from adsorption growth and breakup and is largely governed by the hydrodynamic conditions in the vessel and the particle size distribution of the solids.

The methods to achieve selective flocculation were formulated by Yarar and Kitchener (1970) and reviewed by Attia $(1982,1992)$. These methods may involve either the utilization of selective flocculants or the employment of selective dispersant or activators. There are basically two routes for obtaining selective flocculation. The first route is by the use of specifically designed flocculants, that act on the basis of either chemisorption, stereo selective effects, or hydrophobic interaction, either alone or in combination with a general unselective dispersant. The second route is through the general-type flocculants but with simultaneous use of selective dispersants. The latter is normally achieved either by controlling the particle surface potential or by applying competitive dispersants, or frequently by applying both. 


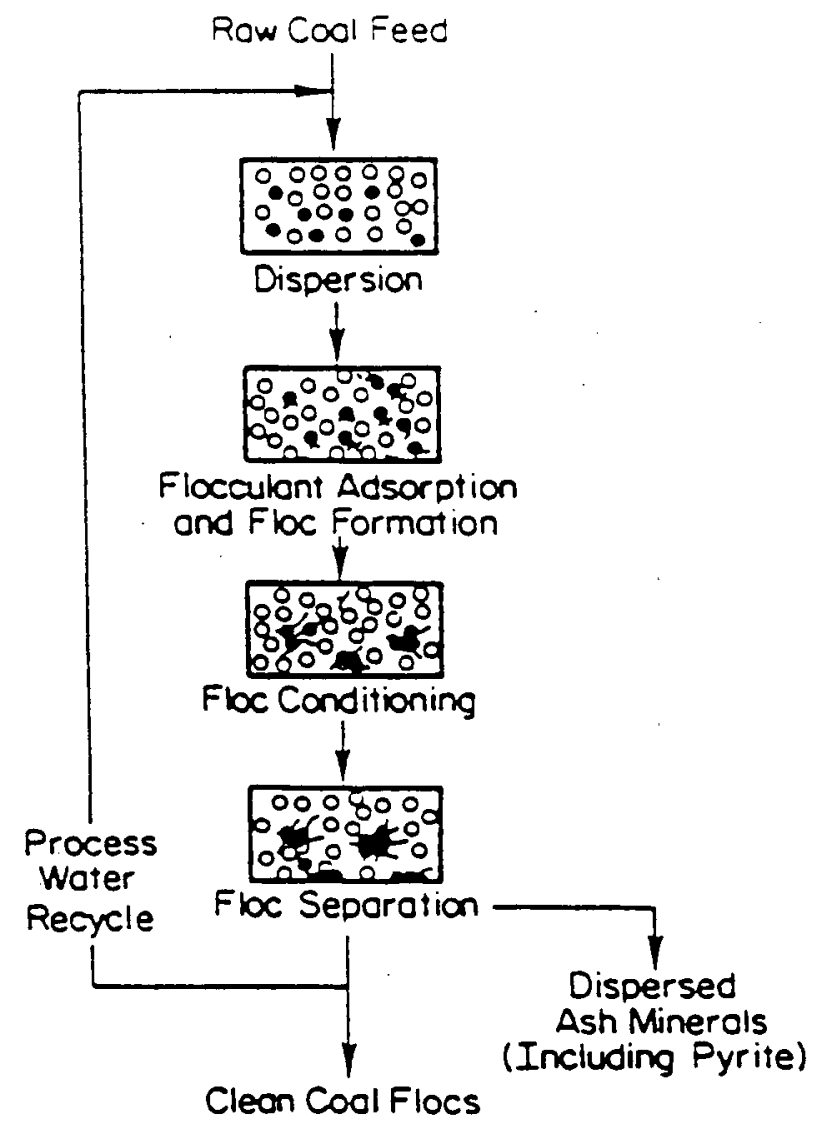

Figure 2.1. Schematic representation of selective flocculation subprocesses

\subsubsection{Floc conditioning}

The purpose of floc conditioning is to achieve the required size, structure and strength of the floc that give minimum entrapment of suspended solids and the ability to withstand subsequent separation from the suspension. Unfortunately, little is known about achieving such requirements, but attempts to minimize entrapment of suspended particles have been made. These attempts include the use of inclined rotating vessels (Iskra et al., 1973), and other techniques such as re-dispersion and re-flocculation (Attia and Fuerstenau, 1981; Attia and Fuerstenau, 1982; Heerema and Iwasaki, 1982). 
Attia and co-workers (Attia et al., 1983) undertook a study to determine the conditions under which floc conditioning would produce large and strong flocs with minimum entrapment of the gangue particles in the shortest possible time. The effects of several parameters such as intensity of agitation, proportions of minerals and the duration of conditioning on the floc grade and recovery were studied. The authors concluded that (a) large flocs can be obtained with extended conditioning periods, low level of agitation and dilute polymer action; (b) conditions that produce large flocs also yield lower grade, (c) the method of conditioning and the number of cleaning stages of redispersion/reflocculation markedly influence the quality of the final flocs obtained; and (d) the quality of the flocs is generally higher in the floc formation stage than after floc conditioning.

\subsubsection{Floc separation}

In the well-known commercial separation by selective flocculation, namely, iron ore processing, the separation of flocs from suspension is achieved in a thickener.

Despite the commercial success of this process, there is much to be done to define the optimum conditions and the appropriate separation methods for obtaining high separation efficiency using a minimum number of cleaning stages. Attia and his co-workers (Attia et al., 1983) studied this process using eight different separation techniques. These included: (a) separation in a centrifugal field, (b) screening through a sieve, (c) sedimentation in a thickener, (d) elutriation, (e) column flotation, (f) fluidized bed elutriation, $(\mathrm{g})$ a combination of separation techniques and $(\mathrm{h})$ dissolved air flotation. It was found that modified thickening, column flotation, modified elutriation, and dissolved air flotation were the most promising. 


\subsection{Applications of selective flocculation}

A number of successful applications of selective flocculation have been demonstrated in laboratories and pilot-plants (Yu and Attia, 1987) but there are only three known commercial applications in North America. These operations are: (1) selective flocculation of iron ore at the Tilden Plant in Ohio, USA, (2) selective flocculation to deslime potash ore before floating sylvite in Saskatchewan, Canada and (3) selective flocculation of anastase and other "opaque" minerals from kaolin at Theile Kaolin Company in Georgia, USA.

Selective flocculation has been tested for the separation of base metal minerals, industrial minerals and cleaning of coals. ( $\mathrm{Yu}$ and Attia, 1987). Some applications to flocculate selectively coal fines are reviewed below.

\subsubsection{Selective flocculation of coal}

The literature on the removal of mineral impurities from coal by selective flocculation is limited. Several investigators have systematically studied the selective flocculation of coal under laboratory conditons. These studies have examined different coals, various dispersing agents, flocculants and the influence of process parameters on selective flocculation performance in order to demonstrate and to establish the feasibility of the technique. The results of the selective flocculation studies of coal by various investigators are listed in Table 2.1. The following is a brief discussion on their findings. Blaschke (1976) examined a variety of dispersants, flocculants and different experimental parameters. The tests showed that the slimes of steaming coal containing about $42 \%$ ash could be cleaned in one stage by selective flocculation to about $29 \%$ ash. None of the tests yielded a concentrate with a very low ash content. Blaschke (1976) also reported on studies in which the minerals particles were flocculated keeping the coal particles dispersed, but although the suspension ash content was undoubtedly low (4-10\%), the 
clean coal yield was less than $15 \%$. In another study coal slimes containing about $39 \%$ ash were selectively flocculated using $3-8 \mathrm{~kg} / \mathrm{ton}$ of the sodium salt of carboxymethylcellulose as a dispersant and $0.4-4 \mathrm{~kg} / \mathrm{ton}$ of an anionic, modified polyacrylamide ("Gigtar") as a flocculant. By this method the ash content of the slimes could be reduced in one stage to about $20 \%$ with a coal recovery of about $40 \%$.

Table 2.1. Laboratory test results on the selective flocculation of coal (Krishnan, 1986)

\begin{tabular}{|c|c|c|c|c|c|c|}
\hline Coal Source & Type & $\begin{array}{l}\text { Feed Ash } \\
\text { Content \% }\end{array}$ & $\begin{array}{l}\text { Prod. Ash } \\
\text { Content \% } \\
\end{array}$ & $\begin{array}{c}\text { Coal Rec. } \\
\% .\end{array}$ & $\begin{array}{c}\text { Ash Removal } \\
\%\end{array}$ & Reference \\
\hline $\begin{array}{l}\text { Coal Slimes, } \\
\text { Poland }\end{array}$ & Coking Coal & 39.2 & 20.0 & 40.0 & 79.6 & Blaschke, 1976 \\
\hline $\begin{array}{c}\text { Santa Catarina, } \\
\text { Brazil }\end{array}$ & Bituminous & 44.8 & 37.2 & 92.0 & 23.6 & $\begin{array}{c}\text { Solari and Rubio, } \\
1982 \\
\end{array}$ \\
\hline $\begin{array}{c}\text { National Coal } \\
\text { Board, England }\end{array}$ & Bituminous & 32.4 & 10.2 & 74.3 & 76.6 & $\begin{array}{c}\text { Attia, Krishna and } \\
\text { Deason, } 1983\end{array}$ \\
\hline $\begin{array}{c}\text { National Coal } \\
\text { Board, England }\end{array}$ & Bituminous & 19.9 & 10.3 & 93.4 & 51.7 & $\begin{array}{c}\text { Attia, Krishnam } \\
\text { and Deason, } 1983\end{array}$ \\
\hline $\begin{array}{c}\text { National Coal } \\
\text { Board, England }\end{array}$ & Bituminous & 16.7 & 8.8 & 94.7 & 50.1 & $\begin{array}{c}\text { Attia, Krishnam } \\
\text { and Deason, } 1983\end{array}$ \\
\hline $\begin{array}{c}\text { National Coal } \\
\text { Board, England }\end{array}$ & Bituminous & 45.5 & 19.9 & 71.1 & 68.9 & \begin{tabular}{|c} 
Attia, Krishnamand \\
Deason, 1983 \\
\end{tabular} \\
\hline $\begin{array}{c}\text { Upper Freeport } \\
\text { Pennsylvania }\end{array}$ & Bituminous & 9.2 & 2.7 & 67.9 & 80.1 & $\begin{array}{c}\text { Krishnam, Deason } \\
\text { and Attia, } 1984 \\
\end{array}$ \\
\hline Ohio $6 \mathrm{~A}$, Ohio & Bituminous & 12.0 & 5.0 & 72.6 & 69.8 & $\begin{array}{c}\text { Krishnam, Deason } \\
\text { and Attia, } 1984\end{array}$ \\
\hline Unidentified & Bituminous & 24.3 & 6.0 & 93.5 & 76.9 & $\begin{array}{c}\text { Ishizuka. Hotta and } \\
\text { Nishimura } 1984\end{array}$ \\
\hline Tatung, China & Bituminous & 8.5 & 1.2 & 93.2 & 86.8 & $\begin{array}{c}\text { Ishizuka. Hotta and } \\
\text { Nishimura } 1984\end{array}$ \\
\hline $\begin{array}{c}\text { Elkhorn Seam, } \\
\text { Kentucky }\end{array}$ & Bituminous & 7.6 & 2.0 & 69.0 & 81.8 & $\begin{array}{c}\text { Conkle, Krishnan } \\
\text { and Chauhan, } 1986 \\
\end{array}$ \\
\hline $\begin{array}{c}\text { Warworth } \\
\text { Seam, Australia } \\
\end{array}$ & Bituminous & 15.0 & 6.8 & 74.5 & 66.2 & $\begin{array}{c}\text { Conkle, Krishnan } \\
\text { and Chauhan, } 1986 \\
\end{array}$ \\
\hline Belga, Alaska & $\begin{array}{c}\text { Sub- } \\
\text { bituminous }\end{array}$ & 10.5 & 2.2 & 93.4 & 80.4 & $\begin{array}{c}\text { Ishizuka, Hotta and } \\
\text { Nishimura } 1984\end{array}$ \\
\hline $\begin{array}{l}\text { Beulah, North } \\
\text { Dakota }\end{array}$ & Lignite & 17.0 & 10.1 & 65.0 & 62.5 & $\begin{array}{c}\text { Krishnam, Deason } \\
\text { and Attia, } 1984\end{array}$ \\
\hline
\end{tabular}


Beneficiation of coal by selective flocculation was also studied by Hucko (1977) on artificial mixtures of a Pittsburgh seam coal (2.5-3.3\% ash) and shale ( $90 \%$ ash) obtained from the same area, and on thickener underflow ( $40 \%$ ash) from a coal preparation plant. Hucko investigated several important process parameters such as type and concentration of the dispersants, $\mathrm{pH}$, type and dosage of the flocculants, and ionic character of the suspension medium. He reported that selective flocculation of coal shale suspension was technically feasible, and that it was favoured by alkaline conditions. Of the flocculants examined, he found that natural organic colloids such as starches and guars were only moderately selective, and that low molecular weight, non ionic polyacrylamides were more selective. A nonionic polyacrylamide with molecular weight of about 4 million exhibited better selectivity than other tested polyelectrolytes in the 0.6 to 8 million range. Of the dispersants examined, sodium hexametaphosphate was the most effective. These studies also revealed that increasing concentration of ionic species such as $\mathrm{Ca}^{2+}$ in the suspension medium decreases selectivity.

Based on these studies, Hucko (1977) concluded that although selective flocculation was feasible, the high cost of reagents, especially dispersants, would make the process prohibitively expensive.

Using commercial modified polyacrylamide, Brookes et al. (1982) found in settling tests with individual suspensions of coal and shale that anionic flocculants produced higher settling rates for the latter. With cationic flocculants, the settling rates for shale were approximately one quarter of those for coal. However, in tests with equal amounts of coal and shale on a weight basis, both types of flocculants produced a low ash coal product. This phenomenon was attributed to the preferential adsorption of the flocculants onto the coal surface, the flocculant requirement for adsorption on coal being satisfied prior to significant adsorption on shale. These researchers found that selectivity could 
also be obtained with commercial flocculants but the minimum ash content achieved (31\%) would not be suitable if only a single stage process were used.

Rubio and Kitchener (1976), showed that the partially hydrophobic polymers such as non-ionic polyethylene (PEO), adsorb selectively onto hydrophobic solids and selectively flocculate them. Gochin and Lekili (1984), studied the flocculation of coal by PEO and the result were correlated with the adsorption of PEO at the coal/water interface. They postulated that the adsorption took place via hydrophobic interactions between the $-\mathrm{CH}_{2}$ in the polymer molecule and the coal surface. Solari and Rubio (1982) studied the beneficiation of a fine metallurgical, high rank coal (44\% ash) and a steam, low rank coal (49\% ash) in a Brazilian coal preparation plant. The flocculants used in the laboratory selective flocculation tests were SuperFloc NI906 (non-ionic polyacrylamide), polyethylene oxide (non-ionic) and corn starch. The dispersants tested were sodium silicate and sodium hexametaphosphate. These investigators found that the tested polymers flocculated the carbonaceous matter yielding high recovery values, with poor selectivity.

The selective flocculation of coal-bentonite mixtures of varying compositions was reported by Klunder and Koopmans (1981). These investigators reported that using waterglass as a dispersant and starch-based flocculants, the ash content of coal could be reduced from $30 \%$ to approximately $10 \%$.

It was early recognized, from the studies of various investigators, that commercially available flocculants designed to be general flocculants were not very effective as selective flocculants. Therefore, partially hydrophobic flocculants were synthesized and Da-Ichi Kogyu Seiyaku Co. Ltd. (Japan) developed F1029-D a partially hydrophobic selective flocculant for coal. 
Selective flocculation of bituminous coal obtained by the National Coal Board, UK, using sodium hexametaphosphate as the dispersant and F1029-D as the selective flocculant, showed that the ash content could be reduced significantly by multistage cleaning to any desired level (Attia et al, 1983), see Table 2.1.

Latex agglomerates were also tested. Lyadov et al (1979) used latex in laboratory and pilot plant trials for the removal of clays from coal prior to flotation. Littlefair and Lowe (1986) used a polystyrene latex produced by emulsion polymerization to selectively aggregate coal from a coal/shale mixture; it was observed that crude polystyrene latex was an effective agglomerant for coal, although de-entrapment of shale from the concentrate was necessary for substantial reductions in final ash content.

In a more recent study by Attia et al. (1985), an $80 \%$ reduction in the ash content was achieved by selective flocculation of high ash $(<45 \mathrm{wt} \%)$ coals, with concentrate yields greater than $90 \%$ using sodium methaphosphate as the dispersant and FR-7A, a totally hydrophobic latex (a Calgon product), as the flocculant. It was reported that super clean coals with ash content lower than $3 \%$ could be obtained (Attia,1988).

Laskowski et al. (1995) used coal samples of different wettability in experiments with totally hydrophobic latices (FR-7A and UBC-1), semi-hydrophobic F-1029D and PEO flocculants, and polyacrylamide (PAM). It was demonstrated that with hydrophobic agglomerants the contact angle on coal increases. Also using hydrophobic agglomerants and mixtures containing 50:50\% coal and kaolin (47.3\% ash), and 90:10\% coal: kaolin (16.5 ash), it is possible to reduce the ash content to $15 \%$ and $10.2 \%$ respectively, in one stage separation at about $95 \%$ and $98 \%$ combustible recoveries.

Application of hydrophobic polymers in selective flocculation of coal from pyrite and other mineral matter was examined by Attia and coworkers. These investigators 
determined that the performance of the hydrophobic polymer was optimum under neutral conditions and it deteriorated above $\mathrm{pH} 9$, especially if the coal surface had undergone aging.

The information regarding coal-pyrite separation is limited. Attia and Fuerstenau (1982) reported that a high molecular weight anionic polyacylamides provided separation. In the same study the use of a specially developed dispersant for pyrite was found to be effective resulting in the separation of coal from both pyrite and shale.

As shown by Usoni et al. (1968), polyelectrolytes may enhance separation selectivity in some flotation operations if their dosage is low. This was further confirmed by Osborne (1978) who used column flotation in the floc flotation experiments with sulphides. Soto and Barbery (1988) also used a column to float flocculated fine particles (in the range from 0.5 to $10 \mu \mathrm{m}$ ) of talc and coal among others. They used synthetic mixtures of minerals; for the coal-kaolinite system, either polyethylene oxide or polyacrylamide were used as flocculating agents. Floc flotation gave better recoveries and grades than sedimentation based separation. Soto and Barbery (1988) pointed out that the hydrophobic character of the solids is essential for floc-flotation and that the character of the polymer is less important. This conclusion is obviously limited to the few flocculants which they investigated. 
Coal is not a mineral of constant composition but is an organic sedimentary rock whose chemical composition changes as coalification advances. It is predominantly composed of organic matter in the form of macerals that have textural characteristics inherited from the original plant material. It also contains inorganic matter that can be estimated from the ash content generated as a part of coal proximate analysis.

Coalification is the progressive enrichment of the coal matrix in organically bound carbon. In general, a higher carbon content indicates a higher rank of coal. Many physical and chemical properties of coal vary with the rank. The chemistry of the coal surface plays an important role in any technological process in which fine coal particles are placed in an aqueous medium (Laskowski and Parfitt, 1989).

Coal is highly heterogeneous; macerals which form the organic part of coal are classified into three groups: vitrinite, exinite and inertinite. There are three important compositional properties that determine coal quality: rank, type and grade. While rank and type reflect properties of the organic part of coal, grade refers to the content of mineral matter associated with coal (ash).

\subsection{Coal properties}

\subsubsection{Chemical composition of coal}

In a chemical sense, coal is a substance of high molecular weight and non-uniform structure. As pointed out in many publications, coal is a highly crosslinked polymer which consists of a number of stable fragments connected by relatively weak cross-links. 
All coals regardless of their origin or type can be arranged in ascending order of carbon content, as shown in Table 3.1. The Figure 3.1 shows the change of chemical composition of coal as it was summarized by Whitehurst et al. (1980). The aromatic carbon content increases with the rank from about $50 \%$, for some submituminous coals, to over $90 \%$ for anthracite.

Table 3.1 Coals arranged in ascending order of carbon content

\begin{tabular}{cccccc|}
\hline Rank & Peat & Lignite & Subbituminous & Bituminous & Antracite \\
\hline$\% \mathrm{C}$ & 60 & 70 & 80 & 93 \\
$\% \mathrm{O}$ & 35 & 25 & 15 & 3 \\
Cal.Value $(\mathrm{MJ} / \mathrm{kg})$ & 28 & 30 & 32.5 & 37 & 36 \\
\hline
\end{tabular}

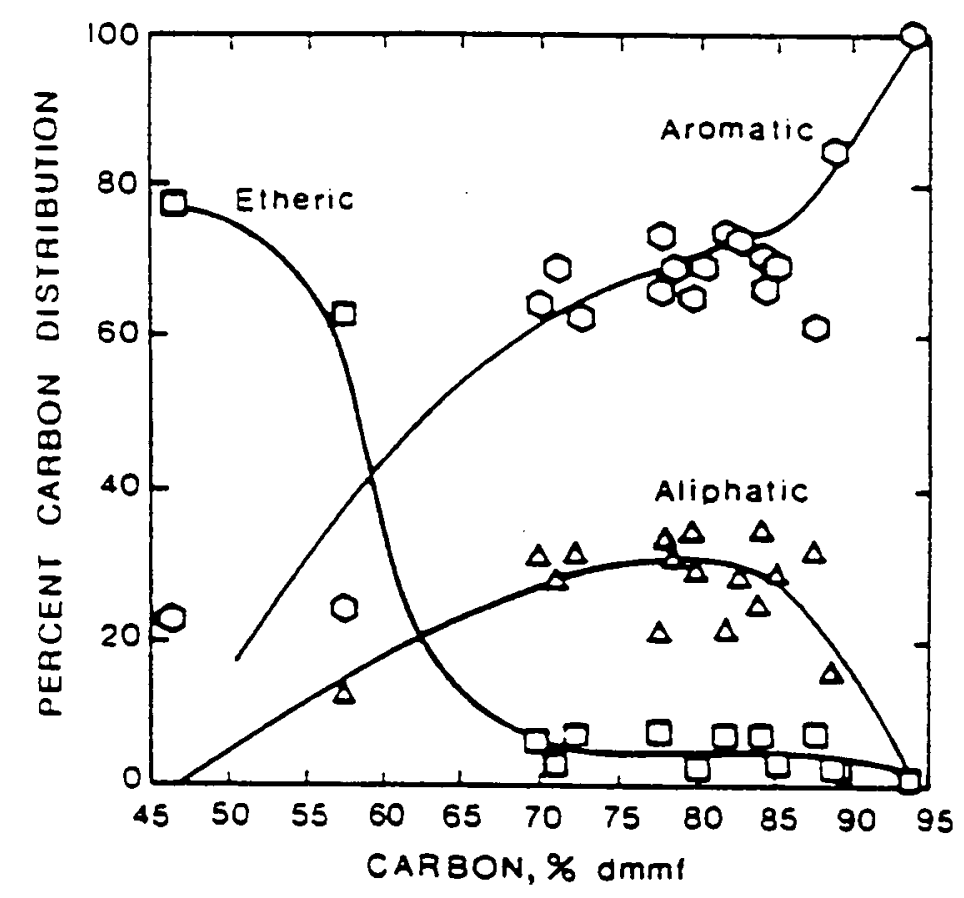

Figure 3.1. Carbon distribution in coals of different ranks (Whitehurst et al., 1980). 
One of the earliest proposed coal structures was that of Van Krevelen in 1954 (in Van Krevelen et al.,1961). Another model of coal was suggested by Given (1960). The most common is the model proposed by Wiser (1975). In this model (Figure 3.2) aromatic structures are predominant, with weak bonding between aromatic units, which accounts for easy degradation of coal into smaller fragments. Oxygen functional groups are incorporated in the carbon skeleton. Coal compositional properties change with changing chemical structure of coal associated with rank.

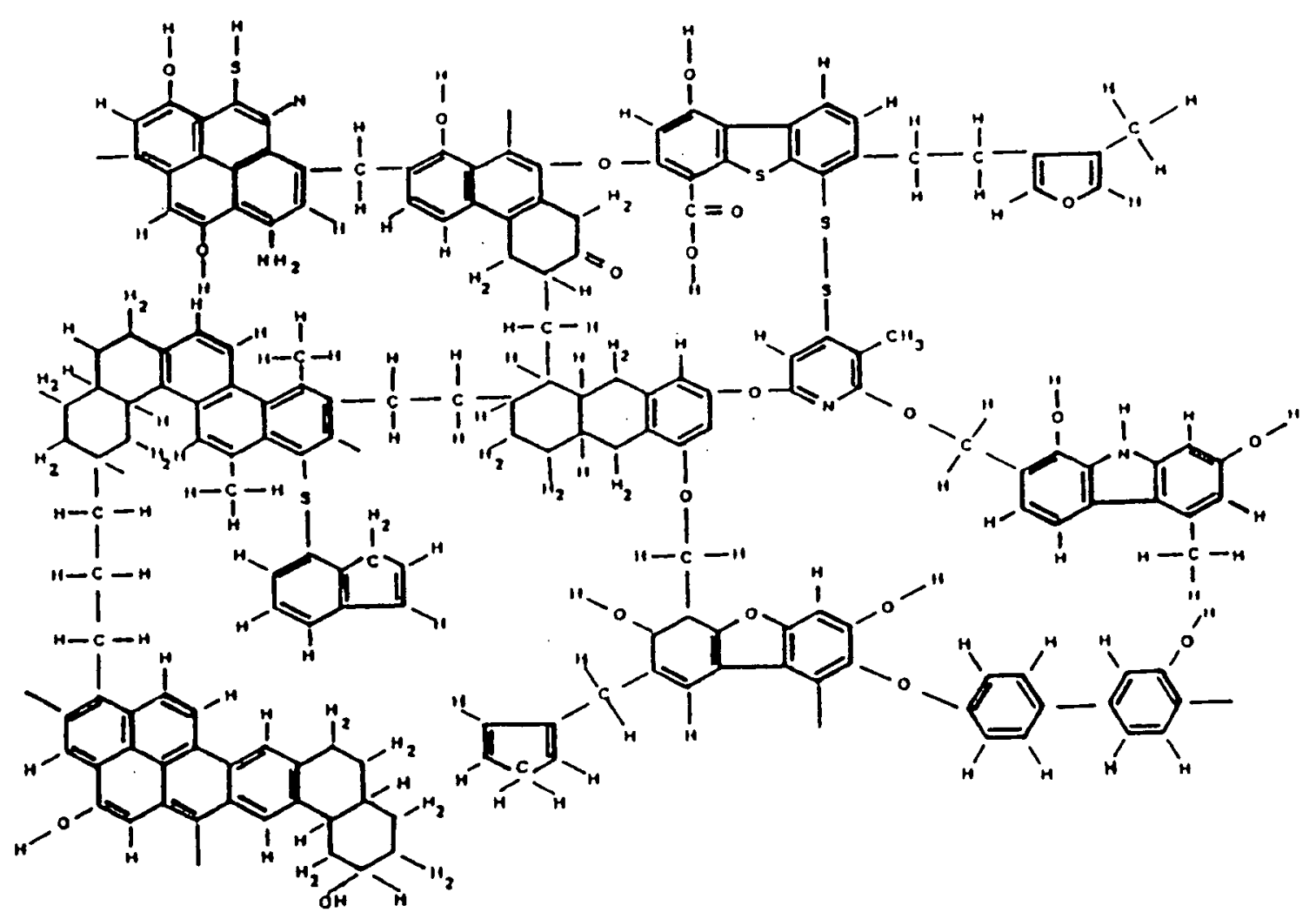

Figure 3.2. The Wiser Model of structural groups and connecting bridges in bituminous coals (Wiser, 1975). 


\subsubsection{Rank}

Rank of coal is not a directly measurable quantity; to define it, it is necessary to refer. to a specific physical or chemical property which reflects change in the course of coalification. Rank of coal can be estimated by chemical parameters, for example, volatile matter content or calorific value (ASTM D 388-77). An international committee on Coal Petrology uses optical properties, e.g. vitrinite reflectance. The new classification, proposed by Alpern (1989), incorporates all parameters within their range of applicability and recognizes petrographic composition as the important element in coal classification.

\subsubsection{Type of coal}

Type of coal reflects different plant and depositional conditions and the extent of change that has occurred during the biochemical and geochemical processes of coal formation. Two major types of coals are humic or banded coals which are formed in situ, and sapropelic or non-banded coals which are formed from different debris material and are deposited in standing waters.

Sapropelic coals differ from humic coals in their uniform texture, great strength and conchoidal fracture. They are distinguished by their high hydrogen content and high yield of volatile matter. Humic coals are predominant; they originated from organic matter which has undergone change by humification, the process of peat formation with restricted oxygen supply. Humic coals usually consist of macroscopically recognizable lithotype bands. 


\subsubsection{Mineral matter}

Coal mineral matter, which can be estimated from the ash content (from coal proximate analysis), conventionally means all forms of inorganic material associated with coal.

Coal inorganic impurities can be classified into three main groups:

1. Strongly chemically bonded elements (such as organic sulfur and nitrogen)

2. Adsorbed and weakly bonded groups

3. Mineral matter which in turn is divided into syngenetic and epigenetic

According to Mackowsky's classification (1982), the syngenetic minerals include those that were incorporated into coal from the very earliest peat-accumulation stage. By this definition most minerals in coal are syngenetic. Pyrite and siderite are among the most important minerals formed in this way, but in some coals clay minerals can also be considered as syngenetic. From a separation point of view, the most important is that the syngenetic minerals are intimately intergrown with coal macerals. In the subsequent epigenetic phase, the solutions of mineral forming ions migrated through coal fractures leading frequently to vein-type mineralization. The mayor epigenetic minerals are carbonates, pyrite and kaolinite.

Physical separation of mineral matter from coal depends on its uniformity of distribution (Cook, 1981). Epigenetic minerals are typically concentrated along cleats, thus being preferentially exposed during breakage of coal. Many physical and chemical coal utilization processes are greatly influenced by the mineral matter content. 
The type and occurrence of mineral matter in coal is particularly important to its washability characteristics and to the sizing and even crushing of thermal coal. Mineral matter content affects the heating value of coal and its ash fusion point, which influences the tendency to form deposits or cause corrosion on surfaces of heating chambers. Only part of the mineral matter is physically separable (epigenetic and epiclastic minerals), but the actual separation efficiency depends on the mineral grain size and liberation.

\subsection{Hydrophobicity of coal}

\subsubsection{Hydrophobicity theories}

The hydrophobic solids are those that display partial or incomplete wettability by water. A number of solids exhibit varying degrees of hydrophobicity when their surfaces are freshly formed (Leja, 1983). These solids are either organic such as hydrocarbons, waxes, graphite, tars, bitumen and coal, or inorganic such as sulfur, talc and molybdenite.

Hydrophobicity is of paramount importance in many surface based processes. The success of froth flotation primarily depends on the hydrophobicity of the floated particles. The hydrophobicity controls not only the thermodynamics of flotation but also the kinetics of the process.

To explain hydrophobicity, Gaudin (1957) showed that during the process of surface formation solids remain naturally hydrophobic only if their fracture or cleavage occurs without rupture of interatomic bonds other than the residual ones. These surfaces can only interact with the aqueous environment through dispersion forces. Breakage of covalent or ionic bonds leads to hydroxylation or ionization of the surface, which in turn renders the solid surface hydrophilic. The hydrophobicity of a solid (water rejection) decreases with an increment in the amount of polar sites (hydroxyl or ionic) on the mineral surface. Through these polar sites water becomes attracted to the surface. 
According to Frumkin and Dieriagin (in Klassen, 1966) low hydration of the mineral surfaces indicates strong hydrophobicity, whereas high hydration indicates hydrophilicity. In view of this theory, three types of films, disjoining particles and bubbles, may be created as a result of surface hydratation: stable, metastable and unstable. The instability of water films on hydrophobic solids is due to the lack of hydrogen bonding in these films as compared to the bulk water. In other words, the proximity of non-polar surfaces imposes on the neighboring water molecules an unfavorable configuration (Laskowski and Kitchener, 1969).

Laskowski and Kitchener (1969) used Fowkes concept of interfacial energies to explain the hydrophobic-hydrophilic transition of the solid surface.

The classical boundary condition for the hydrophilic/hydrophobic transition is equality of $\mathrm{W}_{\mathrm{A}}$ the work of adhesion of liquid to solid and $\mathrm{W}_{\mathrm{C}}$, the work of cohesion of the liquid.

$$
\begin{aligned}
& \mathrm{W}_{\mathrm{A}}=\gamma_{\mathrm{SV}}+\gamma_{\mathrm{LV}}-\gamma_{\mathrm{SL}} \\
& \mathrm{W}_{\mathrm{C}}=2 \gamma_{\mathrm{LV}}
\end{aligned}
$$

By introducing Young equation, equation (3.1) can be converted to:

$$
\mathrm{W}_{\mathrm{A}}=\gamma_{\mathrm{LV}}(1+\cos \theta)
$$

Then

$$
\frac{W_{A}}{W_{C}}=\frac{\gamma_{L V}(1+\cos \theta)}{2 \gamma_{L V}}
$$




$$
\cos \theta=2 \frac{W_{A}}{W_{C}}-1
$$

The condition of hydrophobicity follows from equation (3.5): only for $\mathrm{W}_{A}<\mathrm{W}_{\mathrm{C}}, \theta \neq 0$.

Figure 3.3 depicts a sessile liquid droplet resting on a flat surface. The values of the work of cohesion of the liquid, and the work of adhesion of the liquid to the solid determine the contact angle at the solid/liquid/gas interface, i.e.

$$
W_{A}=W_{A}^{d}+W_{A}^{h}+W_{A}^{e}
$$

where $W_{A} d$ is the contribution from dispersion forces, $W_{A}{ }^{h}$ is the contribution from the hydrogen bonding of water to solid surfaces groups (hydroxyl and similar), and $\mathrm{W}_{\mathrm{A}} \mathrm{e}$ is the contribution from the electrical charge at the interface

According to Fowkes (1969), $\mathrm{W}_{\mathrm{A}} \mathrm{d}$ can be calculated from:

$$
W_{A}^{d}=2\left(\gamma_{H_{2} 0^{d}} \times \gamma^{d}\right)^{1 / 2}
$$

$$
\text { where } \gamma_{H, o^{d}} \approx 22 \mathrm{erg} \mathrm{cm}^{-2}
$$

Laskowski and Kitchener (1969) indicated that no surface (except fluorocarbon) has $\mathrm{W}_{\mathrm{A}}$ as large as the exceptionally high work of cohesion of water $\left(\mathrm{W}_{\mathrm{C}}=145 \mathrm{erg} \mathrm{cm}^{-2}\right)$.

Therefore, because

$$
\cos \theta=2\left\{\frac{W_{A}^{d}+W_{A}^{h}+W_{A}^{c}}{W_{C}}\right\}-1
$$


for $W_{A} h \approx 0$ and $W_{A} e^{2}=0$

$$
\cos \theta=2 \frac{W_{A}^{d}}{W_{c}}-1
$$

It follows from equation (3.9) that the solid is always hydrophobic, $\theta>0^{\circ}$, whenever $\mathrm{W}_{\mathrm{A}} \approx \mathrm{W}_{\mathrm{A}} \mathrm{h}$ The main conclusion is obvious, all solids would be hydrophobic if they did not carry polar or ionic groups (Laskowski and Kitchener, 1969).

Equation (3.8) also explains the effect of the electrical charge of the solids on its wettability. According to this equation, contact angles should reach maximum values, $\theta \rightarrow \theta \max$. when $\mathrm{W}_{\mathrm{A}}^{\mathrm{e}} \rightarrow 0$

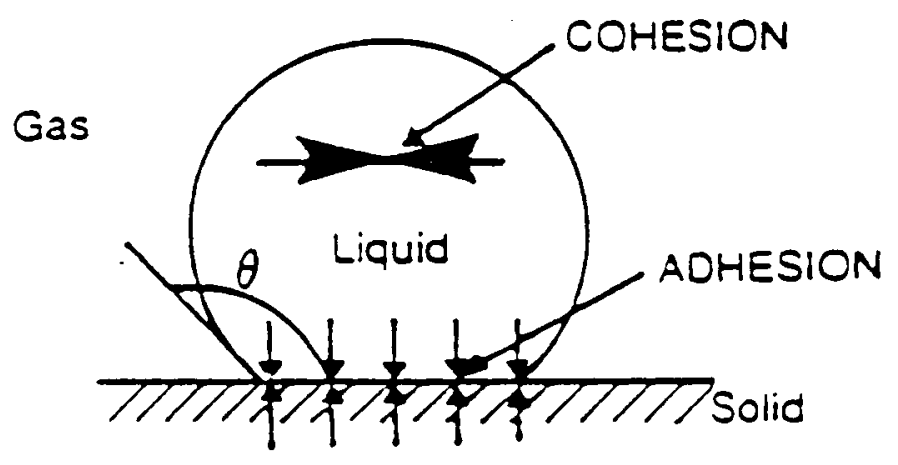

Figure 3.3: The effect of the work of cohesion and adhesion of liquid to solid on the solid wettability (Laskowski, 1992). 


\subsection{Hydrophobic character of coal}

Coal is considered to be naturally hydrophobic. It is the surface of coal which controls the mechanism of interaction with water, and therefore the hydrophilichydrophobic character of coal. The surface properties of coal may be quite different from the properties of the bulk solid, as in the case of surface oxidation, or selective adsorption.

According to Gaudin (1957), hydrophobicity is only possible for solids in which fracture or cleavage occurs without rupture of interatomic bonds other than the residual ones. The thermodynamic condition for hydrophilicity, as discussed in the previous section, implies that the main forces of water attraction to the solid surface are hydrogen bonding (through the surface hydroxyl groups), or the forces arising from the electrical charge at the interface.

In coal, oxygen functional groups such as hydroxyl, carbonyl or carboxyl occur either as a result of oxidation or as a part of the coal structure. The amount and type of these groups change with the rank of coal, as do many other properties. The oxygen functional group content, and their type, were frequently used to relate the change of coal surface properties with rank (Blom et al., 1957). The hydrophobicity of coal was shown to be a function of rank. For a given rank of coal and a controlled level of oxidation, hydrophobicity is primarily dependent on the surface heterogeneity arising from the petrographic composition, as the macerals are known to have various surface properties.

The important factor in estimation of the hydrophobicity of coal is the associated mineral matter. Since coal mineral matter is hydrophilic, intimate association of mineral matter has a strong effect on the hydrophobicity of coal particles. 


\subsubsection{Rank}

The contact angle has long been the only measure of hydrophobicity of coal. From the earliest result (Brady and Gauger, 1940) to the most recent works (GutierrezRodriguez et al., 1984; Aplan, 1983) on the contact angle of different coals, it can be concluded that bituminous coals have the highest contact angle (higher than either anthracite or lignite).

Contact angles are usually determined using either the captive bubble or the sessile drop method. In the former technique an air bubble is deposited on the coal surface in solution, whereas in the latter a drop of water is placed on the dry coal surface. In both methods contact angle is measured through the water phase, the higher the contact angle, the more hydrophobic the surface. Results of contact angle measurements for coals of different rank are depicted in Figure 3.4 after Aplan (1984), Onlin and Aplan (1987) and Arnold and Aplan (1989).

In recent years, other indirect techniques of characterizing hydrophobicity have been successfully developed. These include the rate of disappearance of coal particles deposited on surfactant solutions, the immersion time for particles to sink into liquids having different surface tensions (Fuerstenau et al., 1987; Fuerstenau et al., 1986), and the induction time required for particle to attach to an air bubble (Ye and Miller, 1988). The first two measure the critical surface tension of coal which indirectly characterizes coal hydrophobicity. These measurements have shown a correlation between hydrophobicity and coal rank, which is similar to that obtained for contact angle.

The decreased hydrophobicity of low rank coals is mainly due to the presence of a high concentration of oxygen functional groups in the coal structure. Through these groups water is attracted to the coal surface (Fuerstenau et al., 1983). 


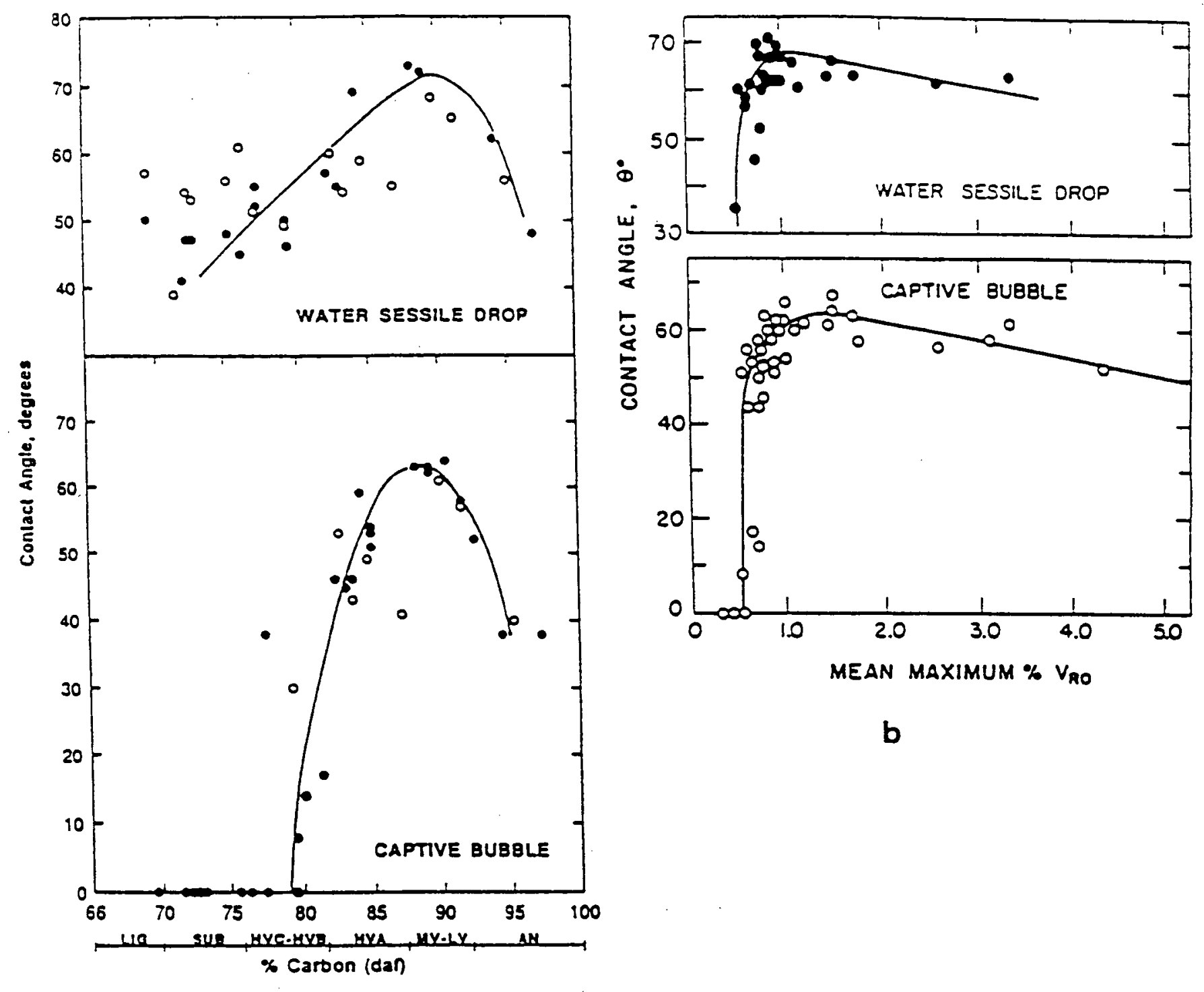

$\mathbf{a}$

Figure 3.4. Contact angles for coals of different ranks measured by captive bubble and sessile drop techniques; a) contact angles vs. $\%$ carbon, b) contact angle vs. vitrinite reflectance. After Aplan (1984), Onlin and Aplan (1987) and Arnold and Aplan (1989). 
In the transition from lignite to higher rank coal $(80 \% \mathrm{C})$, the coal structure loses a significant portion of the oxygen groups, but at the same time the content of aromatic hydrocarbons increases. The results presented by Ihnatowicz (1952) and Blom (1957), show the distribution of functional oxygen groups in coals versus coal ranks (Figure 3.5).

The decreased hydrophobicity of anthracite is often related to its high content of aromatic hydrocarbons, which are less hydrophobic than paraffinic hydrocarbons (Keller, 1986).

\subsubsection{Oxidation}

Oxidation is a chemical process leading to the alteration of coal during weathering (Gray and Lowenhaupt, 1989). The oxidation of coal can occur in situ, during mining and processing, or in stock-piles. Coal oxidation adversely affects many properties of coal. Coking and plastic properties of bituminous coals, flotation recovery, and calorific value are all significantly influenced; some of these properties are lost when coal is oxidized (Ignasiak et al., 1974; Gray et al., 1976; Berkowitz, 1979).

When coal is exposed to the atmosphere, adsorption of oxygen onto the coal surface occurs and it is followed by chemical reactions. As a result, oxygen functional groups such as $-\mathrm{OH},-\mathrm{CO},-\mathrm{COOH}$ and $-\mathrm{OCH}_{3}$ are formed on the surface. The low rank coals are more susceptible to oxidation than the high rank coals (Berkowitz, 1979; Meuzelaar et $a l, .1987)$ as their structure already possesses high concentration of oxygen functional groups, which in turn are sites for oxygen preferential adsorption. The higher is the rank of coal the less susceptible it is to oxidation.

The oxygen functional groups that are produced on the coal surface as a result of oxidation, control wettability and flotation kinetics through the balance of 
hydrophobic/hydrophilic sites (Iskra and Laskowski, 1967; Wen, 1977; Fuerstenau et al., 1983, Laskowski and Parfitt, 1989). The presence of such polar groups leads to the interaction with water molecules, which makes coals hydrophilic. Hydrophobicity of coal is, therefore, significantly influenced by the degree of oxidation.

Numerous sophisticated methods and techniques have been developed to study the oxidation of coal and its effects on technological behavior. Among these are: pyrolysis, mass spectrometry, gas chromatography, thermogravimetry/mass spectroscopy, FTIR spectroscopy (Meuzelar, 1987) along with simpler procedures such as chemical titration

of acidic groups (Ihnatovich, 1952, Shafer, 1970, Fuerstenau et al.,1983), titration of humic acids released on boiling fine coal in a solution of $\mathrm{NaOH}$ (Lovenhaupt and Gray,1980) Free Swelling Index, flotation response (Sun, 1954; Yarar and Leja, 1982), salt flotation method (Iskra and Laskowski, 1967), etc.

Several correlations were reported between the degree of surface oxidation and the contact angle (Horsley and Smith, 1951; Iskra and Laskowski, 1967), immersion time (Garshva et al, 1978, Fuerstenau et al, 1986), electrokinetic potential (Laskowski and Parfitt, 1989) and parameters related to flotability and to the critical surface tension of wetting (Horsnby and Leja, 1980, 1983; Fuerstenau et al., 1985).

\subsubsection{Electrical Charge}

The electrokinetic behavior of coal is difficult to describe due to coal heterogeneity, and its tendency to alter during the exposure to the atmosphere (Laskowski, 1968; Laskowski and Parfitt, 1989). 
The surface of coal can be viewed as a hydrophobic matrix that contains various heteroatoms and functional groups. These sites display different electrochemical characteristics, and contribute to the surface charge of individual particles.

The minerals associated with coal can have very different electrokinetic characteristics. For example, alumino-silicates are known to have a negative charge at the basal planes but their edges are characterized by an isoelectric point (i.e.p.) at $\mathrm{pH}=9.1$, $\left(\mathrm{Al}_{2} \mathrm{O}_{3}\right)$. Quartz is negatively charged over the entire range of $\mathrm{pH}$, while carbonates have their i.e.p. in the slightly alkaline $\mathrm{pH}$ range (Sadowski and Laskowski, 1981).

The type and amount of mineral matter were shown to significantly affect the electrokinetic properties of coal (Fuerstenau et al., 1983; Laskowski, 1989). A high content of mineral matter was found to change the electrokinetic behavior of coal to resemble that of associated minerals (Fuerstenau et al, 1983).

The electric charge on the surface of coal is developed by dissociation of functional groups, and the sign of the surface charge depends on the $\mathrm{pH}$ of the solution (Campbell and Sun, 1970; Laskowski, 1989). The data reported by Sobieraj and Myrcha (1980) confirmed that the isoelectric point (i.e.p.) values for low rank and oxidized coals moved towards the more acidic $\mathrm{pH}$ ranges. A generalized zeta potential versus $\mathrm{pH}$ diagram for various ranks of coal and oxidized coal is shown in Figure 3.6.

The i.e.p. values were also found to change with the rank, as described by Laskowski (Laskowski, 1968; Laskowski and Parfitt, 1989) and shown in Figure 3.7. 


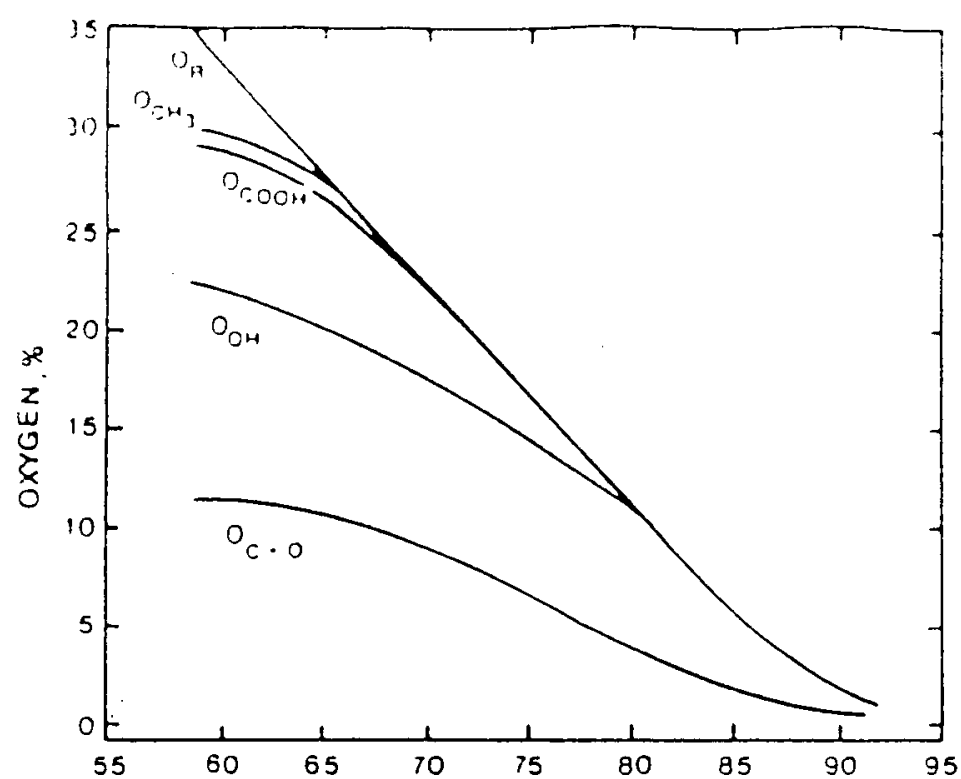

(a)

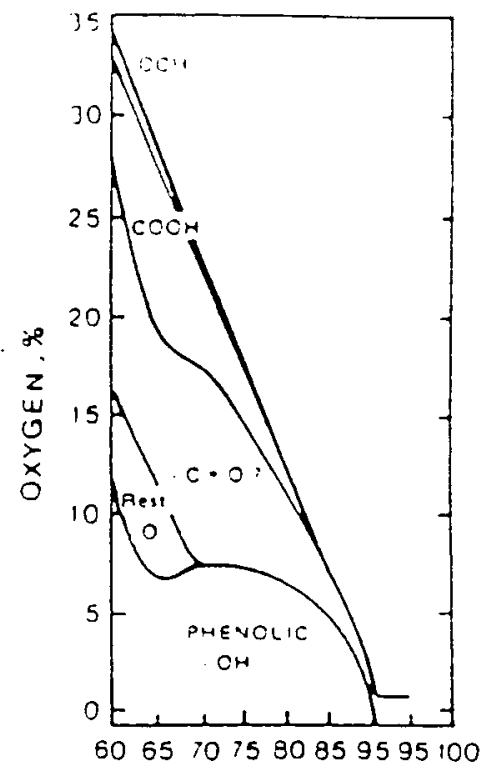

(b) CARBON \% dmmI

Figure 3.5. Distribution of oxygen groups in coals of different ranks, a) after Innatowicz, (1952), b) and Blom, (1957).

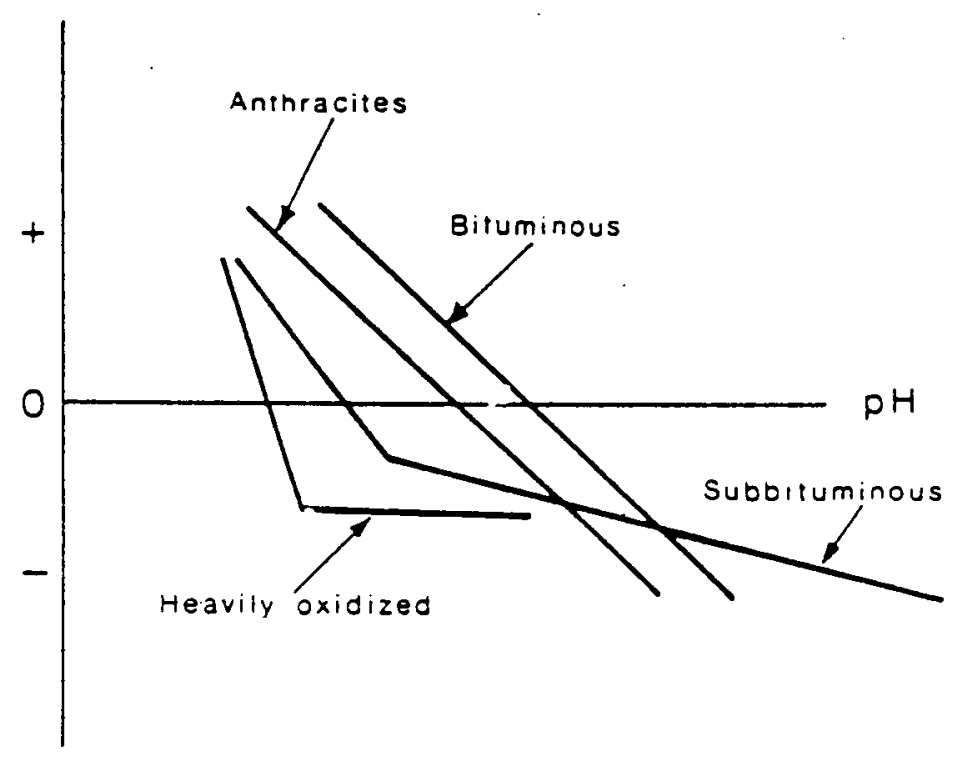

Figure 3.6. Generalized zeta potential versus $\mathrm{pH}$ diagrams for coals of various ranks (Laskowski and Parfitt, 1989). 


\section{3.t Petrographic composition}

Unfortunately, very little is known about the hydrophobicity of pure macerals, mainly because of the difficulty in the obtaining pure maceral concentrates. Most of the studies assessing hydrophobicity of petrographic components were usually limited to lithotype samples, representing natural concentrates of macerals. The very first contact angle measurements performed on lithotypes were reported by Horsley and Smith (1951). They showed that the natural contact angles of different lithotypes differed by nearly 50 degrees, with vitrain being the most hydrophobic, followed by durain and fusain. Sun (1954) suggested that the order of hydrophobicity, based on the calculation of surface properties from the elemental analyses (flotability index), decreases as follows:

$$
\text { clarain }>\text { vitrain }>\text { fusain }>\text { durain }
$$

Frequent discrepancies in the assessment of hydrophobicity of coal lithotypes are attributed to fundamental differences between coals, as well as variations in macerals and minerals.

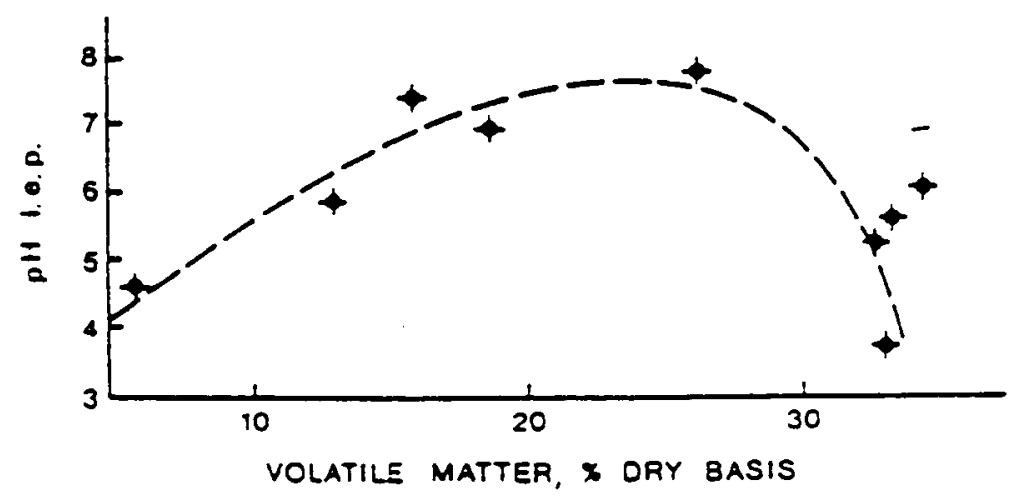

Figure 3.7. Isoelectric points for coal of varying rank (Laskowski, 1968). 


\subsubsection{Mineral matter}

The minerals associated with coal are, as discussed in section 3.1.4, naturally hydrophilic. Consequently, any inclusion of mineral matter in the coal surface will have an influence on its hydrophobicity. The hidrophobicity will then depend on the type of mineral matter and its form of association with particular coal, its texture and liberation characteristics, epigenetic minerals are the easiest to separate from macerals. In terms of hydrophobicity, the syngenetic mineral matter will influence the surface properties of coal particles the most. Epigenetic minerals, which are typically concentrated along the cleats, are usually liberated during breakage.

In the work of Bustamante and Warren (1983), some conclusions were reached as to the direct influence of mineral matter content on flotation recovery of coal particles. In their study, relatively small amount of mineral matter in coal particles depressed the flotation of low rank coal, but when the coal was of higher rank, relatively large proportions of mineral matter had little effect on flotability. The very fact that large amounts of mineral matter are usually associated with fusinite has often been used to explain the very low hydrophobicity of this maceral (Brown, 1962; Klassen, 1966; Bujnowska, 1958a). 


\section{CHAPTER 4: POLYMERS IN FLOCCULATION}

A polymer may be defined as a large molecule comprised of repeating structural units joined by covalent bonds, (Greek: poly $=$ many, meros $=$ part). Polymeric flocculants are those macromolecular organic substances that bridge finely divided particles (flocs). Typical polymeric flocculants are chain macromolecules with molecular weights of $10^{6}$ to $10^{7}$. They may be natural, synthetic or derivatized hybrid organic products. Due to their chain lengths, they are capable of adsorbing simultaneously on several particles.

There are many ways to classify polymeric flocculants; they may be categorized as natural, synthetic or derivative, as high or low molecular weight, or as cationic, anionic or nonionic.

\subsection{Natural Flocculants}

Polymeric flocculants derived from natural sources have been used since very early times. Ancient cultures used natural polymeric substances for clarification of water, beer and wine. However the application of polymeric flocculants in mineral processing is relatively more recent. One of the earliest patents in minerals application details the use of starch and lime for clarification of colliery effluents containing fine coal particles along with clays; the patent was filed in 1928 (Kitchener, 1978).

The natural polymers and their derivatives used as flocculants include starches, galactomannas, cellulose derivatives, alginates and chitin. These are water soluble polymers and vary in structure, molecular weight, biodegradability and ease of dissolution (Krishnan and Attia, 1986). 


\subsection{Synthetic flocculants}

Synthetic man-made polymers dominate as the chief type of polymeric flocculants used by the mineral industry. These polymers are almost invariably based on polyacrylamides, although a significant number of other chemical types also exists. Commercial polymeric flocculants can be anionic, cationic, or nonionic, and it is useful to classify them as such.

\subsubsection{Anionic polymers}

Anionic polymers containing carboxylic groups are by far the most important in this class, both in the high and low molecular weight ranges. The most common are based on polyacrylic acid, salts of polyacrylic acid or acrylamides. The latter type is generally prepared by either polymerization/hydrolysis of acrylamide or by copolymerization/hydrolysis of acrylamide with acrylic acid or acrylate salts. Polyacrylamides contain a rather random distribution of a relatively few carboxylate groups along the predominantly polyacrylamide chain. Since only a fraction of the carboxylate groups are present (15-50\%) these type of polymers are relatively weakly anionic.

\subsubsection{Cationic polymers}

Cationic polymeric flocculants contain positively charged groups, such as amino $\left(-\mathrm{NH}_{3}{ }^{+}\right)$, imino $\left(-\mathrm{CH}_{2}-\mathrm{NH}_{2}-\right)$, or a quaternary amino $\left(-\mathrm{NR}_{4}{ }^{+}\right)$. Most of the high molecular weight cationic polymers available today are made by free-radical copolymerization of acrylamide with minor amounts (10 mol \% or less) of cationic monomer.

While low molecular weight polymers function as coagulants, high molecular weight polymers function as flocculants. Most cationic polymers function by a combination of charge neutralization and bridging. 


\subsubsection{Nonionic polymers}

Nonionic polymers consists chiefly of polyols and unhydrolyzed polyethers and polyamides. Two of the most common nonionic polymeric flocculants used in the mineral industry are polyacrylamide and polyethylene oxide. A truly nonionic polyacrylamide does not exist, most commercial "nonionic" polyacrylamides contain at least $1 \%$ or $2 \%$ of hydrolyzed amide groups, making them slightly anionic.

The other nonionic polymer commonly utilized by the mineral industry as flocculant is polyethylene oxide (PEO). These polymers range in molecular weight from 20,000 to about 5 million.

\subsection{Mechanisms of Adsorption of Polymeric Flocculants}

The forces involved in the adsorption of polymeric flocculants onto mineral particles can be either physical or chemical, or both. The forces that are considered to be physical (do not involve chemical bonding) include the following:

- Electrostatic (Coulombic) forces: these result in the adsorption of counter-ions onto any surface of opposite charge, irrespective of their chemical nature.

- London-Van der Waals forces: in this case, neutral molecules or atoms constitute systems of oscillating charges producing synchronized dipoles that attract each other.

- Hydrophobic association: this results from the tendency of non-polar molecules (or substances) to escape from the aqueous environment. 
Polymer adsorption and the conformation of the macromolecules at the solid/liquid interface is very important and it is the key to understand how polymers function in such processes (Nyamekye and Laskowski, 1992).

The chemical forces resulting in chemisorption, include the following:

- Chemical bonding: this is exemplified by the reaction of the polymer's functional groups with metallic sites on the solid surface which result in the formation of insoluble compounds by covalent or ionic bonding. Chelating or complex formation resulting in polymer attachment to the surface can also be classified in this group.

- Hydrogen bonding: in the organic compounds where the hydrogen atom is combined with a strongly electronegative atom such as $\mathrm{O}, \mathrm{S}$, or $\mathrm{N}$, the hydrogen atom is able to accept electrons from another atom, for intance, from the -OH groups of the hydrated surfaces of an oxide mineral, resulting in the formation of hydrogen bond.

The adsorption of polymers on mineral surfaces by chemical forces against electrostatic repulsion can only happens if the polymer approaches the surface closely by other means or mechanisms. 


\subsubsection{Polymer adsorption onto minerals}

Polymers adsorb onto mineral surfaces in a variety of ways that are discussed below by reference to a particular example.

The adsorption of polyacrylamides onto hematite occurs by hydrogen bonding of the polymer functional group with the hematite surface, with electrostatic interactions only playing a secondary role (Moudgil and Somasudaran, 1982).

Polyacrylamides also adsorb onto apatite, mainly by hydrogen bonding between the $\mathrm{OH}$ groups on the apatite and the amide groups on the polymer, although electrostatic attraction may also play a part (Attia and Fuerstenau, 1980).

On the other hand, adsorption of polyacrylamides onto clays under weakly acidic conditions is a chemisorption phenomenon (Stutzmann and Siffert, 1977) where the polyelectrolyte is adsorbed exclusively onto the external surface of the clay. This appears to occur by replacing adsorbed water molecules from the clay surface (Parfitt and Greenland, 1970). The dissociation of these sites is $\mathrm{pH}$ dependent, which gives rise to a wide variation of adsorption capacity with $\mathrm{pH}$.

Polycation adsorption onto clays takes place largely through electrostatic interactions between the polymer and negatives sites on the clay surface (Van Olphen, 1963). Thus polycation adsorption occurs largely on the faces of the clay platelets, and polyanion adsorption takes place largely on the edges (Ueda and Harada, 1968).

The adsorption of polyethylene oxide onto silica occurs through a combination of hydrogen bonding and hydrophobic association via the silanol and siloxane groups on the silica surface (Rubio and Kitchener, 1976). 
Fixation of polyethylene onto coal takes place by hydrogen bonding through the ether oxygens of the polymer and the hydroxyl groups on the coal surface (Lyadov et al., 1979). At low polyoxyethylene additions, aggregation takes place by charge reduction, although at higher concentrations it occurs mainly by bridging (Lyadov et al., 1979). Flocculation of coal slurries by non-ionic polyacrylamides is found to be greatest at the point of zero charge of the coal.

In summary, it appears that uncharged macromolecules adsorb onto mineral surfaces by hydrogen bonding or hydrophobic interactions. Charged polymers adsorb mainly by electrostatic attraction, although hydrogen bonding, especially with polyacrylamides plays a major role. However, de Araujo et al. (1986), found that chemical interaction plays an extremely important role in the adsorption of carboxymertylcellulose onto graphite. In line with this, Qi Liu and Laskowski (1989) and Laskowski and Nyamekye (1992) showed that dextrin adsorbs onto sulphides also through chemical interaction.

\subsection{Selective polymeric flocculants}

Selective flocculants are used either alone or in combination with general dispersants. Selective flocculant adsorption can be achieved by either designing a specific flocculant or enhancing the polymer's selectivity by chemical modulation of the interface. Specifically designed polymeric flocculants can be classified into three categories:

(a) Chemisorbing or chelating polymers in which the functional groups are strong complex formers with certain ions (Attia and Kitchener, 1975).

b) Stereo selective flocculants which rely on the selective effect of the molecular structure such as hindrance adsorption of polymers having bulky groups in their structures (Attia, 1982). 
c) Hydrophobic or partially hydrophobic flocculants where selective flocculation of hydrophobic colloids from hydrophilic ones is desired (Rubio and Kitchener, 1977; Palmés and Laskowski, 1993).

Enhancement of polymer's selectivity by chemical modulation of the interface involves regulating the surface electrical charge or employing competitive dispersants. In the latter, a dispersant (or a depressant) would compete with the flocculant for bonding sites on a solid surface, thereby inhibiting its adsorption.

\subsection{Design of selective flocculant polymer}

Selective flocculation cannot be achieved unless the polymeric flocculant is selectively adsorbed on the mineral to be flocculated (Yarar and Kitchener, 1970). Therefore, the ability of the polymer's functional groups to exploit the differences in the surface chemical behaviors of the various mineral particles to achieve selective adsorption is of basic concern (Attia and Fuerstenau, 1978; Attia, 1986). In order to select the polymer, three main interactive factors must be carefully considered: flocculant, mineral surface and suspending medium.

The effect of the suspending medium, which is aqueous in most applications, can only be considered in conjunction with the behavior of the flocculant and the mineral surface. It is well known that the aqueous medium affects the properties of the polymeric flocculants. Hence, coiling up and uncoiling (or even decomposition) of the polymers are certainly affected by the type and concentration of electrolytes in solution, hydrodynamic conditions, $\mathrm{pH}$ and the ionic nature of the polymer's functional groups. Similarly, the electrochemical state of the mineral surface is controlled by the aqueous medium. Thus, the adsorption of the polymer on the mineral surface can be strengthened or prevented 
largely by proper control of the physico-chemical conditions. Therefore, although selective polymer adsorption and flocculation depend primarily on the functional groups of the polymer and nature of the surface sites on the mineral, it can be largely influenced by $\mathrm{pH}$, ionic strength, etc.

\subsubsection{Design of the polymer's selective functional groups.}

As a basis for selective adsorption of polymer, it is important that the various minerals to be separated have at least one surface property (such as hydrophobicity, surface charge, or chemical bonding) which is significantly different. The wider the difference in the surface behavior between the fine mineral particles to be separated, the more selective is the adsorption, and thus the easier the separation becomes. However, before a functional group can be selected for incorporation in the polymer's structure, the various mechanisms of polymer adsorption must be considered.

\subsection{Possible mechanisms for selective adsorption}

Ideally, the design of a specific polymer for a particular mineral surface should be based on a "yes" or "no" adsorption. As mentioned earlier, selective polymeric flocculants adsorb primarily by either: a)chemisorption or chelating mechanisms, or b) hydrophobic interactions. Similar to flotation, electrostatic attraction can also be exploited as a mechanism for selective adsorption of a polymer on opposite charged particles. 


\subsubsection{Selective polymers based on chemisorption}

A few examples of selective chemisorbing flocculants can be found in the literature (Attia and Kitchnener, 1975; Drzymala and Fuerstenau, 1975). The development of polyxanthate flocculants for the selective flocculation of sulfide minerals and oxidized copper minerals was first reported by Attia and Kitchener (1975), and was later confirmed by Sresty et al. (1978). A chelating or complexing polymer, polyacrylamideglyoxal-bis-2-hydroxylanil (PAMG), was designed and used for the selective flocculation of copper minerals (Attia, 1977). The use of chemisorbing or chelating polymers for achieving selective flocculation so far represents the most practical and promising mechanism. These types of flocculants are, therefore, very likely to find applications in the mineral processing industry in the future.

\subsubsection{Selective polymers based on hydrophobic effect}

Hydrophobic or partially hydrophobic polymers appear to have the greatest potential for selective flocculation of hydrophobic solids (with natural or induced hydrophobicity) in mixed suspensions with hydrophilic minerals. The application of flocculants in selective flocculation of hydrophobized copper minerals was first reported by Rubio and Kitchener (1977). In their application, the initially hydrophilic surfaces of oxidized copper minerals were selectively made hydrophobic by sulfidization with sodium sulfide and selective adsorption of the collector. Then, by introducing a partially hydrophobic flocculant, polyethylene oxide, selective flocculation of oxidized copper minerals from associated hydrophilic silica and silicate minerals was achieved.

Hydrophobic polymers of high molecular weight, once dissolved in water, have an affinity for any hydrophobic surfaces, and cause flocculation of such minerals. 
The main problem with these polymers is the means by which they are solubilized in water. In order for the hydrophobic polymers to be effective as flocculants they have to be solubilized in water. This may be achieved by any one of the following three methods:

1. The polymer may be dissolved in organic solvent, and the organic phase may then be emulsified in water using an emulsifying agent.

2. The polymer can be dissolved in a solution of surfactant, thereby creating a soluble ion complex of surfactant and organic polymer.(Isemura and Imanishi, 1958).

3. An emulsion of the monomer in water is polymerized to produce a latex by surfactant free emulsion polymerization (Roe and Brass, 1958). These are colloidal particles with some surfactants incorporated in their surface layers.

\subsection{Production of hydrophobic polymers}

Emulsion polymerization of an organic monomer in water is the most effective method of solubilizing hydrophobic polymers. Polystyrene has frequently been produced by this method (Piirma et al., 1975). The synthesis includes emulsification of the

monomer (styrene) and the addition of the initiator for the polymerization; this is followed by the formation of free radicals (Harkins, 1947). In the presence of these radicals, the droplets of emulsified monomer are polymerized into colloidal latex particles, and the surfactant used to emulsify the monomer becomes incorporated into matrix. 
According to Van De Ven et al. (1983), latex particles obtained by emulsion polymerization are characterized by "hairiness"; these are surfactant molecules forming an adsorbed layer on the surface of the latex particles. These "hairs" on the surface of latex spheres protrude from the surface up to distances comparable to the distances where the double layer energy barrier occurs, typically of the order of 5-10 nm. 


\section{CHAPTER 5: SHEAR RATE IN FLOCCULATION TESTS}

Hydrodynamic forces affect all aspects of the flocculation process, from dispersion of polymers to polymer adsorption/attachment, floc formation and floc breaking. Without mixing, fine particles would collide only due to the Brownian motion which is insignificant in coarse disperse systems such as suspensions. For particle interactions resulting from van der Waals attraction and electrostatic repulsion, the magnitude of the energy barrier can be predicted from the DLVO theory. Aggregation between particles is only possible when the kinetic energy of the particles is larger than the energy barrier. This idea has been used in the shear-flocculation process (Warren, 1975), as well as in other types of flocculation (hydrophobic) (Palmés and Laskowski, 1992). It is worthy of mention that the shear rate is difficult to measure: Van de Ven and Mason (1981) constructed stability domain diagrams from which critical shear rates can be anticipated, but the critical shear rate predicted from their theory for shear-flocculation was extremely large, much larger than that measured experimentally. An explanation for this discrepancy is that an additional attractive energy due to the hydrophobic association, which is very important in shear-flocculation, is not considered in the classical DLVO theory.

\subsection{Evaluation of hydrodynamic conditions}

The evaluation of the hydrodynamic conditions in flocculation tests is rather complicated as it depends on the approach selected by each investigator. However, the interpretation of the flocculation tests must be based on the data obtained using well calibrated techniques if they are to be quantitatively meaningful. 
One important variable in the procedure is the mixing intensity, which is not only related to the rotational speed but also to the configuration of the agitator and the geometry of the mixing vessel. The latter is usually overlooked and undefined.

The aggregation process itself is based on the theory of accelerating the collision of two spherical particles. Such a mathematical model, described by the Smoluchowski equation (in Ives,1978), results in the following relationship:

$$
\left.J=[(d v / d z)] N^{2} d^{3}\right] / 3
$$

where $\mathrm{J}=$ the number of collisions/unit time/unit volume, $\mathrm{N}=$ the number of particles/unit volume, $d=$ the particle diameter and $d v / d z=$ the difference in velocities between two streamlines, i.e., the velocity gradient or the shear rate.

Smoluchowski equation is valid only for laminar flow conditions and for spherical particles of uniform size; the theory also assumes that each collision is successful and leads to attachment.

The number of collisions (which should be maximized) is dependent on the number of particles and on the particle diameters. A velocity gradient is set up by mixing the slurry. The velocity gradient will vary with position within the mixing chamber (i.e., distance away from the mixer) and with time at any point. Because these variations are not easily defined, $(\mathrm{dv} / \mathrm{dz})$ is averaged over space and time and is called the temporal mean velocity gradient, $G$. Introducing $G$ into equation (5.1) yields:

$$
J=\left(G N^{2} d^{3}\right) / 3
$$


The type of flow and the degree of mixing are important. In a system with laminar flow, the particles experience the same shear rate throughout the entire flocculation process, while in a perfectly mixed system, such as in a baffled stirred tank, all of the particles would eventually be exposed to the full range of shear rates present.

Most authors who have studied the effect of the shear rate on flocculation have merely quoted impeller speeds. These, of course, are not comparable in terms of shear rates unless the tank and impeller geometry are identical. The geometry of the flocculation tank, the number and size of baffles, the type, size and location of the impeller in the tank, affect the degree of flocculation. However the optimum design of the tank is not yet known. It has been assumed that it is the region of high shear rate in the tank that is most active in causing flocculation. Koh (1984) took this concept further and defined three zones: an impeller zone of high shear rate, a bulk zone of intermediate shear rate and a "dead space" at the top and the bottom of the tank (Fig 5.1) in which the shear rate is below the critical value required for aggregation.

Every impeller transmits its power in two forms: water and particle movement (Camp, 1954), and shear rate (Oldshue, 1966). Each type of impeller splits its power differently between flow and shear rate. Yet, it is not known what the optimal split between pumping and shearing should be for flocculation, even though every impeller exhibits both of those characteristics. The impeller, depending on its design, also acts as a pump and circulates the suspension from the impeller zone to the bulk zone and back again to the impeller. The frequency with which particles circulate through the impeller zone, and the time particles spend in each zone, thus depend on the impeller pumping rate, and the relative volume of the three zones. 
The limitations of the use of an averaged $G$ value must not be overlooked: each type of mixing device will impart a different shear rate distribution throughout the vessel, and the maximum shear rate can be much larger than the average shear.

In spite of these factors, there are at least two reasons why the average velocity gradient is still commonly used: first $G$ is a reasonable accurate estimate of the average shear rate, second $\mathrm{G}$ is easily obtained and is a familiar parameter to most engineers in areas other than mineral processing.

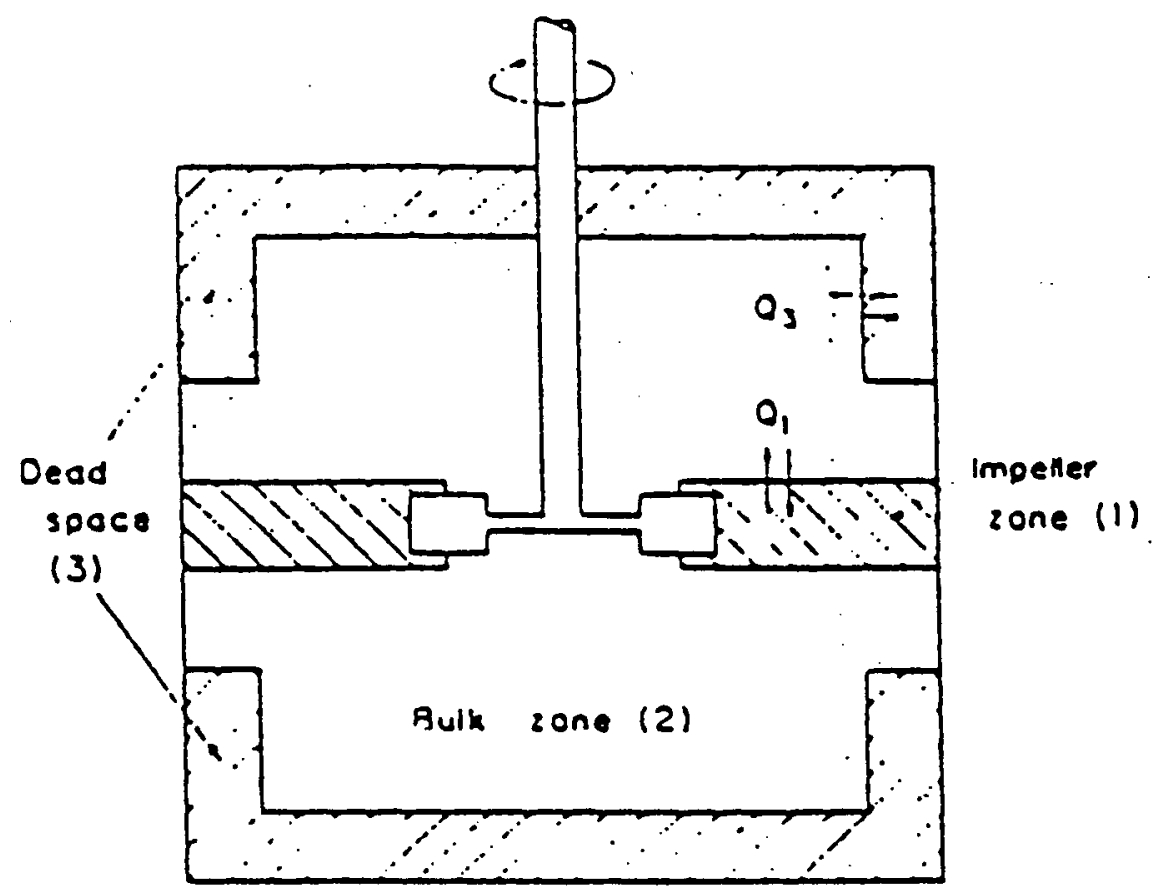

Figure 5.1. Schematic diagram of baffled stirred tank containing dead-space compartment (Koh, 1984). 
The shear rate, $G$ can be calculated as the slope of the relatioship between water velocity and distance from the shaft, but streamline velocities are difficult to measure. Camp and Stein (1943) developed the following relationship for shear along parallel planes of an elemental volume of water:

$$
G=\frac{d v}{d z}=\sqrt{\frac{W}{\mu}}=\sqrt{\frac{P / V}{\mu}}
$$

where $\mathrm{W}=$ dissipation function $=$ power loss per unit volume of fluid $=\mathrm{P} / \mathrm{V}$

and $\mu=$ viscosity of the fluid.( $\left.\mathrm{Nsm}^{-2}\right)$

The $G$ value therefore related to the average value of power inputted to a particular volume of pulp or mixing basin. The basic laboratory tool for evaluating flocculation is the jar test. A stirrer with flat paddles has traditionally been used. Although a 1 liter, round glass beaker is often utilized, various improvements have recently been made. Camp (1954) recognized that glass beakers created a large amount of vortexing, which limited the attainable power input to the water. He developed a beaker with stators to minimize the vortexing. Hudson (Hudson and Wagner, 1981) further modified this design by adding a siphon sampling port and a dosing tube. The siphon allowed the dispersed particles to be removed and the dosing tube allowed the flocculant to be added at the point of maximum mixing.

\subsection{Determination of $\mathrm{G}$}

The evaluation of $\mathrm{G}$ can be accomplished by using equation (5.3), which relates $\mathrm{G}$ to the dissipation function $\mathrm{W}$, an expression for the power applied to the slurry by an impeller. The value of $\mathrm{W}$ depends upon the geometry of the stator, rotor, and container 
and upon the speed of the rotor. Accurate values of $\mathrm{W}$ can be determined by measuring the torque input to the liquid at various speeds and temperatures according to the following expression:

$$
W=\frac{2 \pi s T}{V}
$$

in which $\mathrm{s}$ is the measured rotor speed in $\mathrm{rpm}, \mathrm{T}$ is the measured torque input, in N.m, and V, in $\mathrm{m}^{3}$, is the liquid volume. Once the torque is determined, the value of $\mathrm{W}$, in $\mathrm{N} \mathrm{m}^{-2} \mathrm{~s}^{-1}$, can be calculated, and therefore G vs. rpm curves can be plotted.

\subsection{Measurement of the shear rate}

Torque-meters are sensitive instruments that can measure torque as low as 0.1 to 0.2 g.cm values, normally encountered in laboratory-scale studies on flocculation. However, small torque-meters that can be installed in the impeller shaft are rare, expensive and are not readily available. A new approach using an electrical method was therefore developed, and the technique was used to measure the power input to the impeller mixer. The shear rate, $\mathrm{G}$, was determined by making use of an electrical method (Mhaisalkar et al., 1985) to measure the power input of the stirrer motor. The net power input (in watts) was calculated from the difference in power inputs to the motor measured without load (impeller in air) and with load (impeller in pulp).

For each case, the power input was calculated from the voltage and current measured across the motor armature for a given rotational speed. The velocity gradient (shear rate), was calculated using equation (5.3) (Camp, 1954).

The relationship between $\mathrm{G}$ and impeller speed is shown in Fig.5.2 


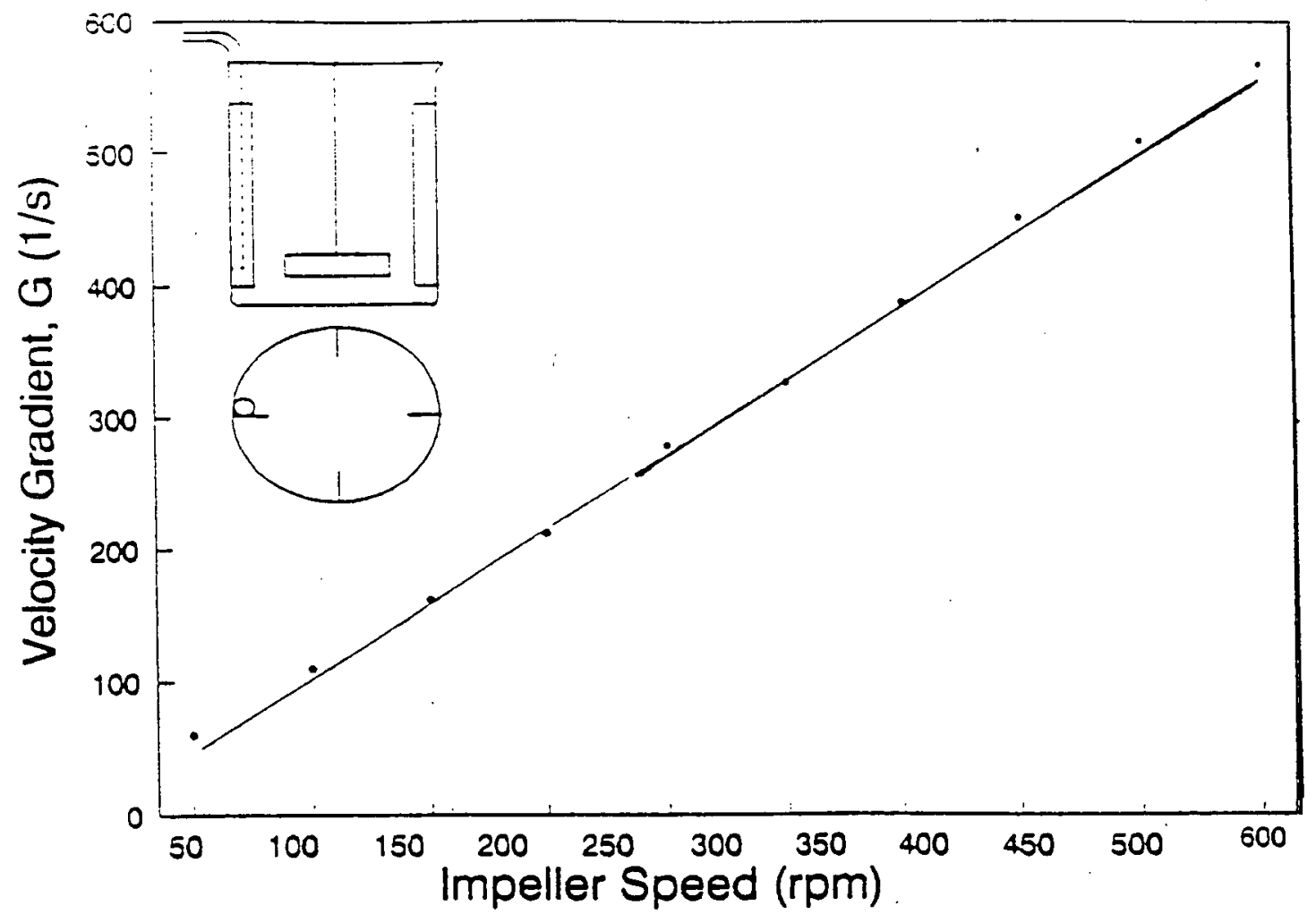

Figure 5.2. Impeller speed vs. velocity gradient curve obtained by the electrical method proposed in this study.

\subsubsection{Experimental set up and procedure}

The Hudson jar with a standard flat paddle, from Phipps and Bird, Richmond, Va. was used throughout this study. The Hudson jar was constructed by gluing four baffles and a capillary (that acted as sampling port and dosing tube) to the 1 liter beaker wall with a silicone sealant. The jar, baffle and paddle are given in Fig. 5.3 

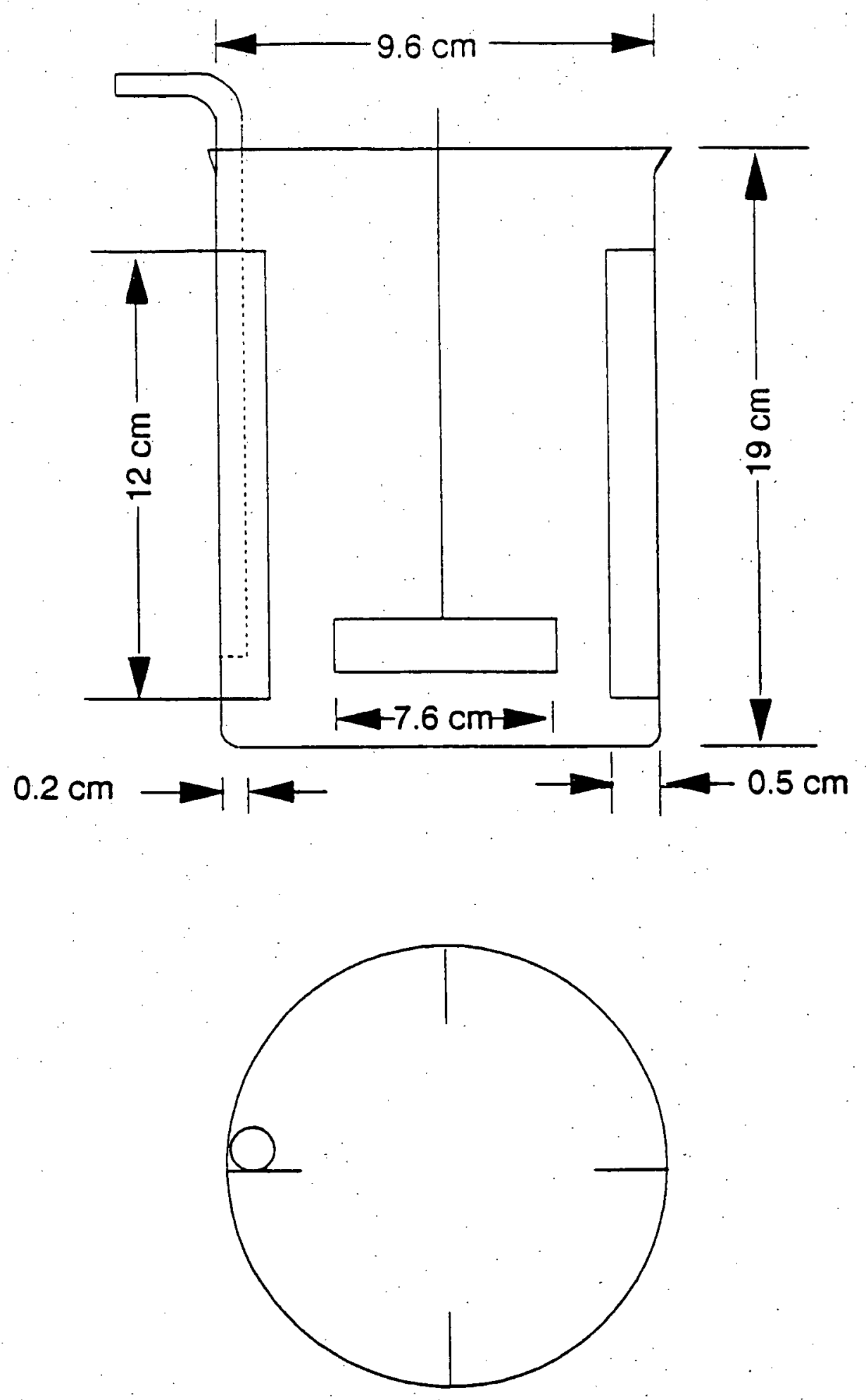

Figure 5.2. Scheme diagram of the Hudson jar constructed for the present study 
The stirrer motor has the following charácteristics: $117 \mathrm{~V}, 1 / 15 \mathrm{hp}$. universal ac/dc., variable speed by a circuitry that interrupts the voltage that provides the electric power. The rotational speed of the paddle impeller is measured accurately using a built-in tachometer. The resistance of the motor was measured to account for the copper losses, when it was subjected to load, and was found to be $80 \Omega$.

The experiments were first performed with the impeller rotating in air, i.e.: without load. The voltage and the current were kept at $30 \mathrm{~V}$ and $1.1 \mathrm{~A}$ respectively. The speed of rotation was altered by varying the motor armature voltage.

The armature current and voltage were measured with a multimeter and were recorded for the desired rotational speed of the impeller.

The impeller was then immersed in a $2 \mathrm{wt} \%$ solid slurry in a beaker of 11 . volume (at $21^{\circ} \mathrm{C}$ ). The power input at with and without load conditions was calculated for various speeds in the range of 10 to $320 \mathrm{rpm}$. The current for a constant rotational speed of the impeller at load and no load conditions remains the same, whereas the armature current varies, and hence the armature resistance losses. Power input to the armature and the losses were calculated as follows:

$\begin{array}{lll} & \text { With load } & \text { With no load } \\ \text { Power input to armature } & \mathrm{P}_{\mathrm{L}}=\mathrm{V}_{\mathrm{L}} \mathrm{I}_{\mathrm{L}} & \mathrm{Po}=\mathrm{Vo} \text { Io } \\ \text { Armature losses } & \mathrm{I}_{\mathrm{L}}{ }^{2} \mathrm{R} & \mathrm{Io}^{2} \mathrm{R}\end{array}$

where 
$\mathrm{P}_{\mathrm{L}}=$ Power input when impeller is rotating in pulp, i.e. with load, in Watts

$\mathrm{I}_{\mathrm{L}}=$ Armature Current at load, in Amps

$\mathrm{V}_{\mathrm{L}}=$ Armature Voltage at load, in Volts

$\mathrm{Po}=$ Power input when impeller is rotating in air, i.e. without load, in Watts

Vo $=$ Armature Voltage at no load, in Volts

Io $=$ Armature Current at load, in Amps

$\mathrm{R}=$ Armature resistance, in $\Omega$.

The net power impute in Watts:

$\mathrm{P}=\left(\mathrm{P}_{\mathrm{L}}-\mathrm{I} \mathrm{L}^{2} \mathrm{R}\right)-\left(\mathrm{Po}^{-\mathrm{Io}^{2} \mathrm{R}}\right)$

or

$$
P=\left(V_{L} I_{L}-I_{L}{ }^{2} R\right)-\left(\text { Vo Io-Io }{ }^{2} R\right)
$$

The velocity gradient can then be calculated by substituting the value of the net power input in equation (5.3).

Typical results of measurement of power requirements are given in Table 5.1. Based on these values, the calculation of velocity gradient, G, for an impeller speed of $256 \mathrm{rpm}$ is given below: 


$$
\begin{aligned}
& \mathrm{Vo}=14.55 \\
& \mathrm{Io}=0.0525 \\
& \mathrm{~V}_{\mathrm{L}}=14.80 \\
& \mathrm{I}_{\mathrm{L}}=0.1190 \\
& \mathrm{R}=80 \Omega \\
& \mathrm{P}=\left[(14.55 \times 0.0525)-(0.0525)^{2} \times 80-(14.85 \times 0.0510)+(0.01190)^{2} \times 80\right] \\
& =0.08493 \mathrm{~W}
\end{aligned}
$$

Now, substituting the values to Eq.(5.3)

$\mathrm{P}=0.08493 \mathrm{Nms}-1$

$$
\mathrm{V}=0.002 \mathrm{~m}^{3}
$$$$
{ }^{*} \mu_{21}=0.9161 \times 10^{-3}
$$

$$
G=\sqrt{\frac{0.08493}{0.001 \times 0.9161 \times 10^{-3}}}=305 s^{-1}
$$

*Although the temperature in the beakers was in the range $21 \pm 2^{\circ} \mathrm{C}$, for calculational purposes a temperature of $21^{\circ} \mathrm{C}$ was assumed. 
Based on the values given in Table 5.1; the curves of power value vs. impeller speed are plotted in Fig 5.4. The value of the net power input "P" was then obtained as the difference between the power inputs for a given speed of the impeller at load and no load conditions. Subsequently, the mean velocity gradient values were calculated by substituting this value of "P" to equation expression 5.3.

Table 5.1: Power requirement for a blade impeller at no load and load conditions.

\begin{tabular}{|c|c|c|c|c|c|c|c|}
\hline \multicolumn{5}{|c|}{ With no load } & \multicolumn{4}{c|}{ With load } \\
\hline rpm & Vo & Io & Po =Vo Io-Io $2 \mathrm{R}$ & rpm & VL & IL & Pl = VL IL-IL ${ }^{2} \mathrm{R}$ \\
\hline 34 & 2.05 & 0.0096 & 0.01231 & 36 & 2.85 & 0.0123 & 0.02295 \\
52 & 3.90 & 0.0147 & 0.04004 & 52 & 3.95 & 0.0289 & 0.04734 \\
72 & 4.40 & 0.0284 & 0.06043 & 72 & 4.89 & 0.0284 & 0.07435 \\
89 & 5.55 & 0.0325 & 0.09588 & 89 & 5.85 & 0.0355 & 0.10685 \\
108 & 7.25 & 0.0398 & 0.16183 & 108 & 7.80 & 0.0408 & 0.18507 \\
122 & 9.35 & 0.0485 & 0.26530 & 122 & 9.95 & 0.0563 & 0.30661 \\
156 & 10.20 & 0.0490 & 0.30772 & 156 & 10.75 & 0.0605 & 0.35755 \\
182 & 11.40 & 0.0500 & 0.37000 & 182 & 11.80 & 0.0796 & 0.43239 \\
217 & 12.40 & 0.0510 & 0.42432 & 217 & 12.87 & 0.0854 & 0.51564 \\
236 & 13.05 & 0.0520 & 0.46228 & 236 & 13.66 & 0.0901 & 0.58132 \\
256 & 14.55 & 0.0525 & 0.54337 & 256 & 14.80 & 0.1190 & 0.62832 \\
281 & 15.60 & 0.0535 & 0.60562 & 281 & 16.30 & 0.1270 & 0.77978 \\
310 & 16.75 & 0.0545 & 0.67525 & 310 & 16.95 & 0.1350 & 0.83025 \\
340 & 17.55 & 0.0555 & 0.7276 & 340 & 18.10 & 0.0148 & 0.92648 \\
367 & 18.45 & 0.0580 & 0.80098 & 367 & 19.20 & 0.0169 & 0.95992 \\
\hline
\end{tabular}




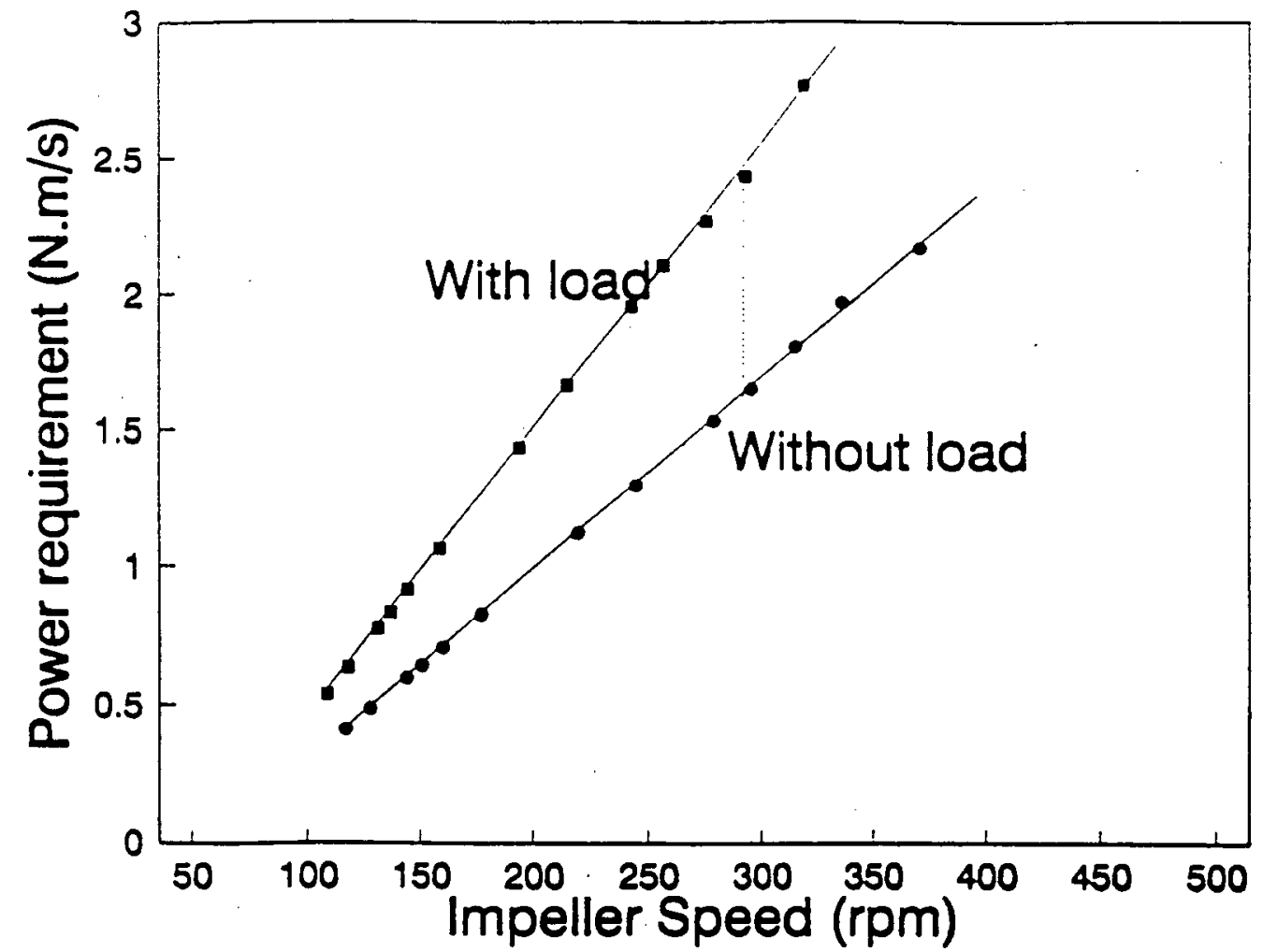

Figure 5.4. Impeller speed vs. power requirement curves at load and no load conditions 


\section{CHAPTER 6 OBJECTIVES AND SCOPE}

It was concluded that although many workers have been able to selectively flocculate coal, no methods have been developed to predict which flocculanting agent will be suitable for a particular system. This is very dependent on the surface properties of coal and the chemical characteristic of the flocculant.

Consequently, the major objective of this research was to study the flocculation of various coals, using various polymers and under varyng conditions and using coals whose surface properties had been previously characterized. A synthetic mixtures of coal and silica particles was used in the selective flocculation experiments.

The following flocculants were selected: a water soluble polyacrylamide (PAM), a semi-hydrophobic polymer (F1029-D), and a totally hydrophobic (FR-7A) obtained from Calgon (Pittsburgh).

The study also included the effect of process parameters such as $\mathrm{pH}$ of slurry, hydrodynamic conditions, shear rate, etc.

Three goals to be achieved included:

a) Clarification of the effect of the coal surface properties and flocculant type in total and selective flocculation of coal.

b) Determination of the effect of process parameters such as $\mathrm{pH}$, shear rate, solid content, dispersant dosage and conditioning on total and selective flocculation.

c) Attempting to explain the main mechanisms involved in the flocculation of coal. 
The present work intends to clarify some of the areas related to the selective flocculation of coal. It is also the author's opinion that this technique has to be fully understood if it is to be incorporated in flotation circuits or used as an independent process. 


\section{CHAPTER 7: MATERIALS AND METHODS}

\subsection{Materials}

\subsubsection{Charaterization of Coal Samples}

Eight coal samples named: LC7, LC8, LC9, LC10A, LC10B, FD4, FD11 and FD13 were obtained from different seams in Western Canadian mines (Line Creek and Fording Coal) and their surface properties were tested using different techniques (Laskowski et al., 1992).

The eight samples were screened and $-2 \mathrm{~mm}$ fractions further ground below $0.5 \mathrm{~mm}$ .were used in the wettability tests. The proximate analyses are given in Table 7.1. The $200 \times 325$ mesh size fractions, used in the film flotation tests, were separated from the $0.5 \mathrm{~mm}$ material.

The methods by which the coal samples were characterized are outlined and the results obtained are briefly discussed.

\subsubsection{Contact Angle}

The contact angle of water on coal was measured on the surface of discs prepared by compressing a fine coal $(70 \%$ below $38 \mu \mathrm{m})$ in a mounting press at a pressure of 17.25 $\mathrm{MPa}(2500 \mathrm{psi})$ following the procedure described by He and Laskowski (1992). The advancing contact angle was obtained by direct reading through a goniometer. For each coal sample, the contact angle value was an average of 28 data points measured on two discs. 


\subsubsection{Total Acidity}

In order to determine the contents of carboxylic and phenolic groups, the coal samples were de-mineralized by the treatment with $40 \% \mathrm{HF}$, followed by filtration, washing with distilled water, treatment with $37 \% \mathrm{HCl}$ and repeatedly conditioning with distilled water and filtering until a constant $\mathrm{pH}$ was reached (Ihnatowicz, 1952; Blom, 1957; Schafer, 1970). The de-mineralized samples were stored in a vacuum desiccator.

\subsubsection{The Alkali-Extraction Test}

Coal oxidation was also determined using Lowenhaupt and Gray's method. A percent light transmission of the solution obtained by boiling one gram of coal sample in $1 \mathrm{~N}$ $\mathrm{NaOH}$ solution was measured at $520 \mathrm{~nm}$ relative to a standard of one normal $\mathrm{NaOH}$ representing $100 \%$ light transmission. This test is not a quantitative measurement of the change in coal oxygen content and can determine an oxidation stage at which humic acids are produced.

\subsubsection{Equilibrium moisture}

Coal equilibrium moisture strongly depends on coal hydrophilic sites and is proportional to the product of the coal oxygen content and specific surface area. (Kaji et al., 1986) For these tests the equilibrium moisture content was determined by placing airdry samples in a disiccator containing a saturated solution of potassium sulfate for $72 \mathrm{~h}$ at room temperature. The samples were then weighed, dried at $110^{\circ} \mathrm{C}$ and weighed again. The weight difference was used to calculate the equilibrium moisture content. 


\subsubsection{The Penetration Rate}

The procedure, as modified by He (1989) was followed. Highly compacted columns were compressed from fine coal samples, $70 \%$ below $38 \mu \mathrm{m}$. The columns after being released from the press were strong enough to withstand handling and liquid penetration. After measuring the heights of the columns with a vernier gauge, the columns were mounted horizontally on a dodecane-saturated wool in a dish. Timing was started when the column touched the cotton. The rise of the borderline separating the wetted bottom part of the column was followed. The wetted column height and penetration time were used to calculate the penetration rate.

\subsubsection{Batch Flotation}

The batch flotation tests were carried out in an Agitair flotation machine with a 4 litre cell on $250 \mathrm{~g}$ coal samples ground below $0.5 \mathrm{~mm}$. The pulp was conditioned with water for $10 \mathrm{~min}$. followed by $1 \mathrm{~min}$. of conditioning with methyl isobutyl carbinol, (MIBC). After 2 min. of flotation the pulp was reconditioned for $1 \mathrm{~min}$. with a second dosage of emulsified dodecane and an additional shot of MIBC just before flotation which took additional $2 \mathrm{~min}$. Dodecane, $90 \mathrm{~g} / \mathrm{t}$ in the first dosage, and $300 \mathrm{~g} / \mathrm{t}$ in the second, was emulsified in a cocktail mixer for one minute together with $50 \mathrm{~g} / \mathrm{t}$ of MIBC in each case. Additional amount of MIBC added just before both flotation periods amounted to $50 \mathrm{~g} / \mathrm{t}$.

\subsubsection{Film Flotation}

Due to the insensitivity of the film flotation tests to coal particle size and following the procedure developed by Fuerstenau et al. (1987), a 200x325 mesh size fraction was used in these experiments. 
The contact angle was found to correlate rather well with the total acidity of coal. The contact angle was measured on whole coal samples, but since the advancing contact angle is determined mainly by the hydrophobic spots on the heterogeneous surface, a good correlation was not surprising. Total acidity was also found to correlate quite well with the equilibrium moisture content. Both were measured on de-mineralized samples and therefore, both characterized the coal organic matter only.

The rate of penetration revealed dependence on coal ash content only. Finally, the flotation tests showed the expected dependence between flotability and the degree of liberation. The results of coal characterization by various techniques are shown in the following Table 7.1 (Laskowski et al.,1992).

Table 7.1: The results of chacterization of coal samples by various techniques

\begin{tabular}{|c|c|c|c|c|c|c|}
\hline Sample & $\begin{array}{c}\text { Demineral. } \\
\text { Coal ash } \\
\%\end{array}$ & $\begin{array}{c}\text { Transmit. } \\
\mathrm{mm}^{2} \\
\%\end{array}$ & $\begin{array}{c}\text { Total } \\
\text { Acidity } 1 \\
\text { Meq/g }\end{array}$ & $\begin{array}{c}\text { Equil. } \\
\text { Moisture } \\
\%\end{array}$ & $\begin{array}{c}\text { Contact } \\
\text { Angle }^{2} \\
\text { deg. }\end{array}$ & $\begin{array}{c}\text { Penetr. } \\
\text { rate } \\
\mathrm{mm}^{2} / \mathrm{s}\end{array}$ \\
\hline LC7 & 0.12 & 96.7 & 0.16 & 1.73 & 75.6 & 0.59 \\
\hline LC8 & 0.48 & 69.0 & 0.26 & 1.18 & 110.4 & 0.70 \\
\hline LC9 & 0.10 & 98.8 & 0.04 & 0.94 & 107.3 & 0.67 \\
\hline LC10A & 0.05 & 94.4 & 0.09 & 0.71 & 105.4 & 0.69 \\
\hline LC10B & 0.42 & 96.7 & 0.06 & 0.73 & 110.8 & 0.64 \\
\hline FD4 & 0.04 & 98.9 & 0.04 & 0.94 & 115.7 & 0.71 \\
\hline FD11 & 0.08 & 96.6 & 0.10 & 1.36 & 108.5 & 0.67 \\
\hline FD13 & 0.55 & 22.1 & 1.22 & 4.59 & 18.01 & 0.60 \\
\hline
\end{tabular}

Notes: 1-on de mineralized coals., 2-on as received coals

Based on these tests, it was concluded that the FD4 sample was the most hydrophobic and the FD13 sample the most hydrophilic with the LC7 sample being somewhere in between these two. Fig.7.1 shows the relationship between contact angle and total acidity. 
These three samples were selected for the flocculation project. Their proximate analyses are given in Table 7.2.

Table 7.2: Proximate Analyses of samples used in flocculation tests

\begin{tabular}{|c|c|c|c|c|}
\hline Sample & $\begin{array}{c}\text { Moisture } \\
\%\end{array}$ & $\begin{array}{c}\text { Ash } \\
\%\end{array}$ & $\begin{array}{c}\text { F. Carbon \% } \\
\text { d.m.m.f* }\end{array}$ & $\begin{array}{c}\text { Volatile matter } \% \\
\text { d.m.m. } .^{* *}\end{array}$ \\
\hline FD4 & 0.79 & $15.50^{*}$ & 81.88 & 18.12 \\
\hline LC7 & 1.06 & $38.20^{*}$ & 69.87 & 30.13 \\
\hline FD13 & 1.66 & $29.50^{*}$ & 69.75 & 30.25 \\
\hline
\end{tabular}

**d.m.m.f.= dry mineral matter free.

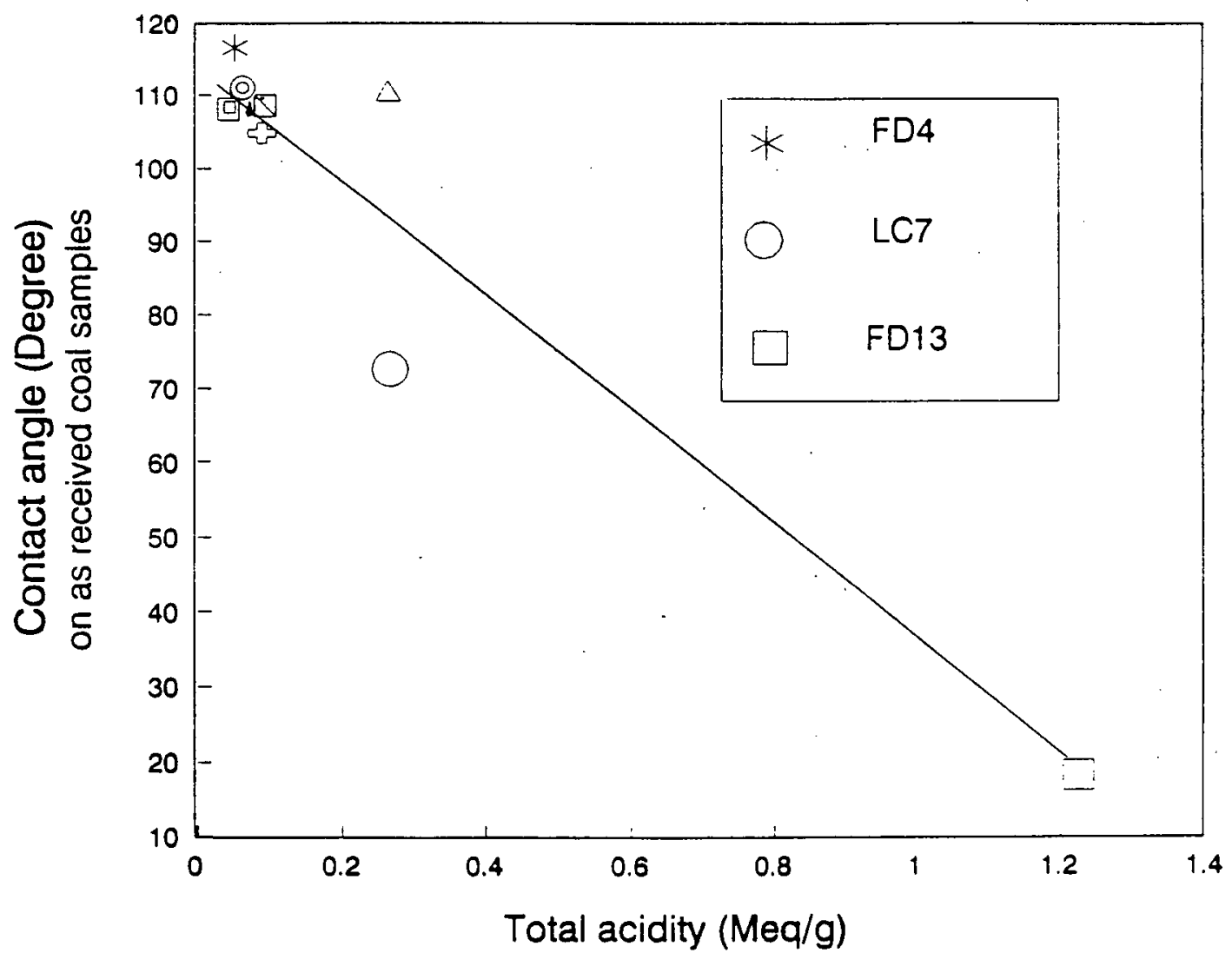

Figure:7.1: The relationship between contact angle and total acidity (after Laskowski et al., 1992). 


\subsubsection{Zeta Potential}

Electrokinetic potential was measured using a Zeta Meter. The samples were placed in an electrophoretic cell that was connected to two electrode compartments. A voltage was applied between the two electrodes to produce a uniform electric field in the connecting chamber and the charged particles responded moving toward one of the electrodes. The microelectrophoretic mobility was used to calculate zeta potential. The results of the measured zeta-potentials of the samples at various $\mathrm{pH}$ values are shown in Figure 7.2. In all cases the measurements were carried out in $10^{-3} \mathrm{M} \mathrm{KNO}_{3}$ to keep the solution ionic strength constant.

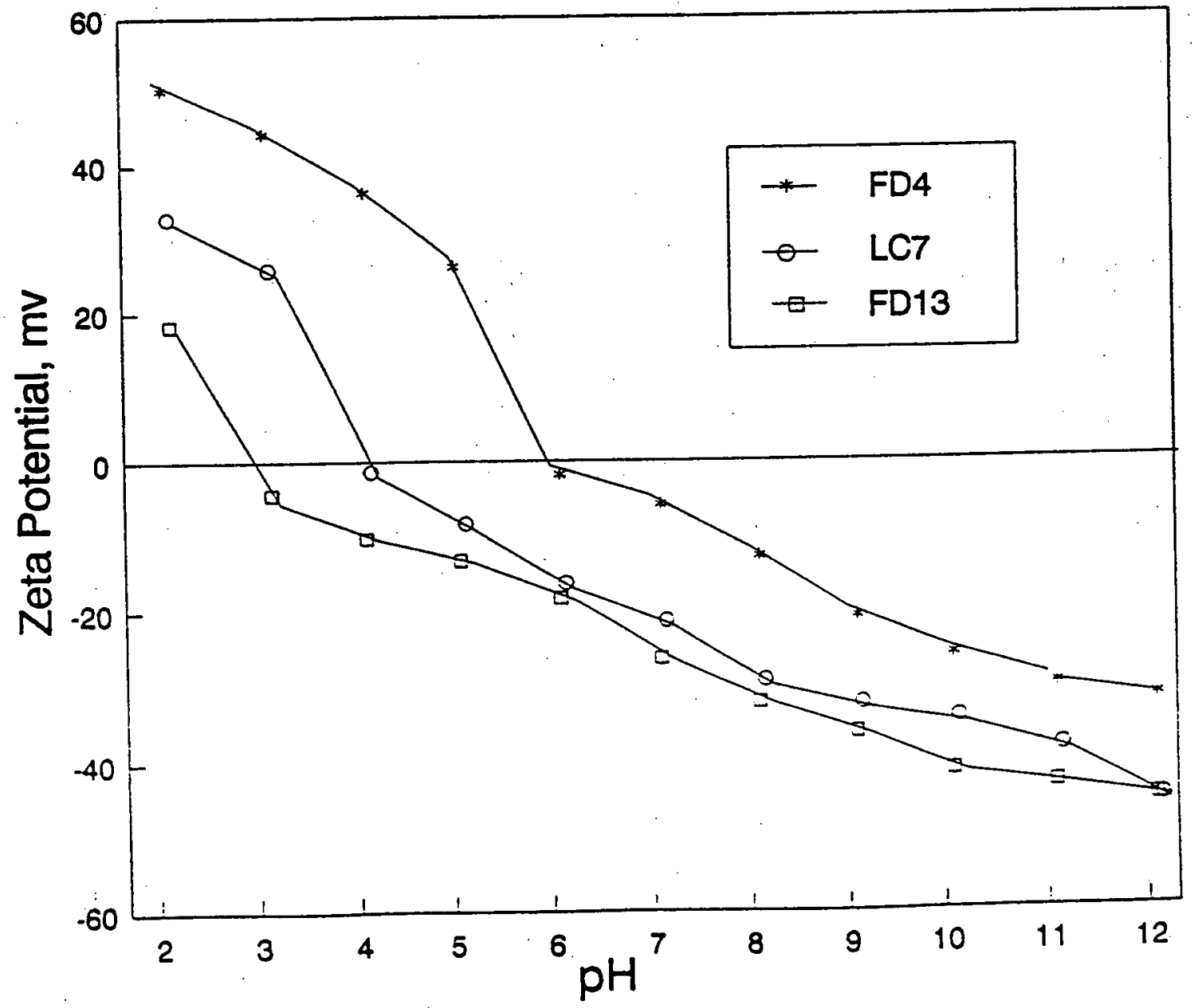

Figure 7.2: The results of zeta-potentials of coal samples at various $\mathrm{pH}$ values 


\subsection{Chemicals}

The FR-7A latex was provided by Calgon Corporation, Pittsburgh. From the zeta potential measurements it was concluded that partilces of FR-7A are negatively charged over the whole $\mathrm{pH}$ range.

In addition, a partially hydrophobic polymer, F1029-D was kindly provided by Daiichi-Kogyo Seiyaku Co. Ltd., Japan and used as a semi-hydrophobic flocculant. This partially hydrophobic polymer consists of about $60-67.5 \%$ of hydrophilic functional groups (acrylamide and acrylic acid) and 32.5-40\% of hydrophobic functional groups (methylacrylate). Its molecular weight is three million (Krishnan and Attia, 1985).

Polyacrylamide (PAM) of $6 \times 10^{6}$ molecular weight from Polysciences, Inc., Warrintong, USA, was selected as a hydrophilic polyelectrolyte.

Sodium hexametaphospate (HMP), obtained from BHD Chemicals Ltd., Poole, England, was used as a dispersing agent. The $\mathrm{pH}$ was adjusted using dilute hydrochloric acid or sodium hydroxide solutions. Distilled water was used throughout.

The chemical formula for the partially hydrophobic flocculant F1029-D is shown in Figure 7.3 


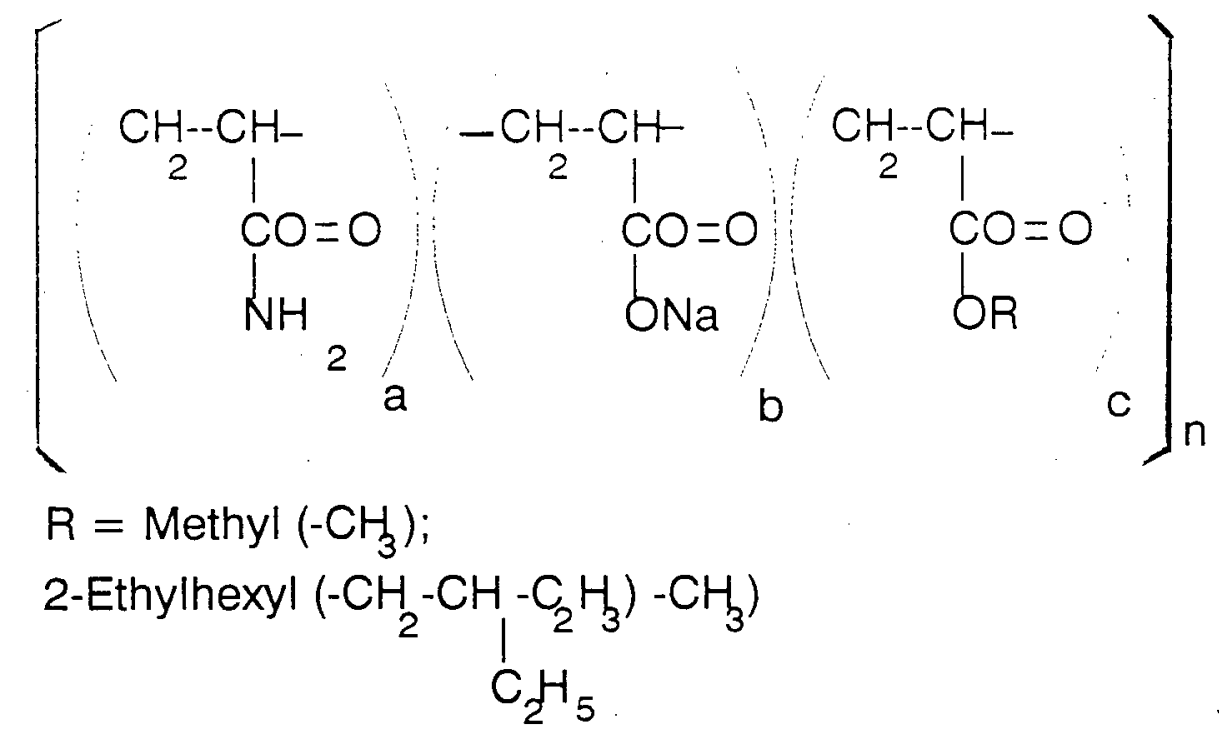

Partially hydrophobic polymer F1029-D

a) Acrylamide $=58-97 \%$

b) Sodium Acrylate $=0-15 \%$

c) Hydrophobic Functionals, $R=10-40 \%$

Figure 7.3: The chemical formula for the partially hydrophobic flocculant F1029-D (Attia, 1992)

\subsection{Sample Preparation for Flocculation Tests}

Each raw coal sample was crushed and screened to $-5 \mathrm{~mm}$ and then cleaned using a shaking table. Their ash contents were reduced to: $8.75 \%$ (FD4), $15.5 \%$ (LC7) and 13.78 $\%$ (FD13). The pre-cleaned coal samples were then wet-ground in a ball mill for four hours at $35 \%$ solids, dried at $50{ }^{\circ} \mathrm{C}$, bagged and kept in the refrigerator ready for the flocculation test.

For the selective flocculation tests the FD4 sample was mixed with Minusil Silica or Pioneer Kaolin, provided by Georgia Kaolin Company, Georgia, USA, (100\% below 10 $\mu \mathrm{m})$. 


\subsection{Flocculation Procedure}

In order to properly disperse the coal samples in water, a given quantity of fine coal or synthetic mixture, and a predetermined amount of hexametaphosphate HMP (300 $\mathrm{mg} / \mathrm{l}$ ) were added to water. Each suspension (18 grams of coal or synthetic mixture in 900 $\mathrm{ml}$ of suspension) was vigorously mixed in a blender for 1 minute before being transferred to a beaker and agitated, for 15 minutes, at maximum stirrer speed. Following $\mathrm{pH}$ adjustment, the slurry was stirred for an additional $5 \mathrm{~min}$.

Next, the flocculant stock solution was slowly added with a syringe over $2 \mathrm{~min}$. period, through the dosing tube, keeping the shear rate at $150 \mathrm{sec}^{-1}$. The shear rate was then adjusted to a given value that was maintained for $3 \mathrm{~min}$.

The suspension was allowed to stand for $3 \mathrm{~min}$. while the coal flocs settled under gravity. Finally the supernatant (top $500 \mathrm{ml}$ ) was separated out from the settling flocs by siphoning through the sampling port. The flocs were then dried at low temperature (50 $\left.\mathrm{C}^{\circ}\right)$ and weighed. The extent of flocculation (\%F) was calculated from the dry weight of the solids obtained from the bottom $400-\mathrm{ml}$ of suspension as follows:

$$
\% \mathrm{~F}=\frac{\frac{\mathrm{M}}{18} 100-44}{56} 100
$$

where $\mathrm{M}$ is the weight of solids in grams.

The identical procedure was followed for the selective flocculation tests, but in this case, the settled flocs were dried and analyzed for ash content. The analysis for ash content was performed following the ASTM procedure. 


\subsection{Hydrodynamic conditions}

In order to work under well defined hydrodynamic conditions, the relationship between shear rate and rpm of the stirrer was determined for a pulp with the same density as the one used in the experiments (2.0 wt \% solids).

The shear rate, $\mathrm{G}$, was determined by using of the electrical method described in Chapter 5 (Mhaisalkar et al., 1985). The flocculation experiments were carried out in a standard six-paddle stirrer with speed control and paddle height adjustment from Phipps \& Bird, Richmond, VA., using Hudson jars (Hudson, 1981) that were constructed by gluing four baffles and a capillary (that acted as sampling port and dosing tube) to the 1 liter beaker wall with a silicone sealant (see Fig 5.3). 


\subsection{Total flocculation}

\subsubsection{Effect of the coal oxidation}

As it can be seen from Figs 8.1, 8.2 and 8.3, the totally hydrophobic flocculant (FR7A) was effective with hydrophobic and slightly oxidized coal. The semi-hydrophobic flocculant (F 1029-D) was found to flocculate all the samples to a different extent (except the oxidized coal that was barely flocculated by this polymer). PAM was able to flocculate all three coal samples. This indicates that while the totally hydrophobic flocculant is sensitive towards coal wettability, the adsorption mechanism involved when PAM is utilized is quite different and does not depend on solid wettability at all.

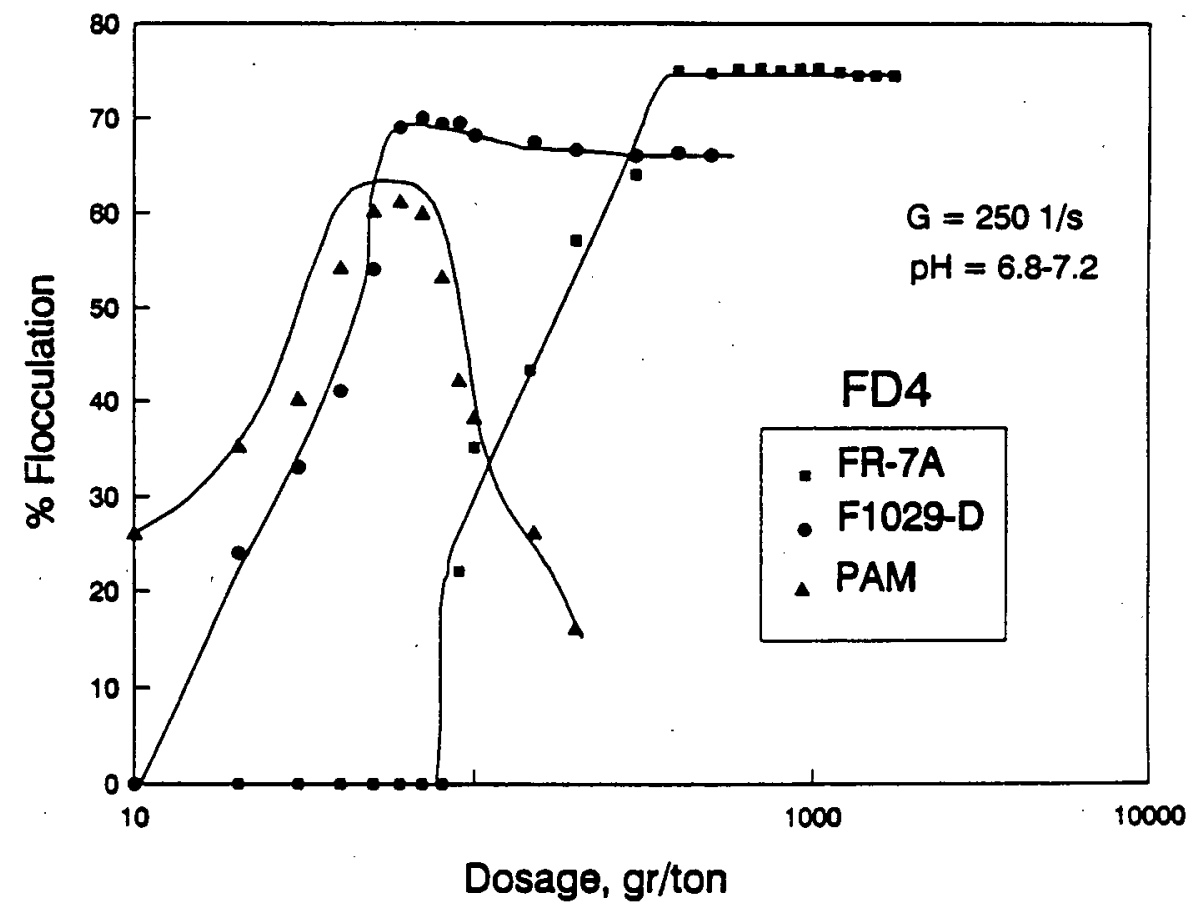

Figure 8.1: The relationship between flocculant dosage and flocculation degree fur Fording 4 Coal. 


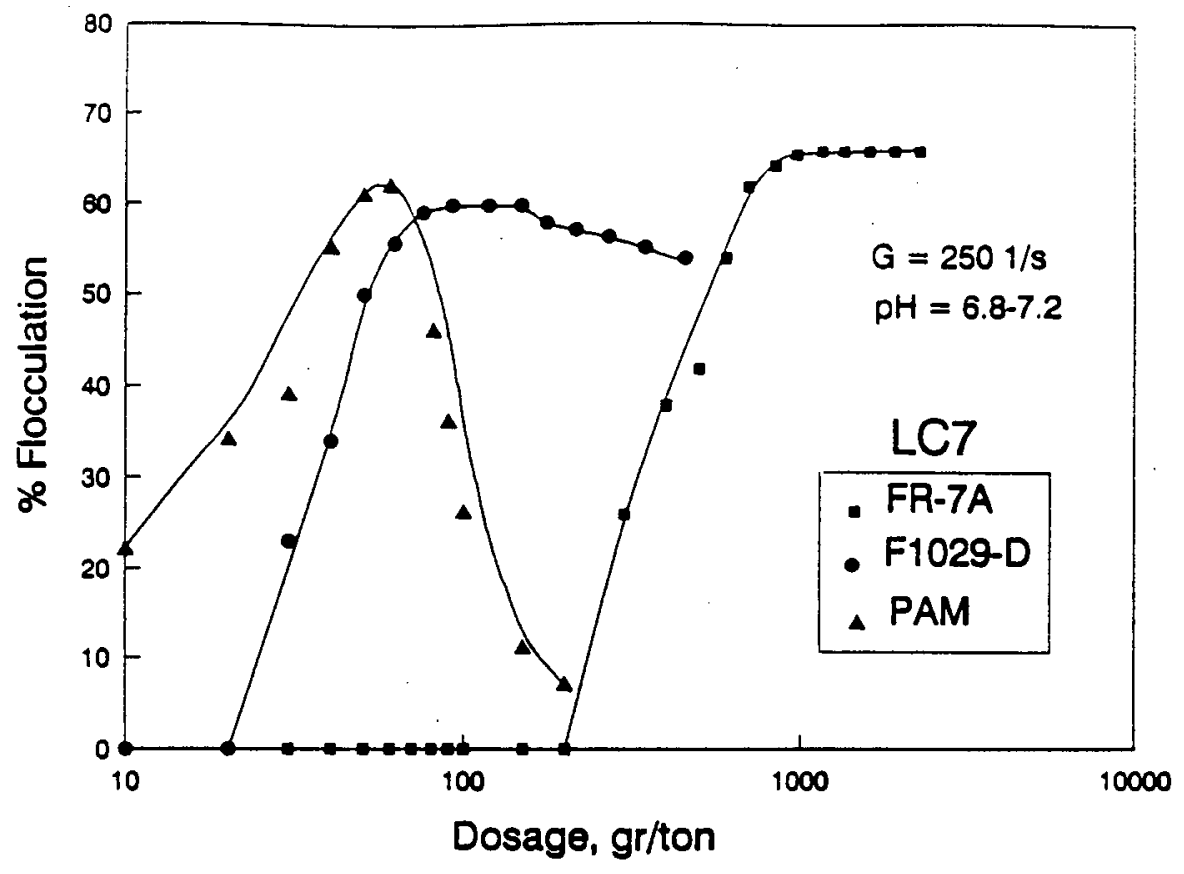

Figure 8.2: The relationship between flocculant dosage and flocculation degree for Line Creek 7 Coal.

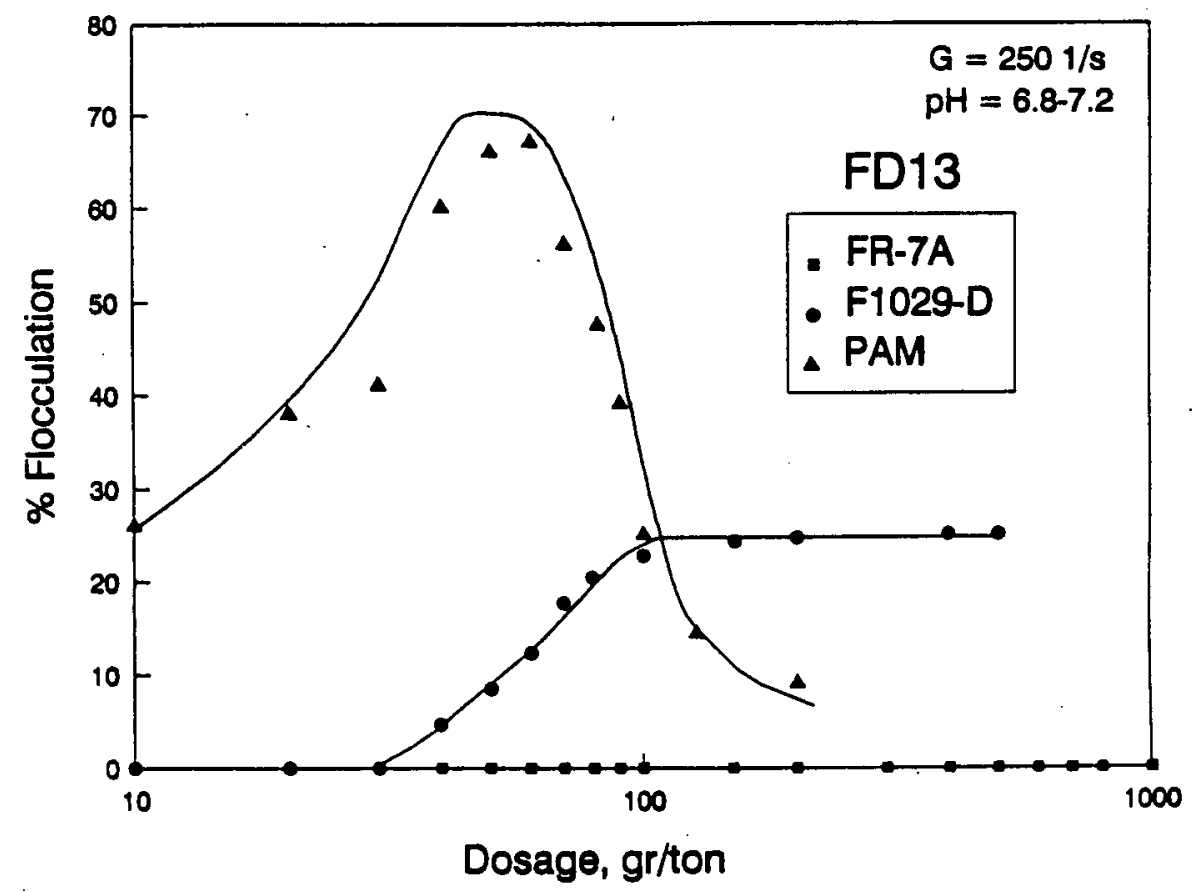

Figure 8.3: The relationship between flocculant dosage and flocculation degree for Fording 13 Coal. 


\subsubsection{Effect of sodium hexamethaphosphate}

Fig 8:4 shows the effect of HMP on the total flocculation of the FD4 coal sample. Since in the presence of HMP anions coal surface is rendered more negative, increased HMP concentration affects flocculation and decreases the amount of flocculated coal.

\subsubsection{Effect of flocculant type and dosage}

As it can be seen from Figs 8.1, 8.2 and 8.3 for both the hydrophilic and semihydrophobic flocculants there was an optimum flocculant dosage $(65 \mathrm{~g} / \mathrm{t} \mathrm{PAM}$ and $80 \mathrm{~g} / \mathrm{t}$ for F1029-D). For the latex, the degree of flocculation reached a plateau at $500 \mathrm{~g} / \mathrm{t}$

\subsubsection{Effect of shear rate}

The effect of shear rate on the flocculation of coal was also investigated (Figs. 8:5, 8.6 and 8.7). Whereas for PAM and F1029-D, the optimum hydrodynamic conditions were clearly observed and the degree of flocculation decreased at too high a shear rate, for FR-7A the degree of flocculation increased with the shear rate over the whole tested range. It is also important to note that higher shear rates were necessary to obtain the same degree of flocculation with more hydrophilic coal samples. While for the hydrophobic and semi-hydrophobic flocculants, a minimum level of energy (shear rate) had to be reached to set out flocculation, for PAM sufficient conditioning to guarantee a complete distribution of the flocculant in the slurry was enough to initiate flocculation. 


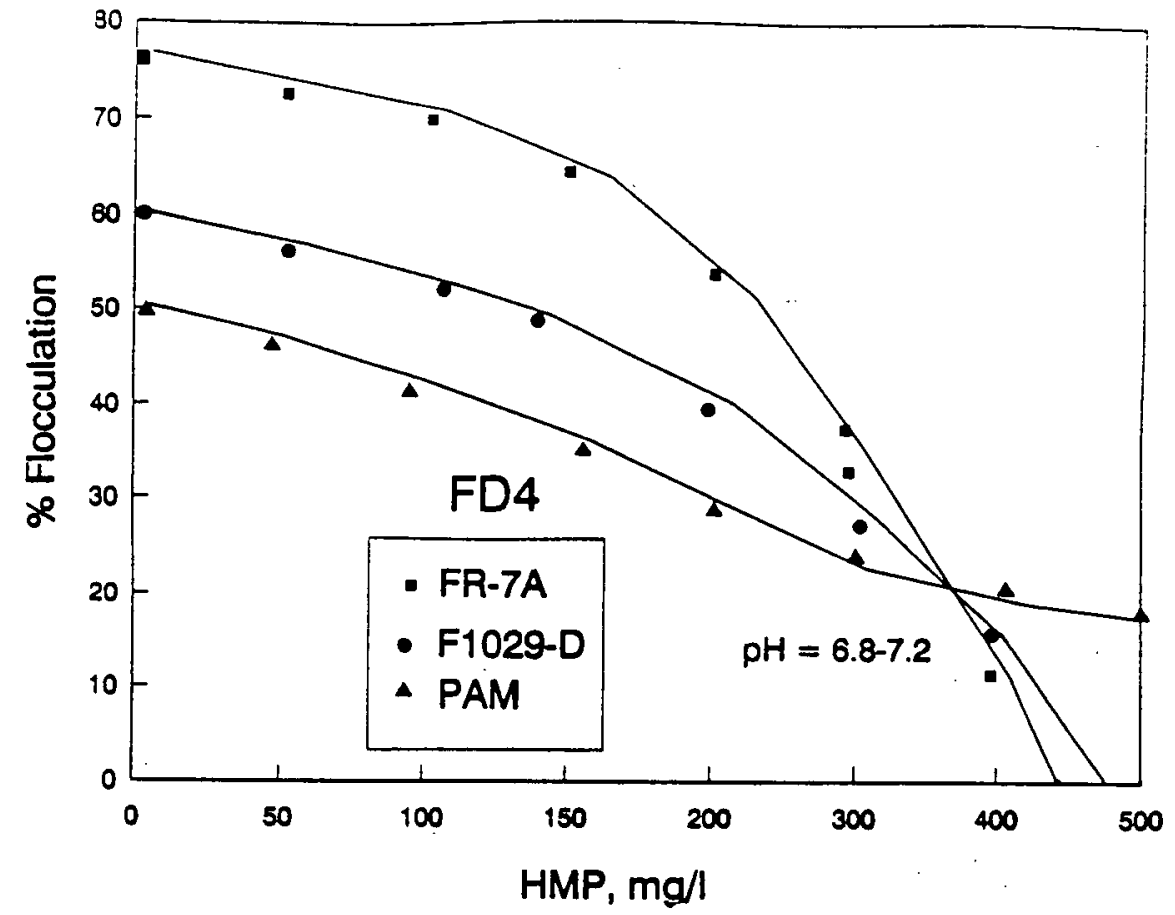

8.4: The relationship between sodium hexametaphosphate dosage and flocculation degree for Fording 4 Coal.

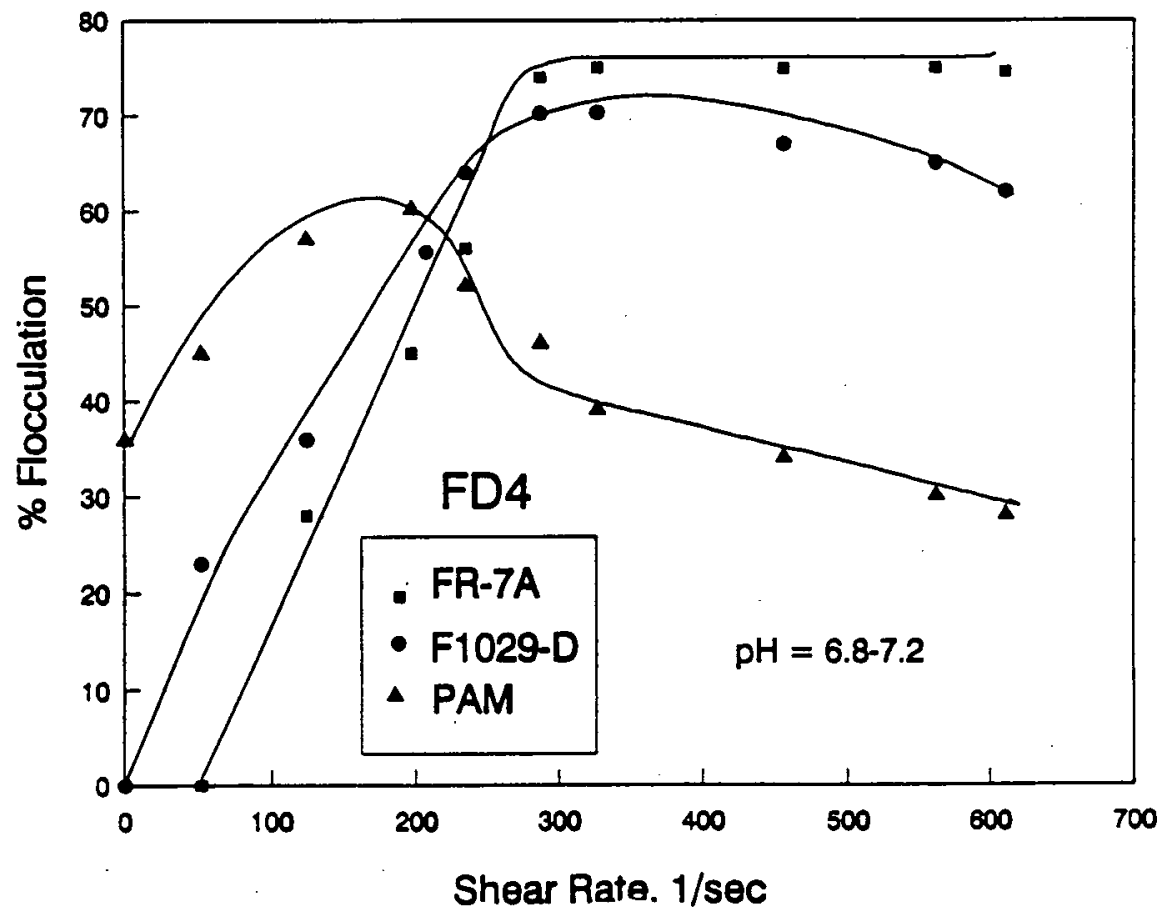

Figure 8.5: The relationship between shear rate and flocculation degree for Fording 4 Coal. 


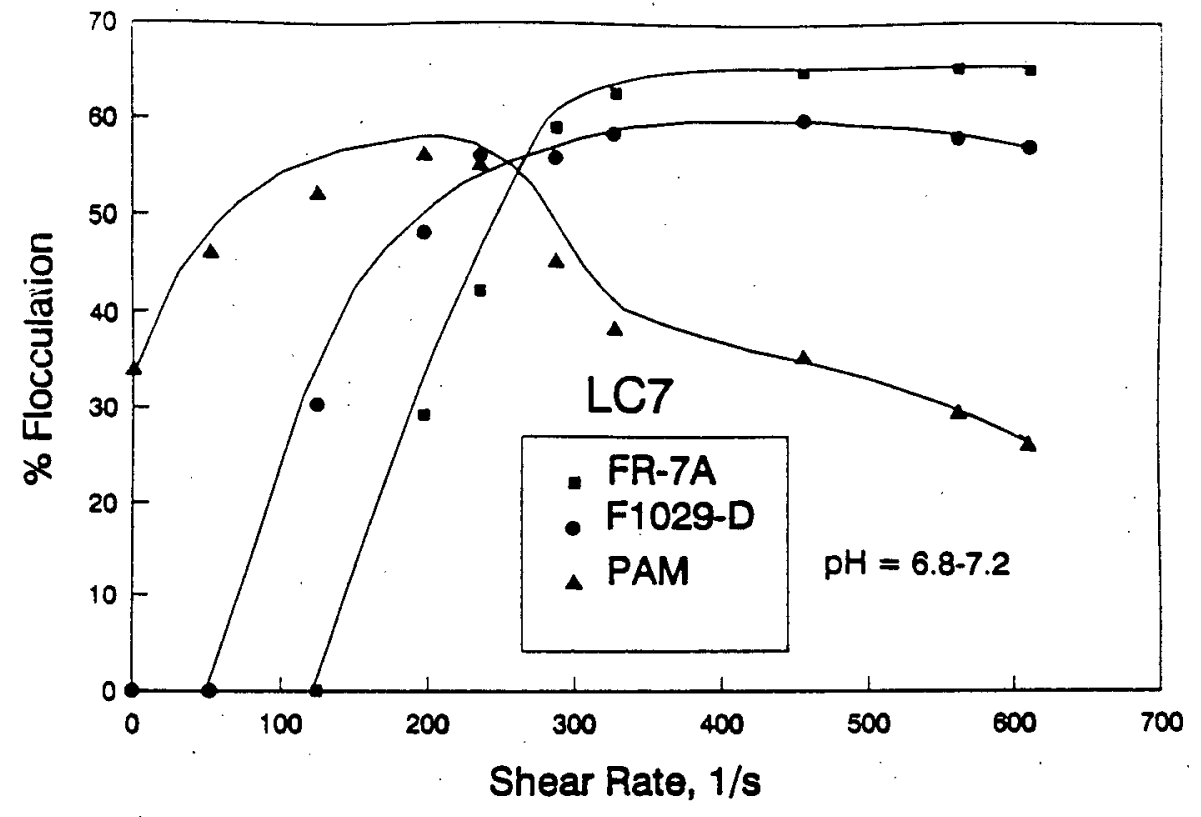

Figure 8.6: The relationship between shear rate and flocculation degree for Line Creek 7 Coal.

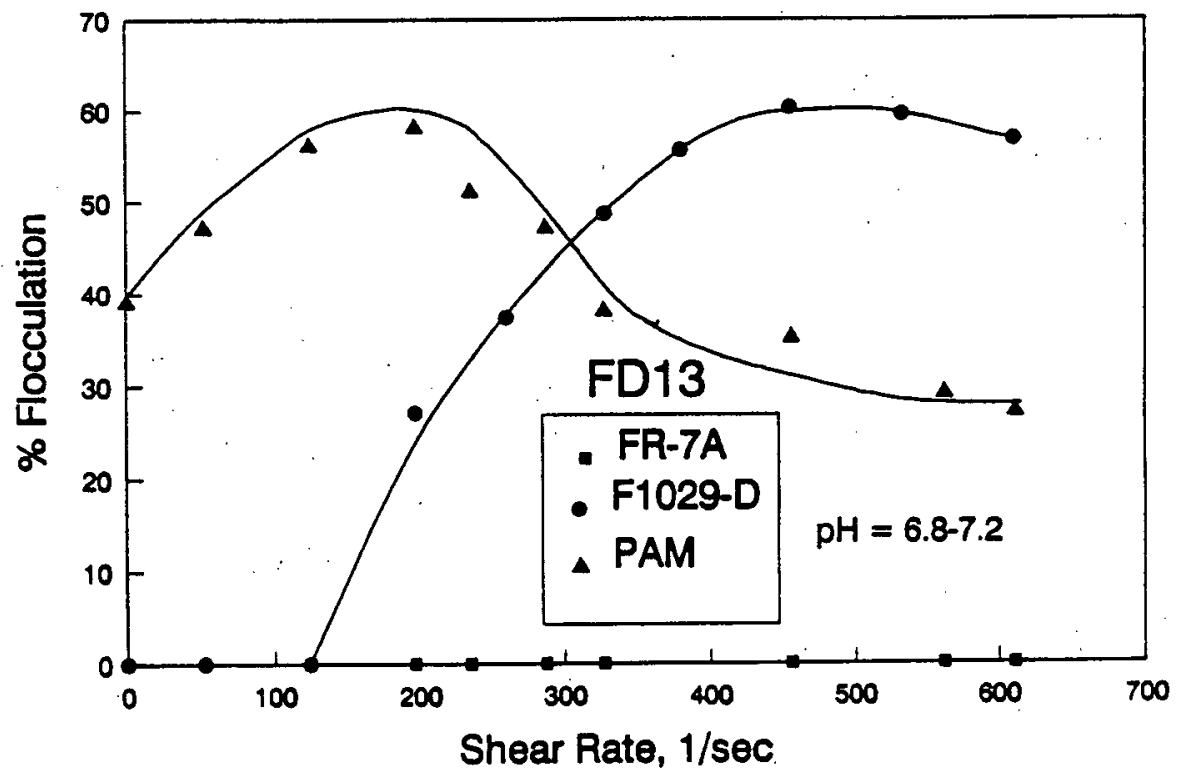

Figure 8.7: The relationship between shear rate and flocculation degree for Fording 13 Coal. 


\subsubsection{Effect of solid content:}

The effect of solids content on coal flocculation is shown in Fig 8.8. At a high solid content the degree of flocculation was as high as nearly $100 \%$. This could be attributed to a high collision rates of the coal particles to form flocs. However at high solid content, it was difficult to separate the flocs by sedimentation.

\subsection{Selective Flocculation}

For selective flocculation tests, the Gaudin Index and the flocculation degree $(\% \mathrm{~F})$ were used as evaluation criteria. The Gaudin Index (G.I.) is defined as:

$$
G . I .=\frac{\left(100-A_{c}\right) \times A_{t} t^{\prime 2}}{A c \times\left(100-A_{t}\right)}
$$

where Ac is the ash content in the flocs (concentrate) and At is the ash content in the tailings. High G.I. stand for a high selectivity.

\subsubsection{Effect of sodium hexamethaphosphate}

Fig 8.9 shows the effect of HMP on flocculation degree and ash removal. Evidently the adsorption of HMP causes a decreased in coal yield and an increase in the flocculation selectivity. It was confirmed that the presence of HMP enhanced the removal of silica from a coal slurry through a selective flocculation process. However, as HMP concentration was increased beyond 300 p.p.m. a plateau was reached without further improvement of the results. 


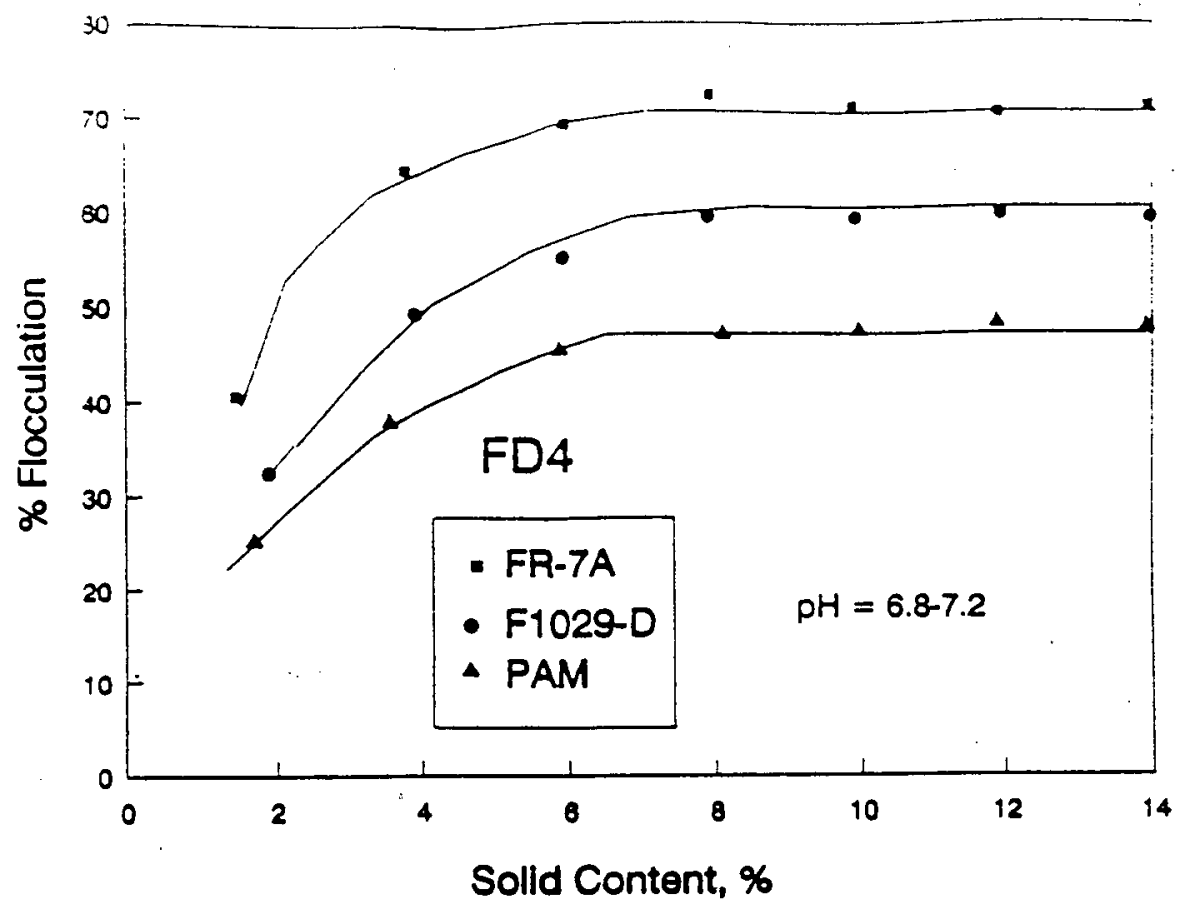

Fig 8.8: The relationship between solids content and flocculation degree for Fording 4 Coal.

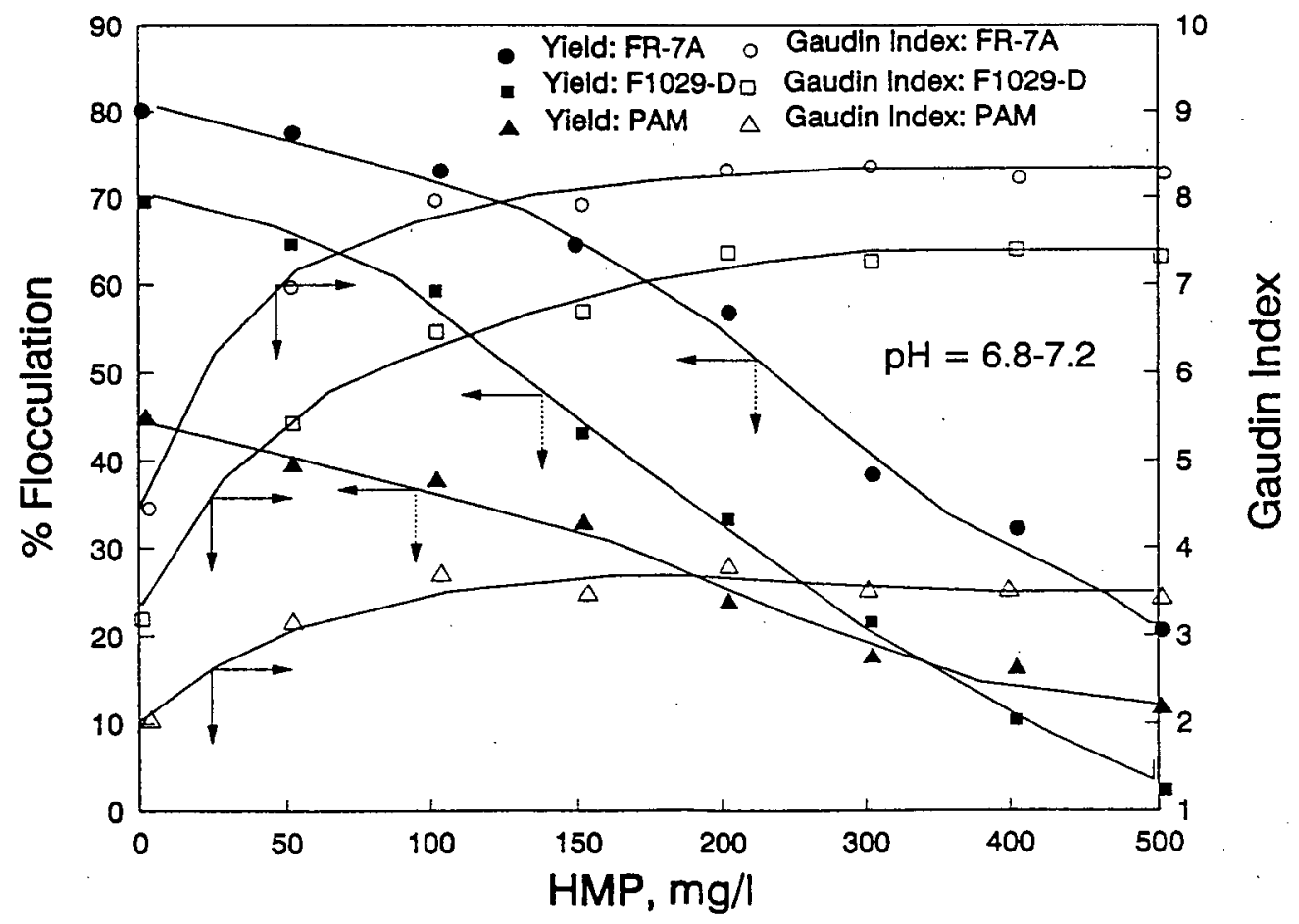

Fig 8.9: The effect of HMP on selectivity and on flocculation degree for a 1:1 Mixture: Minusil silica, Fording 4 Coal. 


\subsubsection{Effect of solid content}

The effect of solids content on coal selective flocculation is shown in Fig.8.10. The high solid content yields higher flocculation degree, but at low mineral matter rejection. These results indicate that an efficient removal of ash minerals from coal slurries should be conducted at a relatively low solid content, especially for an ultra fine coal. The figure also indicates that ash removal was very efficient at low solid content. However, with very dilute slurry, the coal flocculation degree was correspondingly low, probably because of the lower collision frequency between coal particles.

\subsubsection{Effect of the shear rate}

Fig. 8.11 shows the effect of shear rate on selective flocculation which was tested on a 50:50 mixture of FD-4 coal sample and Minusil Silica, at constant flocculant consumption. In line with the results of Fig. 8.5, there is a clear shear rate optimum for PAM, while for the latex and the semi-hydrophobic flocculant, flocculation was found to be better at higher shear rates. A minimum shear rate was confirmed to be needed to initiate flocculation when FR-7A was used.

\subsubsection{Effect of flocculant dosage}

Fig. 8.12 shows the effect of flocculant dosage on selective flocculation at a constant shear rate of $250 \mathrm{sec}-1$. The Gaudin Selectivity Index was found to be relatively high for FR-7A and F1029-D, while the selectivity with PAM was poor over the whole tested dosage range. Overdosing was observed to have a deleterious effect on the coal yield for F1029-D and PAM. 


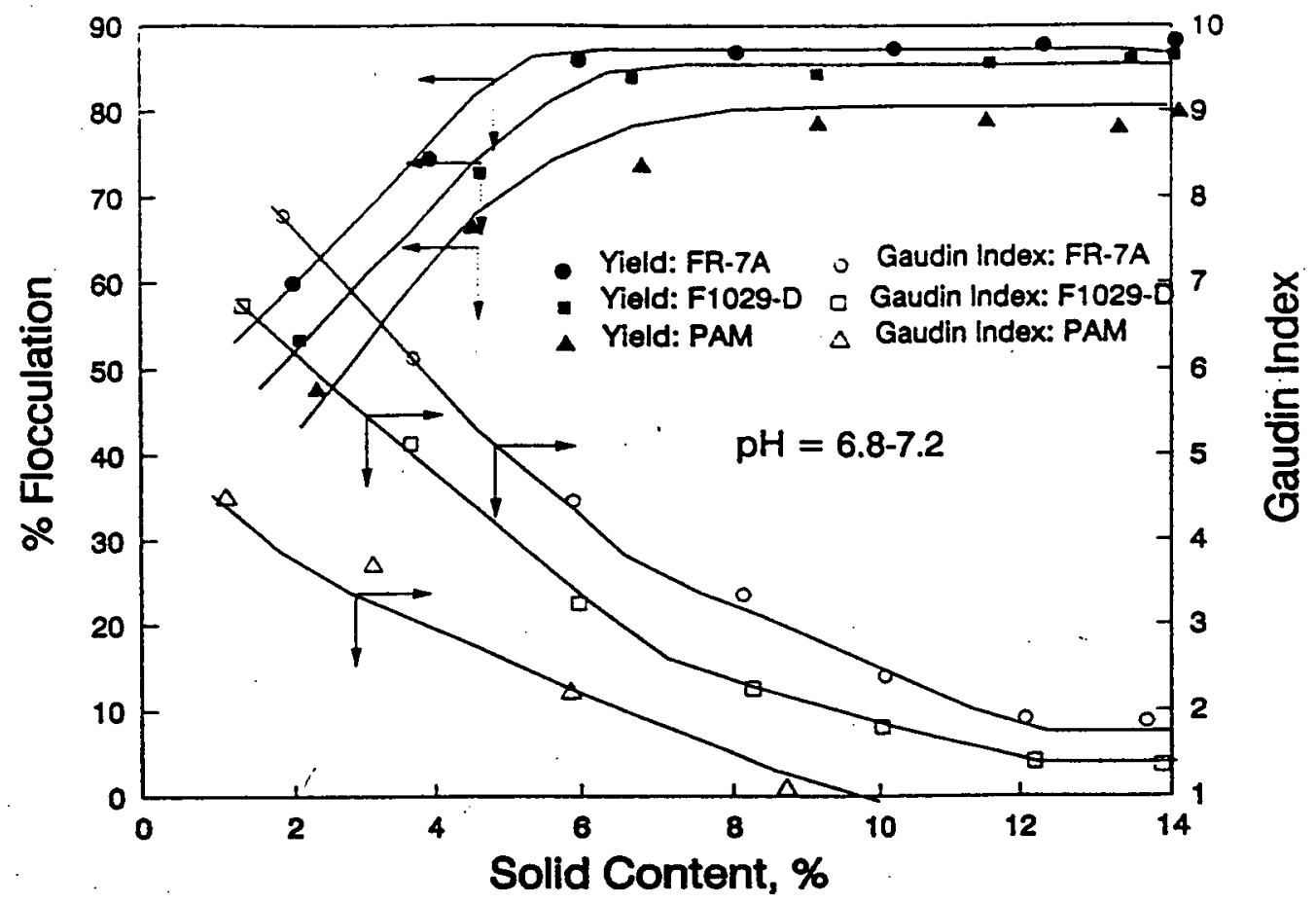

Figure 8.10: The effect of solid content on selectivity and on flocculation degree for a 1:1 Minusil Silica, Fording 4 Coal Mixture.

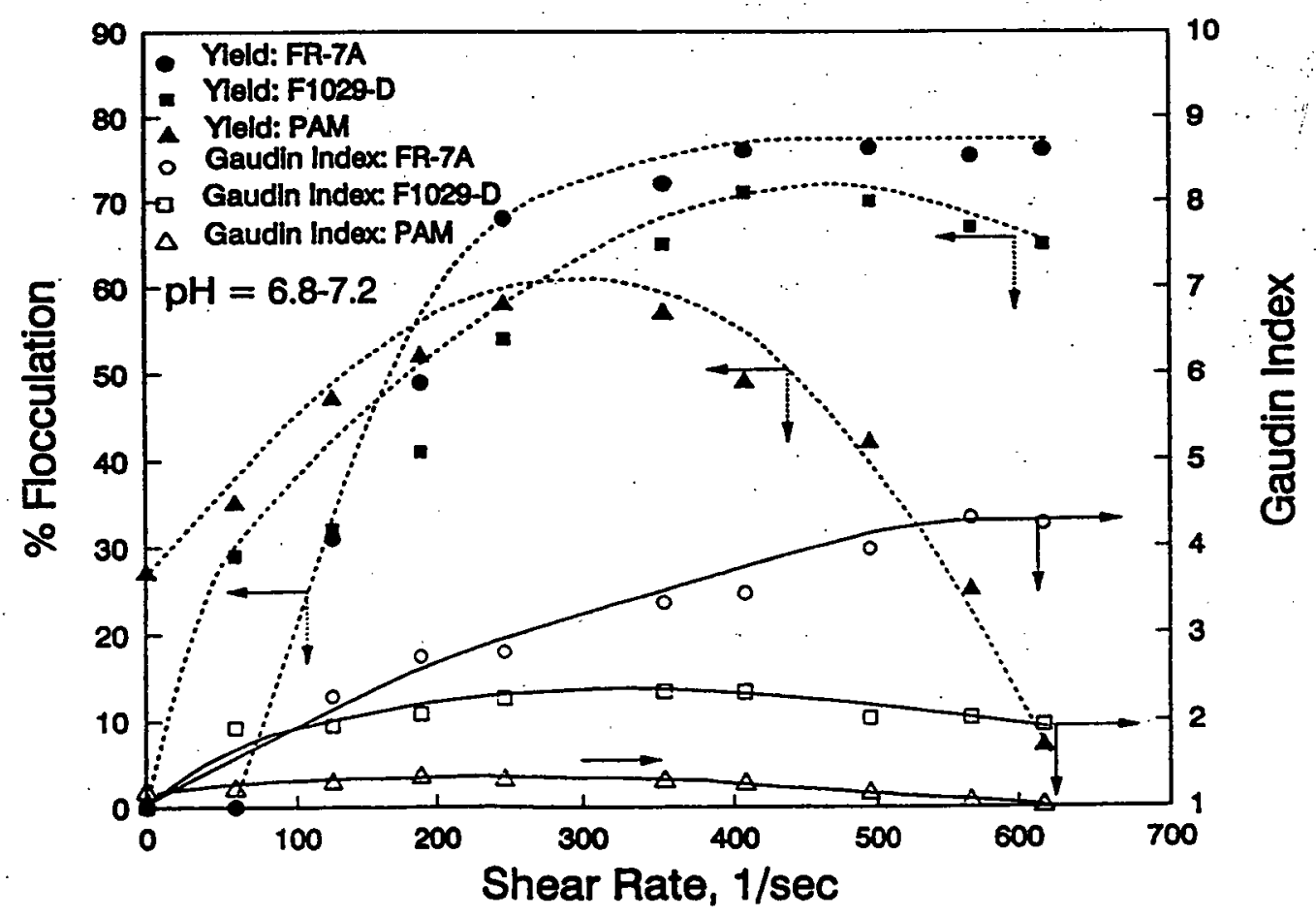

Figure 8.11: The effect of shear rate on selectivity and on flocculation degree for a 1:1 Minusil Silica, Fording 4 Coal Mixture. 


\subsubsection{Effect of $\mathrm{pH}$}

Fig.8.13 illustrates the effect of $\mathrm{pH}$ on both the clean coal yield and selectivity at a constant shear rate of $250 \mathrm{sec}-1$ and at constant dosages of the flocculants $(60 \mathrm{~g} / \mathrm{t}$ for PAM, $80 \mathrm{~g} / \mathrm{t}$ for F1029-D and $350 \mathrm{~g} / \mathrm{t}$ for FR-7A). As seen, while the flocculation degree is high in the acidic $\mathrm{pH}$ ranges and decreases sharply at $\mathrm{pH}$ higher than 10 , the selectivity was found to be better in alkaline environment. The best trade off flocculation and selectivity results can, therefore be obtained over the $\mathrm{pH}$ range from 7 to 8 . 


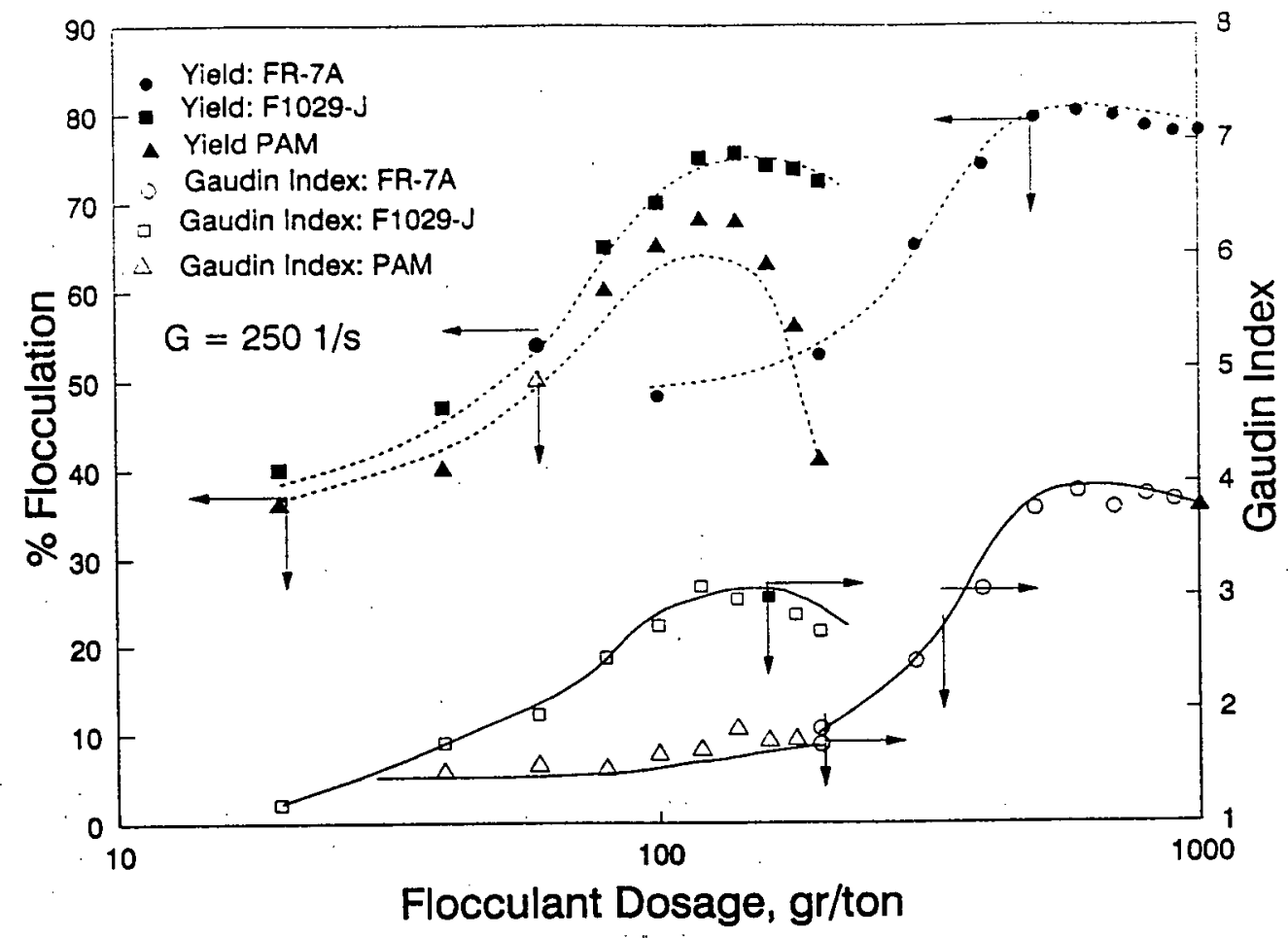

Figure 8.12: The effect of flocculant dosage on selectivity and on flocculation degree for a 1:1 Mixture: Minusil Silica, Fording 4 Seam Coal.

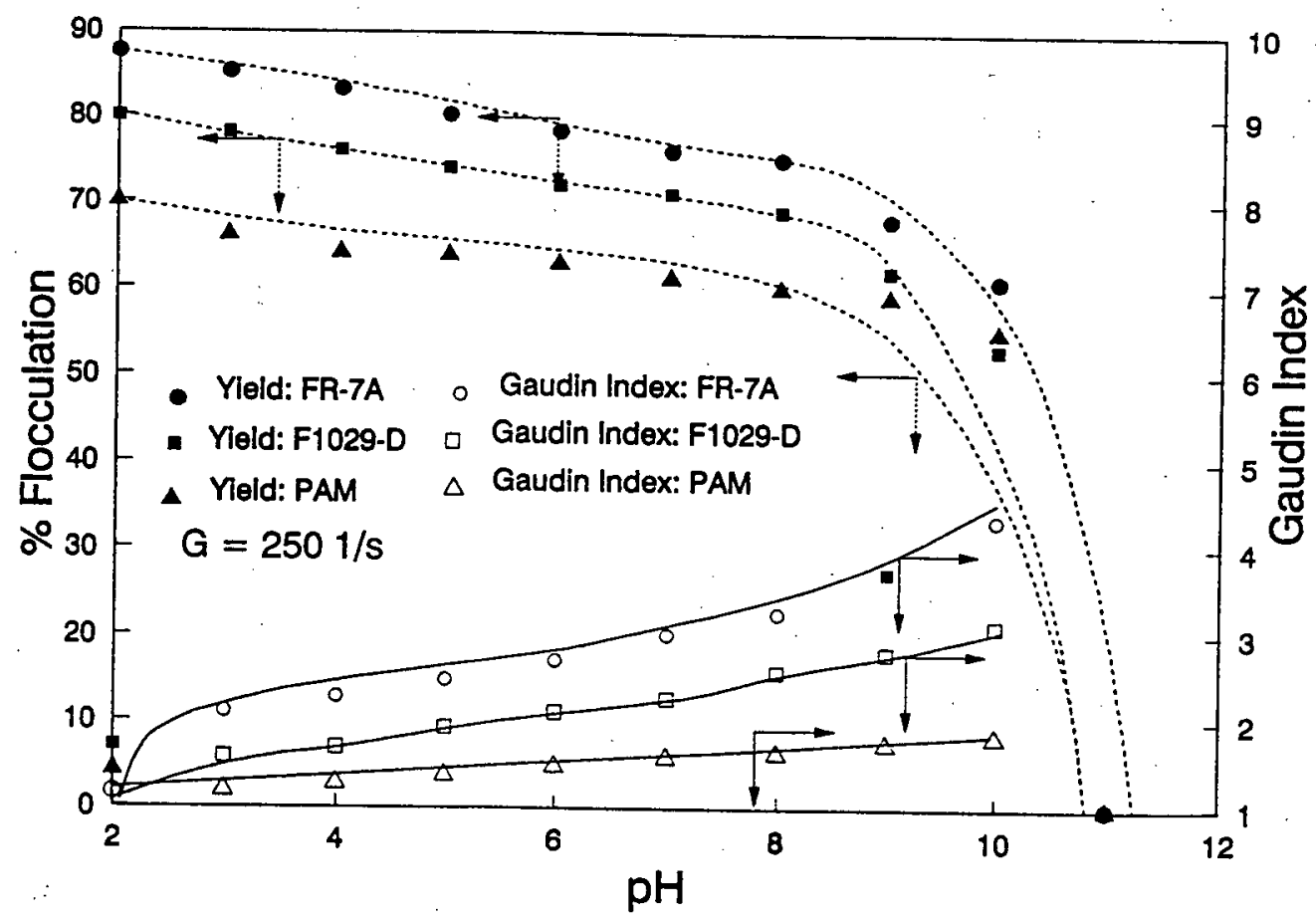

Figure 8.13: The effect of $\mathrm{pH}$ on selectivity and on flocculation degree for a 1:1 Mixture: Minusil silica, Fording 4 Coal. 


\section{CHAPTER 9: DISCUSSION AND CONCLUSIONS}

\subsection{Discussion of the results}

As shown in Figs 8.1, 8.2 and 8.3, PAM flocculated all the tested coal samples and in all cases the flocculation vs. dosage curves were bell-shaped with a clear optima. At higher dosages, the coal suspensions were stabilized when this flocculant was used.

Flocculants such as polyacrylamide are known to stabilize suspensions at higher concentrations. This phenomenon is referred to as steric stabilization, which results from the formation of protective hydrophilic layers on the solid particles. Since the protective substance-protective substance interactions are weaker than the protective substancewater interactions, the adsorption layers stabilize the system.

The hydrophobic and semi-hydrophobic flocculants were found to produce good flocculation and selectivity on the non oxidized hydrophobic coal only.

With semi-hydrophobic F1029-D and with totally hydrophobic FR-7A, a plateau was reached at higher flocculation dosages, and the stabilization was not observed. This reveals fundamental differences in the properties of the adsorbed layers formed on the surfaces of the coal particles when these different flocculants were used. Apparently, the adsorbed layers which were formed on coal particles when F1029-D and FR-7A were used were hydrophobic. This finding was corroborated by Laskowski et al. (1995) by direct measurements of coal wettability in the presence of FR-7A, UBC-1 (a totally hydrophobic latex synthesized at the Department of Mining and Mineral Processing Engineering, BC) and PAM. While receding angle in solutions of PAM decreases, the contact angle increases in the presence of both FR.-7A and BC-1 lattices (Fig 9.1). 


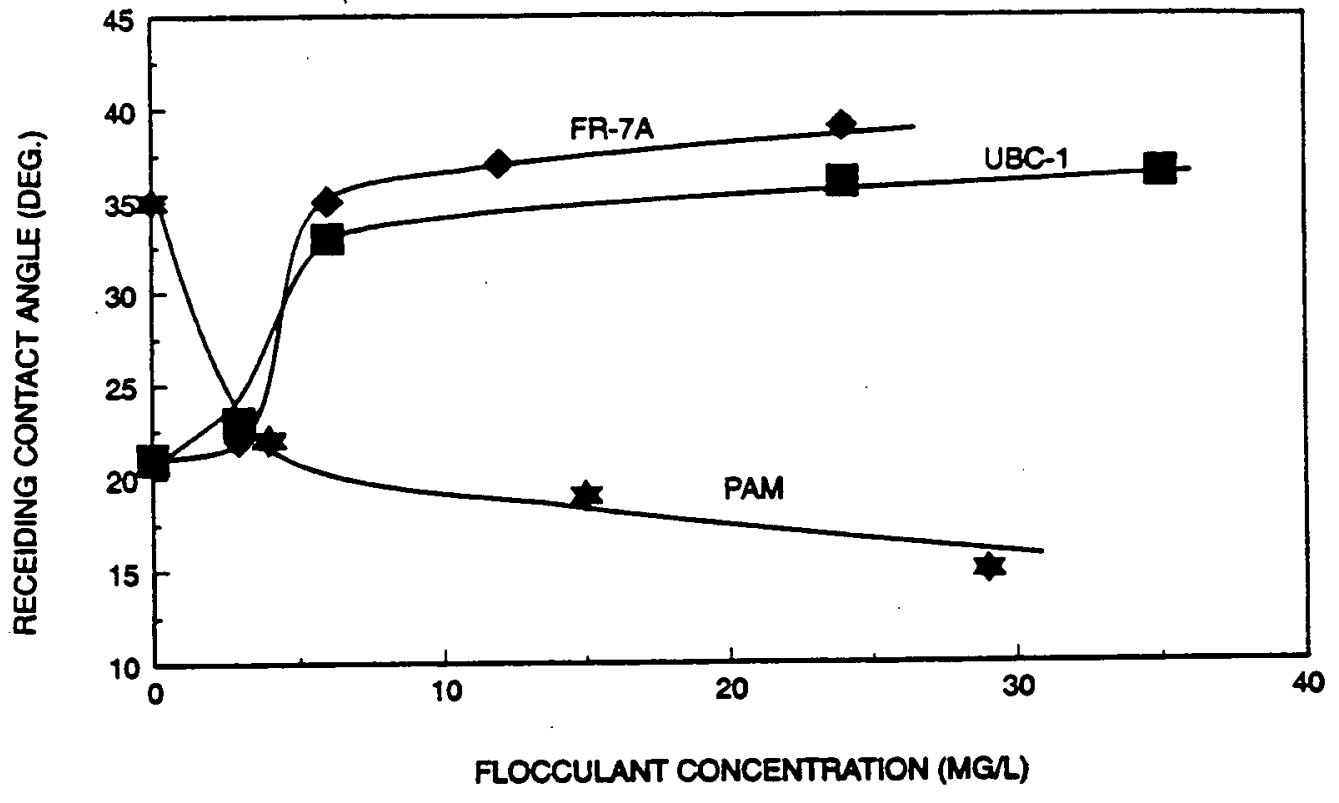

Fig. 9.1: The effect of FR-7A and UBC-1 lattices and PAM on receiding contact angle on coal (after Laskowski et al., 1995).

Both soluble flocculants (F1029-D and PAM) were anionic, and the particles of the latex (FR-7A) were also found to be negatively charged over the whole $\mathrm{pH}$ range. The zeta potential measurements for the coal samples revealed negative values over the neutral and alkaline $\mathrm{pH}$ ranges (see Fig 7.3), and flocculation deteriorated at higher $\mathrm{pH}$ values. (Fig 8.13). The fact that the alkaline $\mathrm{pH}$ regions favored selectivity while coal yield was higher in acidic solutions arises from the part played by the electrical charge in interaction between solid particles and tested flocculants. The optimum selectivity at high recoveries was observed over neutral $\mathrm{pH}$ range. 
FR-7A is an entirely different type of flocculant with special characteristics: it is insoluble in water and appears in the form of colloidal "hairy" particles (van den Ven et al., 1983) in aqueous solution. Therefore, since such flocculating species must first attach to mineral particles, stirring is needed to initiate attachment and bridging, which leads to flocculation. As shown in Figs 8.5 and 8.6, some degree of conditioning was required to initiate flocculation when FR-7A was used. FR-7A particles apparently interact with coal via hydrophobic bonding; as a result no flocculation with FR-7A was observed with oxidized hydrophilic coal.

Fig 8.8 shows the effect of HMP on the total flocculation of the FD4 coal sample. Since in the presence of HMP anions coal surface is rendered more negative, increased HMP concentration affects flocculation and decreases the amount of flocculated coal. The effect of sodium hexametaphosphate (HMP) dosage on coal yield and ash removal was also studied (see Fig. 8.9). The adsorption of HMP also causes a decrease in coal yield and an increase in the flocculation selectivity. It was confirmed that the presence of HMP enhanced the removal of silica from a coal slurry. However, as HMP concentration was increased beyond 300 p.p.m. a plateau was reached without further improvement.

Fig 8.10. shows the effect of solids' content on selectivity and on clean coal yield for a 1:1 Minusil Silica: Fording 4 Seam Coal mixture. A constant shear rate of $250 \mathrm{sec}^{-1}$ and constant dosages of the flocculants $(60 \mathrm{~g} / \mathrm{t}$ for PAM, $80 \mathrm{~g} / \mathrm{t}$ for F1029-D and $350 \mathrm{~g} / \mathrm{t}$ for FR-7A) were used. The high solid content yields higher coal recovery, but low mineral matter rejection. The high coal recovery could be attributed to the high collision frequency of coal particles to form flocs. However, at high solid content, the slurry became very viscous, therefore, the entrainment and entrapment of impurities in coal flocs were high, consequently, ash removal was poor. 
These results indicate that an efficient removal of ash minerals from coal slurries should be conducted at a relatively low solid content, especially for fine coal. Figure 8.10 also indicates that ash removal was very efficient at low solid content. However, with very dilute slurry, the coal recovery was correspondingly low, probably because of the lower collision frequency between coal particles.

The effect of the shear rate on the flocculation of coal was also investigated (Figs 8.5 to 8.7). Whereas for PAM and F1029-D the optimum hydrodynamic conditions were clearly observed and the degree of flocculation decreased at a too high shear rate, for FR7A the degree of flocculation increased with shear rate over the whole tested range.

The requirement of a minimum level of energy (shear rate) to initiate flocculation when the hydrophobic and semi-hydrophobic flocculants are used can be explained by the fact that in such systems the hydrophobic particles are also charged and repeal each other, it is then necessary to give them additional kinetic energy so that they can approach closely enough to allow the attractive hydrophobic forces to take over.

For all the tested coal samples a typical polyelectrolyte such as PAM was very efficient, it effectively flocculated all three coal samples and in line with these data, was very unselective in the selective flocculation tests.

\subsection{Recommendations-Future Tests:}

Floc separation techniques which avoid floc break up and mechanical entrainment should be studied. In this regard, the flotation of hydrophobic aggregates made of fine particles will require different hydrodynamic conditions from the ones prevailing in the mechanical flotation cells (Soto and Barbery, 1988). There are some indications that such favorable conditions could be created in a flotation columns. Different flotation devices (subaeration batch cell, column flotation, etc.) should be evaluated. 
Since selective flocculation is one of the most promising methods of beneficiation of fine coal, it would be beneficial to repeat the selective flocculation tests (performed in this study on synthetic mixture between coal and silica) on individual coal samples. The aptitude of the hydrophobic latex for reducing the ash content of coal will then be evaluated.

Beneficiation of other inherently hydrophobic minerals such as molybdenite, graphite, talc, or sulphur should be tested using total hydrophobic latices and selective flocculation techniques. Separation tests of minerals with different hydrophobicity (fluorite, calcite and apatite, among others), made hydrophobic through the use of surfactants, should also be conducted.

\subsection{Conclusions}

1 In discussing the mode of action of flocculants, account must be taken of the surface properties of the treated fine coal particles.

2 Flocculation tests performed on three coal samples, characterized by different degree of wettability, with three different flocculants revealed that the totally hydrophobic FR-7A cannot flocculate hydrophilic oxidized coal. In accordance with these findings, it was shown that a totally hydrophobic latex (FR-7A) is extremely selective in agglomerating hydrophobic coal particles. Hydrophobic latex and semi-hydrophobic flocculant were found to produce good flocculation and selectivity on the non-oxidized hydrophobic coal only. This is a clear indication that the main mechanism of flocculation for these types of flocculants is hydrophobic aggregation, this was also confirmed by direct measurements of coal wettability in the presence of the tested flocculants. 
3 The hydrophobic flocculation is a new process similar to oil agglomeration in which hydrophobic latex is utilized. However, since the optimum latex dosage is around $500 \mathrm{~g} / \mathrm{t}$, the consumption of this agglomerant is about 100 times lower than the consumption of oil required in the oil agglomeration process.

4 The efficiency of the semihydrophobic flocculant, F1029-D, was also found to depend on the coal surface properties, and this flocculant was much less efficient with hydrophilic coal.

5 In order to initiate flocculation with the FR-7A, totally hydrophobic flocculant, some minimum level of conditioning is needed while for the polyelectrolyte a good mixture is sufficient to achieve some flocculation. Apparently the flocs produced with FR-7A and F1029-D are much stronger, and unlike the flocculation vs. shearing curves for PAM, such curves for FR-7A and F1029-D did not exhibit a clear optima.

6 When coal becomes more hydrophilic it is necessary to use higher shear rates and/or dosage to obtain the same degree of flocculation.

7 The typical polyelectrolyte, PAM, flocculated all the coal samples irrespective of the coal surface properties. In accordance with these results, PAM was the least selective in the selective flocculation tests.

8 The fact that stabilization was not observed at higher concentrations of both the hydrophobic (FR-7A) and the semi-hydrophobic (F1029-D) indicates that the adsorbed layers formed on coal surfaces when these flocculants are used are fundamentally different from the adsorption layers formed on the coal surface when PAM is used. The latter is apparently hydrophilic, and this is most likely responsible for the steric stabilization of coal suspension at higher PAM concentrations. 
9 The study on the effect of $\mathrm{pH}$ suggests that selective flocculation using the totally hydrophobic latex should be conducted at neutral to alkaline environment while the total flocculation and clean coal yield, are much better at acidic $\mathrm{pH}$ ranges.

10 The alkaline $\mathrm{pH}$ regions favour selectivity while coal yield is higher in acidic solutions. This arises from the part played by the electrical charge interaction between solid particles and tested flocculants.

11 Since in the presence of HMP anions the coal surface is rendered more negative, an increased HMP concentration affects flocculation and decreases the amount of flocculated coal. The adsorption of HMP also causes a decrease in coal yield and an increase in the flocculation selectivity.

12 The high solid content yields higher coal recovery, but low mineral matter rejection. Conversely, at low solid content the coal recovery was correspondingly low and ash removal was very efficient. These results indicate that an efficient removal of ash minerals from coal slurries should be conducted at a relatively low solid content, especially for fine coal. 


\section{REFERENCES}

Alpern, B. Lemos de Souza, M. J. Flores, D., 1989, A progress report on the Alpern Coal Classification; International Journal of Coal Geology, 13, p. 1.

American Standards for Testing Materials, ASTM D $3888-77$.

Aplan F. F., 1983, Estimating the floatability of Western Coal, in Gold, Silver, Uranium and Coal: Geology, Mining Extraction and the Environment, AIME, M. C. Fuerstenau and B. R. Palmer eds., New York, p. 380.

Aplan, F. F., 1989, How the nature of raw coal influences its cleaning; Industrial Practice of fine Coal Processing, Chapter 13, pp. 99-111.

Arnold B. J. and Aplan F. F.,1989, The hydrophobicity of coals macerals; Fuel 68, p.651.

Attia, Y. A. and Fuerstenau, D. W., 1980, The adsorption of polyacrylamide flocculants on apatite, Colloid and Polymer Science, 258, p. 1343.

Attia, Y. A., 1977, Development of a Selective Flocculation Process for a Complex Copper Ore, Int. J. Min. Proc., V4, p. 209.

Attia, Y. A., 1982, Fine Particle Separation by Selective Flocculation, Sepn.Sci \& Tech, $17(3)$, p. 483.

Attia, Y. A., 1985, Cleaning and Desulfurization of Coal Suspensions by Selective Flocculation, in: Processing and Utilization of High Sulfur Coals, (Y. A. Attia, (ed.) Elsevier, p. 267.

Attia, Y. A., and Kitchener, J. A.,1975, Development of complexing polymers for the selective flocculation of copper minerals, Proc. 11th Int. Mineral Process Congress, Cagliari, p. 1233.

Attia, Y. A., Yu, Shaning and Vecci, S., 1987, Selective Flocculation Cleaning of Upper Freeport Coal with a Totally Hydrophobic Polymeric Flocculant, Flocculation in Biotechnology and Separation Systems, Elsevier, Amsterdam, p. 547. 
Attia, Y.A., and Fuerstenau, D. W., 1982, Feasibility of Cleaning High Sulfur Coal Fines by Selective Flocculation, XIV Int. Min. Proc. Congress, Toronto, 1982, Paper VII-4.

Attia, Y.A., and Fuerstenau, D.W., 1978, Principles of Separation of Ore Minerals by Selective Flocculation, in: Recent development in Separation Science, IV Ch.5, ed. N. Li, p. 51.

Attia, Y.A., Krishnan, S.V., and Deason, D. M., 1983, Selective Flocculation Technology, Final Report, Batelle-Columbus Laboratories.

Banks, A. F., 1979, Selective Flocculation-Flotation of Slimes from a Sylvinite Ore, in Beneficiation of Mineral Fines, NSW Workshop Report.

Berkowitz, N., 1979, Chemical properties in an introduction to coal technology; Academic Press, New York, p. 95.

Blaschke, Z., 1976, Beneficiation of Coal Fines by Selective Flocculation, Proc. 7th Int. Coal Prep. Cong., p. 1.

Blom, L. L., Edelhausen and van Krevelen, 1957, Chemical structures and properties of coal - oxygen groups in coal related products, Fuel, 36, p. 135.

Brady G. A. and Gauger, A. W., 1940; Properties of coal surface, Ind. Eng. Chem., 32 p.1599.

Brookes G. F., et al., 1982, The Selective Flocculation of Coal/Shale Mixtures Using Commercial and Modified Polyacrylamide Polymers, XIV Int. Min. Proc. Congress, Toronto, 1982, Paper VII-7.

Brown, D. J., 1962, Coal Flotation, in Froth Flotation 50th Anniversary Volume, D. W. Fuerstenau, ed. AIME, New York, p. 518.

Bujnowska, B., 1958a, Floatability of petrographic constituents of coals of various coalification degree; Proc. International Conference on Coal Science, Sydney, Australia, publ. by Pergamon Press, p. 541. 
Bustamante, H. and Warren, L. J., 1983, Relations between the relative density of composite coaly grains and their flotation recovery, International Journal of Mineral Processing, 10, p. 1 .

Camp ,T. R. and Stein P. C., 1943, Velocity gradient and internal work in fluid motion, Journal of Boston Society of Civil Engineers, 30, p. 219.

Camp, T. R. and Asce, M., 1954, Flocculation and Flocculation Basins, Paper No 2722. Transaction American Society of Civil Engineers (ASCE) Vol. 20 , p.1.

Campbell J. A. L. and Sun, S. C., 1970, Bituminous coal electrokinetics, Trans. SME/AIME, 247, p. 11.

Chen, S., Misra, M., and Smith, R. W., 1992a, Flocculation of Mineral Fines Using Hydrophobic Mycobacterium Phlei, Proceedings of the International Symposium on Waste Processing and Recycling in Mining and Metallurgical Industries, CIM, August 23-27, Edmonton, Canada

Chen, S.,Misra, M., Schneider, I., and Smith, R. W., 1995, Adhesion of Hydrophobic Microorganism on hematite and its effect on flotation, SME Annual Meeting, Preprint 23-184, Reno, Nevada

Cook. A. C., 1981, What are we trying to separate?; Separation Science and Technology, $16(10)$, pp. 154-1569.

Dejarguin, B. V., and Dukin, S. S., 1961,Trans. IMM, 70, p. 221.

Drzymala, J., and Fuerstenau, D. W., 1981, Selective flocculation of Hematite in Hematite-Quartz-Ferric Ion-polyacrylic Acid System. Part 1. Activation and Deactivation of Quartz, Int. J. Mineral Process, 8, p. 265.

Fowkes, F. M., 1963, Dispersion force contribution to surface and interfacial tensions, contact angles and heats of immersion. Advances in Chemistry Series, 43, Contact angles wettability and adhesion, p. 99.

Frommer, D.W., and Colombo, A. F., 1966, Process for improved flotation. Treatment of Iron Ores by Selective Flocculation, US Patent No2, 292, 780, 1966. 
Fuerstenau, D. W., and Williams M. C., 1987, Characterization of the Lyophobicity of Particles by Film Flotation; Colloids and Surface, 2 , p. 87.

Fuerstenau, D. W., Rosenbaum, J. M., and Laskowski, J, 1983, Effect of surface functional groups on the flotation of coal; Colloids and Surfaces, 8, p. 153.

Fuerstenau, D. W., Williams M. C., and Urbina, R. H., 1985, Assessing the effect of oxidation on the wettability and flotation response of coal; Proc.: International Conference on Coal Science, Pergamon, Sydney, Australia, p. 517.

Fuerstenau, W., Yang, G. C. C., and Laskowski, J. 1986, Oxidation phenomena in coal flotation. Part 1. Correlation between oxygen functional group concentration, immersion wettability and salt flotation response, Coal Preparation 2, p. 1.

Garshva, S., Contreras, S., and Goldfarb, J., 1978, Hydrophobic characterization of powder; Colloid and Polymer Science, 256, p. 202.

Gaudin A. M., 1957, Flotation, second edition, MacGraw Hill, New York.

Given, P.H., 1960, The distribution of hydrogen in coals and its relation to coal structures; Fuel, 39, p. 147.

Gochin, R. J., Lekili, M., and Shergold G. L., 1985, The Mechanism of Flocculation of Coal Particles by Polyethyleneoxide, Coal Preparation. Vol. 2, p. 19.

Gray, R. J., and Lowenhaupt, D. E., 1989, Aging and weathering; Sample Selection, Aging and Reactivity of Coal, R. Klein and R. Wellek, John Wiley and Sons, eds., New York, p. 255.

Gray, R. J., Rhodes, A. H., and King, D. T., 1976; Detection of oxidized coal and the effect of oxidation on the technological properties; Trans. of SME/AIME, 260, p. 334.

Gutierrez-Rodriguez J. A., Purcell, R. J. and Aplan, F. F., 1984; Estimating the hydrophobicity of coal, Colloids and Surfaces, 12, p. 1 . 
Harkins, W. D., 1947, A generall theory of the mechanism of emulsion polymerization, $\underline{\text {. }}$ Am. Chem. Soc., 69, p.1428.

He, Y. B., 1989, Contact Angle Measurements on Fine Coal Particles,_M.A.Sc. Thesis, The University of British Columbia

He, Y. B., and Laskowski, J. S., 1992, Contact Angles Measurements on Discs Compressed From Fine Coal, Coal Preparation, Vol. 10, p. 19.

Heerema, R. H., Lipp, R. J., and Iwasaki, I., 1982, Complexation of Calcium Ion in Selective Flocculation of Iron Ores, Trans. SME-AIME, 272, p. 1879.

Holuszko, M. E., 1991, Wettability and Flotability of Coal Macerals as Derived from Flotation in Metanol Solutions, M.A.Sc Thesis, The University of British Columbia, Vancouver.

Hornsby, D. T. and Leja, J., 1980, Critical Surface tension and the selective separation of inherently hydrophobic solids, Colloids and Surfaces, 1, p. 425.

Hornsby, D. T. and Leja, J., 1983, Critical Surface tension of flotability; Colloids and Surfaces, 7 , p. 339.

Horsley R. M., and Smith H. G., 1951; Principles of coal flotation; Fuel 30, p. 54.

Hucko, R. E., 1977, Beneficiation of Coal by Selective Flocculation, ÙSBM Report of Investigation 8234.

Hudson, H. E. Jr. and Wagner E. G., 1981, "Conduct and uses of jar test", Journal American Water Works Association, Vol. 73, p.218.

Ignasiak, B. S., Szladow, A. J., and Montgomery, D. S., 1974; Oxidation studies on coking coal related to weathering. The influence of acidic hydroxyl groups, created during oxidation, on the plasticity and dilatation of the weathered coking coal; Fuel. 53, (2), p.3.42.

Ihnatowicz, A., 1952, Studies of oxygen groups in bituminous coals, Prace Glowengo Insytutu Gornictwa, Komunikat, No 125. Polish Text. 
Isemura, T, and Imanishi, A., 1958, The dissolution of water soluble polymers in the surfactant solution. The polyelectrolite like behavior of the dissolved polymers, Journal Polymer Science, 33, p. 337.

Iskra, J., and Laskowski, J. S., 1967; New possibilities for investigating air-oxidation of coal surfaces at low temperatures; Fuel, 46, p. 5.

Iskra, J., Gutierrez , C., and Kitchener, J.A., 1973, Trans. IIM, Sec C p.73.

Iwasaki, A. I., 1986, Control of Montmorillonite via Complexation in the Selective Flocculation of Iron Ores, AIME, Annual Meeting, New Orleans, Louisiana, Preprint No 86-12, AIME, New York.

Iwasaki, I., 1981, Selective flocculation, magnetic separation and floatation of ores, US. Patent $4,298,169$.

Jameson, G. H., Nam, S., and Moo Young, M., 1977, Physical factors affecting recovery rates in flotation, Miner. Sci. Eng. 9 (3), p. 103.

Kaji, R., Muranaka, Y, Otsuka, K., Hishinuma, Y, 1986, Water Absorption by Coals: Effect of Pore Structure and Surface Oxygen, Fuel Vol. 65, p. 288.

Keller, D. V., Jr., 1987, The contact angle of water on coal; Colloids and Surfaces, 22, p. 21.

Kitchener, J. A., 1972, Principles of Action of Polymeric Flocculants, Br. Polym J., vol. 4, p. 217.

Kitchener, J. A., 1978, Flocculation in Mineral Processing, in: The Scientific Basis of Flocculation, K. J. Ives (ed.), pp. 283-328.

Klunder, H. and Koopman,s K., 1981, Delft Prog. Rep. 6(3), Cf. CA 96, p. 145.

Krishnan, S. V., Selective Flocculation of Fine Coal, 1986, Fine Coal Processing, Mishra, S. K. and Klimpel R. R. (ed.), Noyes Pub., Park Ridge, New Jersey, USA, p. 160. 
Krishnan, S., and Attia, Y. A., 1986, in B. M Moudgil and P. Somasundaran (Editors), Flocculation, Sedimentation and Consolidation, Engineering Foundation, p. 229.

Lai, R. L., Hudson Jr., H. E., and Singley J. E.,1975, Velocity Gradient Calibration of Jar-Test Equipment, Journal of American Waterworks Assn, 67, p. 553.

Laskowski J. S., He Y. B. and Zhan Y.,1992, "Coal Wettability and its Correlation with Flotability", 121St.SME Annual Meeting and Exibition, Phoenix 1992, Preprint No 92125.

Laskowski, J. and Kitchener, J. A., 1969, The hydrophilic-hydrophobic transition on silica; Journal of Colloid and Interface Science, vol. 29, No, April 1969, p. 670.

Laskowski, J. S., and Parfitt, G. D., 1989, Electrokinetics of coal-water suspensions; Interfacial Phenomena in Coal Technology ed. G. D. Botsaris, and Y. M. Glazman, eds., Marcel Dekker, Inc. New York, p. 279.

Laskowski, J. S., Yu, Z., and Zhan, Y., 1995, Hydrophobic Agglomeration of fine coal, Proceedings of the 1st UBC-McGill Bi-Annual International Symposium on Fundamental of Mineral Processing, ed. Laskowski , J.S., and Poling, G.W., Metal Society of CIM, Vancouver, p. 245.

Leja J., 1983, Surface Chemistry of Froth Flotation; Plenum Press, New York.

Littlefair, M.J. and Lowe, N. R. S., 1986, "On the Selective Flocculation using Polystyrene Latex", Int. J. Mineral Processing Vol. 17 p. 187.

Liu, Qi, and Laskowski, J. S., 1989, The role of metal hydroxides at mineral surfaces in dextrin adsorption, Int. J. Min. Proc., 26, p. 297.

Lowenhaupt, D. E., and Gray, R. J., 1980, The alkali-extraction test as reliable method of detecting oxidized metallurgical coal; International Journal of Coal Geology 1, p 63.

Lyadov, V. V., Gryanko, V. I.., Nikitin, I .N., Preobrazhenskii, B. P., and Tsyrlov, M. Ya., 1979 "Selective Flocculation of Coal Slurries using Latexes", Coke Chemistry USSR (Eng. Translation.), Vol. 9, p. 12. 
Lyndov, V. I., Orjanko, V. I., and Nikitin, I. N., 1979, Selective flocculation of coal slurries using latexes, Koks Khim, 9, p 9.

Mackowsky, M. Th., 1982, Minerals and trace elements occurring in coal; Coal Petrology, third edition, E. Stach, M. Th. Mackowsky, M. Teichmuller, G.H. Taylor, D. Chandra and R. Teichmuller, eds., Gerbruder Borntraeger, Berlin-Stuttgart, p. 153.

Meuzelaar, H. L. C., Hill G. R., Yun, Y., Jakab, E., Winding W., Urban, D., Yon, K. Y.,Oestreich, J. and East, J., 1987, Weathering effects on the structure and reactivity of US. coal; DOE Final Report.

Mhaisalkar V. A., Paramasivam, R., and Bhole, A. G., 1986, An innovative technique for determining velocity gradient in coagulation-flocculation process, Water Research Vol. 20, No 10 , p. 1307.

Misra, M., Smith, R. W., Dubel, J. and Chen, S., 1992 "Selective Flocculation of Fine Coal with Hydrophobic Mycobacterium Phlei", 121St.SME Annual Meeting and Exibition, Phoenix 1992. Preprint No 92-87.

Moudgil, B. M., and Somasudaran, P., 1982, Adsorption of charged and uncharged polyacrylamides on hematite, SME-AIME Annual Meeting. Dallas, Texas, Preprint 82$\underline{160 .}$

Nyamekye, G. A., and Laskowski, J. S., 1992, Adsorption and Electrokinetic Studies on the Dextrin-Sulfide Mineral Interactions, Journal of Colloidal Interface Sci., p. 456.

Oldshue, J. Y. and Mady O. B., 1979, Flocculation impellers: a comparison; Chemical Engineering Prog., 46, p. 395.

Onlin, T. J. and Aplan F. F., 1987, Use of oily collectors for the flotation in coal of various ranks; Annual AIME Meeting, Denver, CO, 1987.

Osborne, D. G., 1978, "Recovery of Slimes by a Combination of Selective Flocculation and Flotation", Trans. IMM, Sec. C, Vol. 87, p. 189.

Palmés, J. R., and Laskowski, J. S., 1993, Effect of the properties of coal surface and flocculant type on the flocculation of fine coal; Minerals and Metallurgical Processing. November 1993 , p. 218. 
Parfitt, R. L., and Greeland, D. J., 1970, The adsorption of polyethylene glycols on clay minerals, Clay Minerals, 8 , p. 305.

Piirma, I., Kamath, V. R. and Morton, M., 1975, The kinetics of styrene emulsion polymerization, J. Polymer Sci., 13, p. 2087.

Pugh, R. J., and Kitchener, J. A, 1971, J. Colloid Interface Sci, 35, p. 656

Raichur, A. M., Misra, M. and Smith, R. W., 1995, Differential Adhesion of Hydrophobic Bacteria onto Coal and Associated Minerals, Coal Preparation, Vol. 16, p. 51.

Roe, C.P., and Brass, P .D., 1957, The rate of particle growth in persulphate initiated emulsion polymerization, J. Polymer Sci., 24, p. 401.

Rubio, J., and Kitchener, J. A., 1976, The Mechanism of Adsorption of Poly(ehtyleneoxide) Flocculant on Silica, J. Coll Interf. Sci, 57, p.132.

Rubio, J., and Kitchener, J. A., 1977, New basis for selective flocculation of mineral Slurries, Trans. AIME/SME,86, p. 97.

Sadowski, Z., and Laskowski, J. S., 1980, Selective Coagulation and Selective Flocculation of the Quartz-Carbonate Mineral Binary Suspensions, Fine Particles Processing, Chap. 55, P. Somasundaram ed. AIME, New York

Schafer, H. N., 1970, Carboxyl groups and ion exchange in low rank coals; Fuel 49, p. 197.

Slater, R.W., and Kitchener, J. A., 1966, Characteristics of Flocculation of Mineral Suspension Polymers, Disc. Farad. Soc., No. 42, p. 267.

Smoluchowski, M. V., 1917, Phys. Chem. 92, p. 129.

Solari , J. A., and Rubio, J., 1984, The effect of polymer flocculant on dissolved air flotation of heavy metals. In: Reagents in Mineral Industry, Jones, M. J., and Oblatt, R., (ed.), IIM, Rome, p. 271. 
Solari, J. A., de Araujo A. C., and Laskowski, J. S., 1986, The effect of carboxymethyl cellulose on the flotation and surface properties of graphite. Coal Preparation, 3 , p. 15.

Soto, H. and Barbery, G., 1988, "Separation of Fine Particles by Floc Flotation", Production and Processing of Fine Particles, Plumpton (Ed.), p. 297.

Sresty, G. C., Raja, A. and Somasundaran, P., 1978, Selective Flocculation of Mineral Slimes Using Polymers, Recent Advances in Separation Science, Vol. 4., CRC Press.

Stutzmann, T. H., and Siffert, B., 1977, Contribution to the adsorption mechanism of acetamide and polyacrylamide on to clays, Clay and Clay Minerals, 25, pp. 392-406.

Sun, S. C., 1954a; Hypothesis for different floatabilities of coals, carbons and hydrocarbons minerals; Trans. AIME, 199, p. 67.

Sun, S. C., 1954b; Effects of oxidation of coals on their flotation properties; Trans. AIME, 200 p. 89.

Trahar, W. J., 1981, A rational interpretation of the role of particle size in flotation, Int. J. Miner. Process, 8, p. 289.

Trahar, W. J., and Warren, L. J., 1976, The flotability of very fine particles-a review, Int. Journal of Mineral Process, 3, 1976, p. 103.

Ueda, T., and Harada, S., 1968, Effect of the structure of cationic polysulphone on the flocculation of kaolinite, J. Applied Polymer Sci.. 12, p. 2383.

Usoni, L., Rinelli G., Marabini A., 1968, Selective Properties of Flocculants and possibilities of their use in the flotation of finely ground ores. Proc.8th Int. Mineral Processing Congress, (Leningrad 1968), Institut Mekhanobr, Leningrad, 1969, Vol. 1, p. 514.

Van De Ven, T. G. M., Dabros T., Czarnecki, J., 1983, Flexible Bonds between Latex Particles and Solid Surfaces, Journal of Colloid and Interface Science, Vol. 93, No 2, p. 580. 
Van de Ven, T. G. M., and Mason, S. G., 1976, Microrheology of Colloidal Dispersions Pair of Interacting Spheres in Shear Flow, J. Coll. Interf. Sci., 57, p. 505.

Van Krevelen, D. W,1961, Coal Science, Elsevier, Amsterdam, 1961

Van Olphen, H., 1963, Clay Colloid Chemistry, Wiley, New York

Warren, L. J., 1975, Shear-flocculation of ultrafine scheelite in sodium oleate solutions. J. Colloid Interface Sci., 50, p. 307.

Wen, W. W., 1977; Electrokinetic behavior and flotation of oxidized coal; $\mathrm{Ph}$. D. Thesis, Pennsylvania State University.

Whitehurst, D. D., Mitchell, T. O., and Farcasiu, M., 1980, Coal Liquefaction; Academic Press, New York.

Wiser, W., 1975, Prepr. Amer. Chem. Soc. Div. Petr. Chem., 7, (3), p. 99.

Yarar, B. and Leja, 1982, Floatation of weathered coal fines from Western Canada; Technical Papers of 9th International Preparation Congress, New Deli, India, p. C5-1.

Yarar, B., and Kitchener J. A., 1970, Selective flocculation of minerals: 1-Basic principles; 2-Experimental investigation of quartz, calcite and galena, Trans. Inst. Min. Metal, 79, p. 23.

Ye, Y., and Miller, J. D., 1988, Bubble/particle contact time in the analysis of coal flotation; Coal Preparation, 5, pp.147-166.

Yoon, R. H., and Luttrell, G. H., 1989, The effect of the bubble size on fine particle flotation, Frothing in Flotation, J. S. Laskowski, (Ed ) Gordon and Breach, New York, p. 101. 